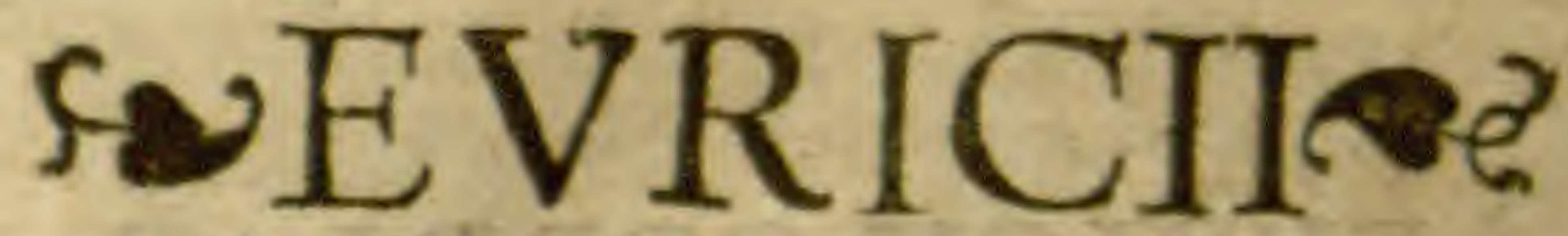

CORDI SIMESVSII MEDICI Botanologicon.

\title{
HEVS MEDICE
}

Vis usvias aliter quàm doctuses battenus berbas

Scire, noums multas ifte libellus bubet.

$V t$ retinax primum fibi tefta referuet odorem,

Sex nifi quadrantes o breuis hors perit.

Que i quadm noftris luf forum perdere chart is

Malis, turc aliquid doctius ade tuum.

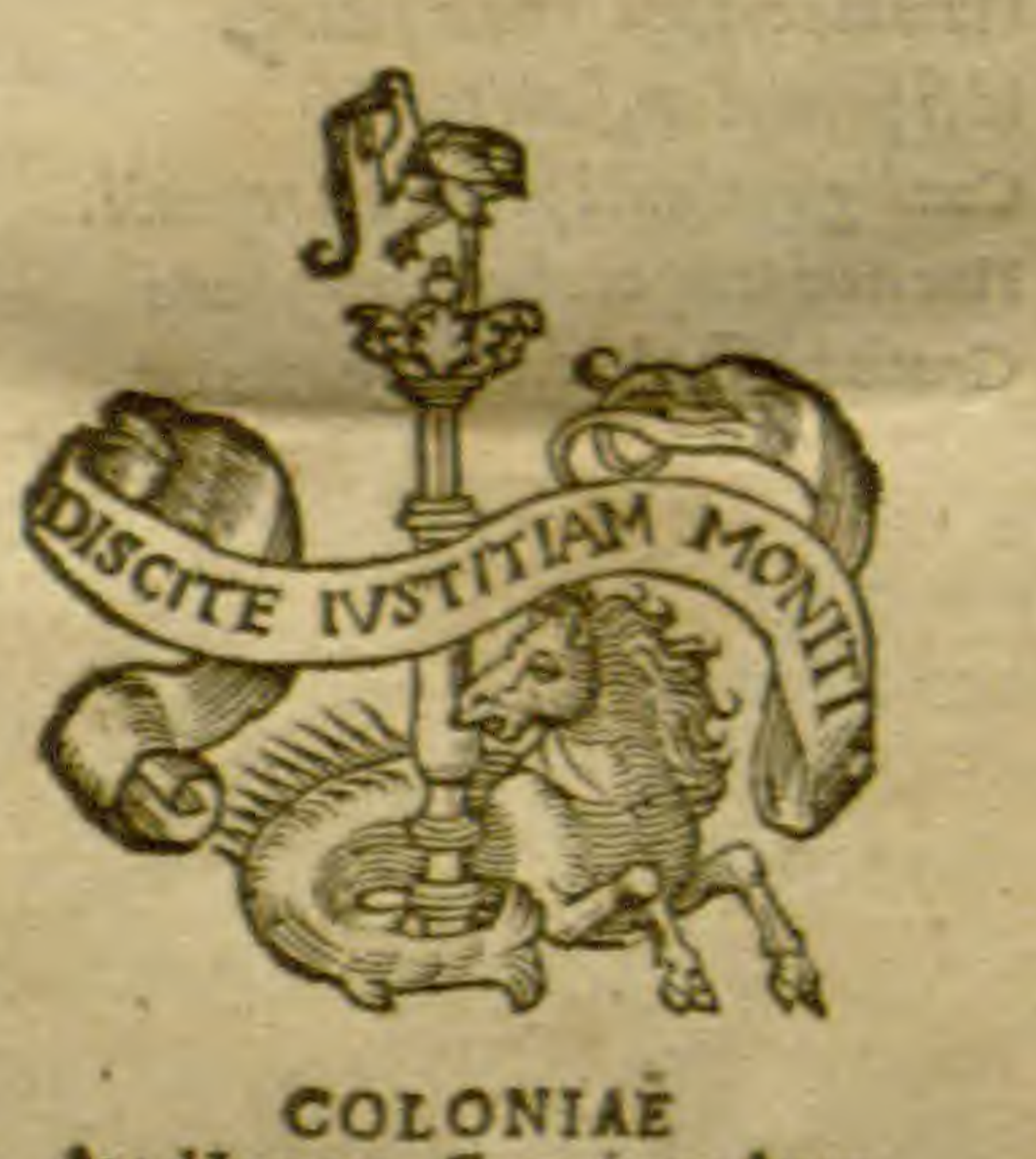

Apud loannem Gymnicum Anbe

D $M$ Xxxumb.

\section{Mo.Bot. Garden,}




\section{EVRICII CORDI AD}

SENATVM BREMENSEM

epigramma.

Sitam charus Afellij Sabini

Scriptus de Ganed or gula libellus

Romano potuit deo placere

Vt feftertia redderet ducentd,

Hanc fanctißime, non reor, fendtw

Ingratam fore lucabrationem,

Cuius materid illd conftat, in qui

Humand est fita fanit ds falus q.

1d fi percipiam, fat is putabo

Condignum mihi premium rependi.

Hoc nam tempore barbaroóp feclo

Gratis polfe placere magnares est. 


\section{PRVDENTISSIMIS CIRCVM} fpectiffimiśç uiris, Senatui pcpulóque Bremenfi Euricius Cordus Simefufius medicus fuus

$$
\text { S. D. P. }
$$

Elebris eft Platonis fententia, non folis nobis natos efienos, fed partê noftri parentibus, partem patrix, \& partem amicis deberi,Cui ut parerem,affiduum, dum perpëde reccepi, defyderium fuit . Cum autem parentes meos, eo tempore, quo plus ego ipforum mea ipfiope indigerent, amiferim, primo eius dieti preccepto fatis facere non potui. Veruma donec aliquis mei ufus effe copiffet, ut eo patrię inferuirem, proximum erat uotum. Quo factum ut, cum illuftrifimus Hefforum Princeps Philippus, propter interpolatam religio nem contemptis acexulătibus Mufis nouums hic afylum, adeo'f; onnium artium uniuerfalem, quam uocăt, fcholam inftauraret, co me, ut medicinam docerem, acciri facilius libentius'̧́ fim paffus. Tametfi ipfa patria quantüuis hortida fua quogue, nefcio qua, dulcedine me traxit, Septem itaqz annis ipfam medicinam hic publice fum profeffus, quăta autem uel lau de uel ignominia difcipuli mei dixerint. Exer cuiffem quoq; non tam mea unius utilitate, $\overrightarrow{\mathrm{g}}$ communi omniumfaluterespecta, niff barba 
rior quàm putaueram, \& iuxta principi fuo pro tanto beneficio ingratus populus, ut omnes bonas literas, fic $\&$ ipfam medicinam contemneret, folifque uagis ac impoftoribus empiricis \& agyrthis gauderet. Quod uitium cum hic maius quàm ufquă alibi, offendiffem, ftatim pietatem facilitatem que meam incufa re coepi,et continua ductus poenitentia iugiter hinc alio quopiam fufpiraui, Quantumuisenim liberali, non tamen quo duodecimus uiue re queam, ftipëdio mereo. Quinetiam dudum demigraffem, nifiblanda ipe facraquędam an chora me hactenus, non in paruum rei familiaris detrimentŭ retinuiffet.Qua tandem per femper euectricem meam inuidiam refecta, clim crebro iam rumore terrerer, fcholam fci licet noftram, non ita multa frecula permanfu ram, et tum, fifecuta fides, cum aulicam uitam (in quam forte ubi res foeliciter ceciderit, adfcifcerer) abhorrerê, tamen hinc me concedereneceffitas cogeret, prudentix adeoq; totici uitati ueftræ futurum me medicū obftrinxi, Quod autē in hücufqz diem abfum, non mea, red eiufdem inuidir culpa eft . qux ut amplius noceat, ita meremoratur ut ante $\mathrm{Pa}$ afchales fe rias nullam aduentus mei expectationem pol Liceri queä. Et ut omnia expedita fuerint, quis 


\section{NVNCVPAT ORIA.}

in tanta hyemis iniuria, cum tăta familiatantum iter ingrediatur? Vt tamen uel abfentem meueftrumeffe intelligatis, ueftrum hunc effe uolo quem interim ingenij mei foetum peperi, Puta non adeo cótemnendam nec inanem, ut fpero de aliquot herbis difputatiốem*Quă non ut uel tătillam hinc gloriolam uæner, fed ut atris ignorantię tenebris obfcuratamueritatem indagem,fúfcepi.Cuius tandē oritura, dicinon poteft, quant a cupiditate tenear ${ }_{+}$Indi caui graues in quibuifdam difficultates, dubiumq;, ut altius cogitaret, lectorem reliqui . In plerifque uero contra receptos inueteratofq, errores meam nunc fententiam protuli, nunc opinionem oftendi, Atq 3 id in his tantum que ipfe inter legendũ obiter animaduerti.Vt non alienis me plumis,uelut Aefopicus ille graculus, exornauerim. Licet in quiburdă, quos de hinc uidi, autoribus, nonnulla meis eadem re pererim, qua difcipulos meos priufquam illo rum libros uidiffem, docueram. Porro quia non omnia, qua complura huiufmodi habeo, uno hoc dialogo, quod feruandum erat decorum,explicare potui, fi publicatis his precium operæ feciffe me comperiam, forte unum \& alterum adhuc, modo per otium licuerit, addam, Interea uos prudentiffimi uiri, \& quot- 
6 EPISTOLA quot eritis lectores, hunc qualemcunque laborem, quo \& meam in iuuanda medicina uoluntatem exhibere toolui, grato animo fufcipite, ac boni confulite oro. Marpurgi

ipfis Ianuarï calendis anno

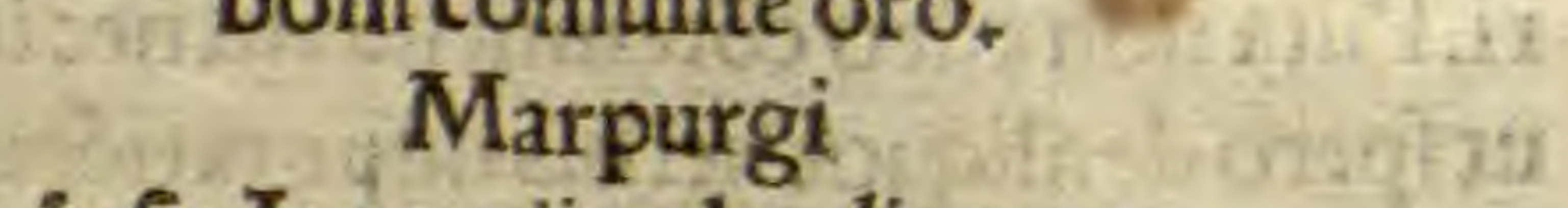

\section{D XXXIII.} it:

$+3$

sit:

7

of 20

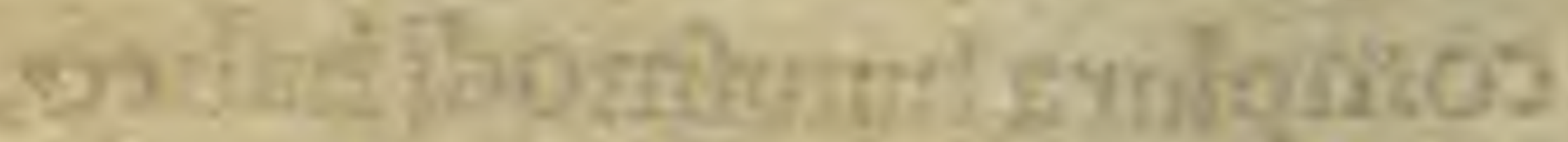

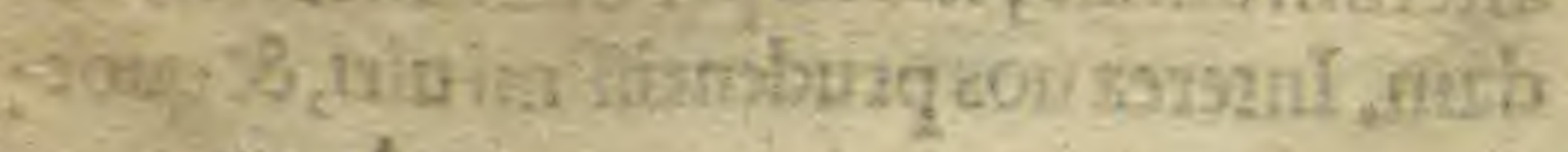

ह $A$ 


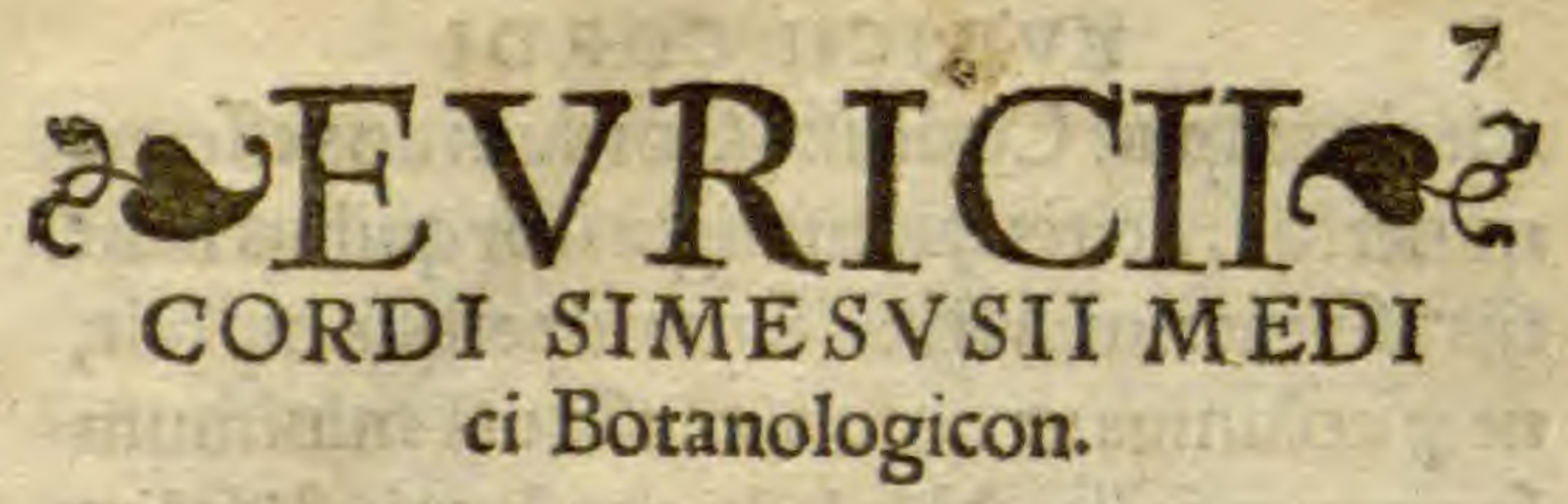

EVRICIVS CORDVS, IOHANNES MEGOBACCHVS, ANTO NIV.S NIGER. IOHANNES RALLA, GVLIELMVS BIGOTIVS,

TORD. Foelicem hunc diê iudico in quo Uueterisillius Erfordiam, id eft,fynceriffimi fodalitij tam chara capita, te feilicet fuauiffime Megobacche, \& candidiffime Nigex una cum affine meo Iohanne Ralla tádem uidere mihi licet. Atqu utinam proeo, quiuobis debetur honore, \& meo erga uos animo tractare uos queam. Certe quantum ad hoc pran diolum attinet, boni côfulatis tenuitatem me amoro. Vt femper defyderatiffimi, fic iam ino pini ueniftis hofpites, quibus nihil ultra äquo ego \& familia mea contenti fumus, quotidianos nimirücibos, appofui $\div$ Lautior forte cosna, fed quatenus per Marpurgenfe macellum licebir, inftruetur. Noloergo ut Aefopicas pa tinas expectetis, imout Myfnięac Thuringię ueftręoblitos, in macra, quam uocant, Heffia, A 4 
adeoque apud Codrum Cordumuos effe me mineritis. Scitis quătus liguritor quibus lauti tijs affueuerim.MEG. Satis fuperque hic fuit, neq; nolumus ut noftra cauffa uel minimum fumptum facias. Nihil ultra uulgaria \& folita coeme, memor dicti tui, quo olim Erfordix non inuitatos nos conuiuas excipere folebas. CORD. Cuius meidicti? MEG . Aut amici aiebas, aut inimic mei ueniftis, fillit, quouis mecum contenti eritis, fin hi, nihilo uos di gnos iudicauero, CORD. Non mihi tam libere uobifcum iocari nunclicet. NIG. Quid nit CORD. Quia in magnos \& graues iam uiros euafiftis. RAL. Quam grauis ego fim, equus meus fciuerit, quod ad magnitudinem attinet, ex pigmeorum genere progenitum me putetis. MEGOBAC. Vt tuos tu, ficmeos ego mores immutaui. CORDVS. Nihil ergo Italia in toto hoe triennio te infecit? MEGO. Qualem uterque alterum reliquit, talem inuenit. RALLA. Falfum ergo in uobis prouerbium eft, quo dicitur, honores mutant mores! CORDVS. Quos tu honores dicis? pluris olim femeftris difcipulus fiebat, quam nunc quantureung doetor. NIGER, Hoc uelim cordatiffime Corde perfuafiffimü habeas perinde adhuc ac olim Nigrum tur̆ affectum, 
te amare, colere, uereri, uenerari, \& loco patris habere, atq; fi quid more tuo ioceris, id candidiffime interpretari ac ferre. Meg.Idem de me fenti.Nig.Imo gaudeo uiciffim, quod tantum teueterem $\&$ integrum amicú meun coram uidere $8 \times$ audireliceat: Cuius unius ergo huc ueni \& Lypfiá reliqui, Cord, Ex quo ita ludis, afpice $\&$ intuere me adfatiem ufq. Nig. Non ludo. Cord.Qui placet tibibarbatulus \& rugo fulus Cordus: Quantü mutatus ab illo eft Cor do, qui ante xvi, annos Erfordiæ Marianüludú aperuit, te tota trieteride coadiutore $\&$ hypodidafcalo? Quando pro hoceodë officio fo larium tuũexigis? Nig. Tã gratam tibí \& dif́ci pulis tuis utilem operam meam fuiffeuelim, $\vec{q}$ fatis magnum ego hoftimentürecepi.Quantuี putas cumulú eruditioni exercitiū illud adịcere: Cord. Non adeo multo fructu inftituunt, $f \mathbf{f}$ non et iuxta exerceantur iutenes.Meg. Hei mi hi quă tacito curfu properans tempus labitur, eodem anno e Lypfia Erfordiam ueni.Nig. Non adeo interim confenuiffeuideris Corde, ego te iam canú efíe fufpicabar, Cord, Effem quogi fi affiduę curæe \& follicitudines, ut dicun tur, canos accelerent: Qủan̈̈ interíperí barbx pruina prominere incipiat, neqs intempeftiue.Meg, Quotum ergo annum agis? COrd. A 5 
Quadragefimú octauum iă fum ingreffus, $\mathrm{Ni}$. Dìte nobis diu incolumêrferuent, ut tantundê adhuc fuperftes maneas, oro, Cord, In quam tandem frugẽ \& utilitatem? Ego, fi nondũ ex creta proles patrefuo carere poffet, uixiffe me trelim, ut iă humanæ fe res habēt, turbidifíima hac tempeftate, in qua omnes bonæe artes fordent, Nig, Rogas, in quă frugẽ ? Spero ut quon dam in humanioribus literis, fic nune quoggin re medica doctiorem me experientia tua fieri. Cord.Scilicet ut me irrideas huc uenifti, egóne fus Mineruam: Iam pluribus annis huic rei ftrenuam operă nauas, \& quidem græcă cum Latina callens linguam, $\&$ meus adhuc difcipulus eris? culus hic quofdam, qui indigniores funt, quam qui matulam tibi porrigăt, pudet. Mego. Hos magnos fatuos, uel ualde inuidos effe oportet. Nig. Quantus fit meus uel in græe cis, uel in medicina profectus, nefcio, hoc autë conftat, quod fedulum ftudiū \& acre iudicium ad consequendam fcientiam plurimú ualeant, Quo utroque infignen te uirum, quicunqz no: uit, pradicat, contemnant te quicunque uelint fcioli.Cord.Modeftius hrec in faciē, f́cisquam libenter audiam imnerito me laudari. NIG. Quod loquor ut uerum eft ita fentio, fed qui funt illi tui contemptores: Cord,Malo ab alins 


\section{BOTANOL OGICON.}

quam ex me id difcas: Refcies tamen fialiquan diu hic fueris, \& mecum hos communes forte habebis.Meg.Quo autem merito: Cord.Nul lo quod fciam alıo, quàm quod nouam hreefim in medicis rebus meexcitare culpët.Meg. Quam harefim? Cord. Quod fuperiori anno fimplicia medicamenta profeffus omnes fere feplafiarios multis iam freculis erroneam corum cognitionem habuiffe dixerim. NIG. Quis contra manifeftam ueritatem pugnet? Meg. Eo maiorem authoritatem ac gratiam mereri debes. Ral, Tantum abeft, ut ob id tibi fuccenfeam ut impatientiffimo defyderio herbarium tuum expectem, Meg. De hoc mihi inItaliamufq q $_{3}$ criptum eft, atq $q_{3}$ utinam tandé eum abfolutum uideam. Cord. Ne inchoatus quidem eft, neqz inchoandü fperate. Ral, Quid audio: Cord. Quod uerum eft, Ral. Non fcribis ergo herbarium? Cord.Nullú. Ral. Nonne recepiftite quëdam de medicis rebus filins tuis librum adornare? Quo hunc alio quă herbarij nomineappellë: Cord. Quouis, ubifcripfero, Nig. Cur ergo deftitifti? Cord. Nó deftiti quia nondum incepi, fed fentêtiam mutaui, RAL. Nunc magno mepudore confundis, qui tantå cius omnibus apud nosexpectationéfecerim, Sednon parua fit caula oportet, quas te ab hoe 
inftituto retraxit, ad quod tanto feruore rapiebaris. Cord. Maior eft guuelim. Nig. Qux ergo? Cord.Ignorantia.Nig.Nulla cauffa eft. Meg.Facis quod rari folēt, dum infcitiă tuam, fi qua modoeft, Cord.Maxima. Meg. Tam in genue fateris, Complures enim magis ut doeti appareant,ğut fint, ftudent. Cord. Nung̈ placuit mihi fucus, apertus fum, ut fruftra quis feneftratum mihi pectus optauerit.Nig. Nifi te modeftiorē fimpliciorem ${ }_{q_{3}}$ fcirem furpicarer te aliquoderuditionis tux Encomium defyde rare.Cord.Eruditio nung̈ fatis laudari poteft, red mea ne nominanda quidem eft, Ral,Efto, tanta, quantæ te inffimulas, ignorantia fueris, cur eam non prius quàm hanc nobisf́pemere xeras,agnouifti: Cord.Quia quod poftea didi ci, tum nefciui. Ral, Ergo difcereelt ignorantram conciliare: Cord. Quo plus didiceris, eo minus te fcire cognofces: Meg. Verum id, hine ille dixit: hoc unum fcio, quod nihıl fcio, Cor. Fateor, cum animaduerterē plerofqg imo oẽs fere pharmacopolas in tăta errorum caligine uerfari, ut ne dimídiă quidem partem eorum, quæ illisf fribimus, fimplicium uel nofcantue! habeant, doluiuehementer, et qualëcunq, huie rei opem pro uirili mea ferreuolui: Non quod tantæ moli pares me humeros habere confide 
rem, fed ut onus illud fubeuntibus athlantibus quotus ego quafi tibicen affifterê: Solent eñ́ in erigendis apud nos ædificiijs nổ ingentia tantü faxa, uerum $\&$ fifiles adeo'fy tenues lapides, fragiles'qu affulæ, donecipfum fundamentum fubijciatur infarciri, \& de hinc abijci:Vbi aute fuperioribus núdinis Frăcofordi nouos quols dam nouoz: medicorum libros emiffem, $\&$ bonameorum partem infigni eruditione pre ditos, græcéć, doctos uiros aliquot, qux ego tentareuolui, præeftitiffe, aliquot uero promittere intelligerë pene fero à ftulto hoc meo $p$ pofito refilin: Omnium tamen maxime abfter ruit me Ioannes Dryander, feu, ut germanico eum nomine appellè, Eychmannus Vetteranus e Gallia nuper reperfus.Qui cum temeritatem hanc meam percepiffet, bono quidem, (ut ego interpretor) animo, fed mirum tamen quăto fupercilio, quanto faftidio, quanta autoritate. quam item contemptim prefentibus Ioanne Ferrario, \& Sebaftiano Augufto affinibus, me irrifit \& ne tale quid tentem, diffuafit. Tu ne, inquiens, in hoc tam docto $\&$ oculato freculo, feriptis tuis prodire in publicum audebis: Defifte obfecro bone Corde, ne toti te mundo de ridendum, \& ludibrio propines. Tamfano ac amico confilio, quo meæulle me inf́citiæ tă can 
14. EVRICII CORDI

dide \& fideliter admonuit,nó acquiefcam? Ad huc ego inter tain dulce canêtes olores fibilus anfer perftrepani? Meg. Tam fubito in medicina adeo profecit Dryander ille, ut tătum fibi arroget? \& hrectibi quondam pręceptorifuo dicere nố uereatur? Nig. Conincio quale fit ho minis ingenium exindole illa, quă olim Erfor dix, dum puer tuis effet, perfpexi, fi modo eft; quem dominum famulú uocare folebas. Cor. Idem, fed longe alius iam uit eft: Dixitquogs Iohannem Ruelliü, nefcio quæ de herbis ęditu rum. Legiftis \& ipfrLeonhardum Fuchfiúno uas pádectas polliceri: $\mathrm{VtOtthonem} \mathrm{Brunfel}$ fium taceam, cuius toties promiffa fynonima propediem uidebitis. Interim ingẽtes eius To mi circurnferuntur, \& magnøapplaufu legun tur. Ad quos \& uos remitto, fiDiofcoridem, fieius interpretes $\&$ fcholiaftas Hermolaum Barbarum, \& Virgilium Marcellú, alios'qu me dicæ rei fcriptores coniunctim habere defyde ratis.Nig. Placent in eis ad genetricé naturam expreffæ herbarum Icones \& Cord. Quo fimi-

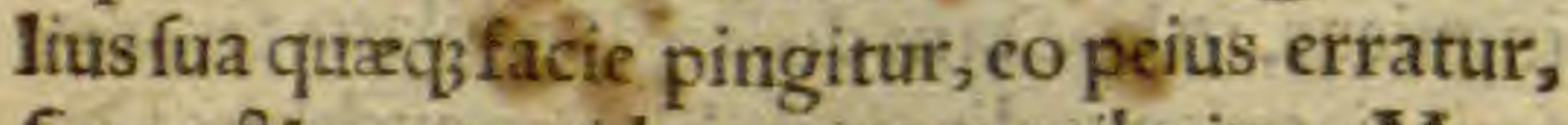
fi non \& uerum eidem nomen tribuitur. $\mathrm{Meg}$. Id ergonon factum putas? Cord,Sunt nớnulia quæ diligentius perpenfa \& circüfpectauelim: Quod non ideo dico, ut bonuี illum \& eruditü 


\section{BOTANOLOGICON.}

uirum fugillem, imo egregium eius conatuni laudo, boníg; confulo, adeóq multis gratiam habeo+Nig. Interim periculofi Funt harum rerum errores. Cord. Eos ipfe ali quando penitiora huius icientix adyta ingref fus repurgabit, tam feruens eft eius ftudium \& indefeffa in colligëdo fedulitas.Nig.Dolet qui bufdam uietis rancidis'́z medicis quod tătum ram fubito poffit. Cord. Plus unus is preftitit paucis illis annis $\mathrm{g}$ tota cốtemnentiü eum col huies, tasto, dum medicină profitêtur, tempo re.Meg.Dum hanc illi cură negligunt, oportet ut fint, qui fufcipiant, Nig* Solent, qui bonas Ii teras feetantur, longe aptiora ad omné etian fcientiam ingenia habere, g̈ amufum illud doctorculorñuulgus, Cord, Sed interim ab illis etiam ftrenue contemni, fugillari, \& nihil minus $\ddot{q}$ medici reputari, quafi, qui eruditus eft, huic ineptus ftudio fit. Meg. Quẫ autể ob rem, $\$$ unde hrec, malü, urefania? Cord. Nefcio, fed it fieri uel iṕe cöperi,etenim quidam æmulus meus, quod, cum ei uocatus ad rgrun collega cổmifius effem,erroneă in medendo rationem à me nō probari intelligeret, \& futo tamen folius omia confflio geri, primas' $q_{3}$ ęftimationis partes obtinere cuperet, apud eum, qui me uocauit, ut infcitiă fuam tựetur, poéticum ho' 
16

minē effe me, \& medicas res ignorare infinu lauit.Meg.Si eft quem ego fufpicor, potius eft, pene dixeram quis, quä medicus, Cord, Scio quẽ dicturus eras, ob id etiam plus in delitrijs, quamæftimatione habetur. Nig. Magnă tibi facit iniuriấ,quicüqz fic de te exiftimat, Cord. Hoc de me non uanus \& citra iactantiam affir mare aufim, humanioribus ftudijs, quę tamen infra mediocritatem attigi, me fapiffime fuiffe adiutum, ut ea quę in medicina legi faciliore captu deprehenderim acriori etiā iuditio intel lexerim, imo \& hodie medică materiamexactius ğ uitilitigatores illi, cognof́că atq̧ accómodatius opportunius'q̧ ea uti calleă. Putant qui epigrămata mea legunt,me totü in his pan gendis occupatũ à uerfandis medicis retrahi. Nig* Id falfum uel ipfilibri tui fordidatis fuis auriculis (ut uidi, teftantur. Cord ${ }_{4}$ Porro, fi quando admiffis, ut blandiculz funt, mufis, ad ludicras eane nugas defcendo, nulla id difficulrate aut ingenip fatigatione, imo uegetante po tius recreatione, atq his horis fit, quę feueriori Ftudio non côpetunt:ut uel inter cổuiuandum, uel, quoties aliquo uocor, dum equo infideo in itinere:dum illi, qui me cauillis fuis inceffunt, tempus iftud, q̊d ebrietatibus \& aleis fcaciśq? perdunt, nihil imputent, Mego. Nouimus mi 
Corde, qux ingenij tui dexteritas fit, qua, nefcio quid effe poffit, quod non foelicius quã ftu pidi quidam bardiaffequaris. Nig. Haclaude contentus, quod candidis \& eruditis omnibus places, ofores illos egregie uiciffim contemne. Cord,Id uel nô iuffus facio. Ral. Alio quă quo uelim digredimini, ad inceptum fermonë reuertamur. Ego nouas illas de quos iă dixeras, uel faltem ueteres repurgatas pandectas, una cũ illis Brunfellíị fynonimis tandē euulgari cu perề:Nă unü eft iă hoc ftudiǔet defideriū meū, ut res illas, quibus inftruendũ eft pharmacopo lium, cognofcam, Cord, Om̌res fic affectos uel medicos uelim.Nig. Nunquid Ralla \& tufyno nima illa habes, qux feplafiarij quidă ueluti arcanü \& facrü aliqgd ali 9 ab alio accipiūt, et mul tis uix precib? acdonis, ut ea fibi exfcribereliceat,obtinētr' Ral.Facta mihi eft fernel ea uidē di, nõ autẽ exfcribēdi copia. Cor.Burchardus Mithobius Mathematicus nofter ea habet, \& quafi preciofum thefaurum penes fe cuftodit. Quamuis legenda mihi nuper ultro obtulit, fi forte aliquis eorum ufus effet: At ego, ut fímile pandectis colluuie, , illa reieci, nihil enim dubito non pauciores in j̈s etiă errores fcatere. Meg. O quales lacunę, quę ex huiufmodi pandectage \& fynonimorum fontibus trăffundunt. Cord. 
Impuriffim $x$, atq has aliquis defecandas \& percolandas fufcipiat: hoc plane effet fordidiffimum \& quafi Augiæ ftabulú repurgare. Foe Iicius $\ddot{g}$ his nugis bona ingenia occupari porfunt. Ral.Video quantiluminaria noftra facia tis, qux tamenfi nobis auferant, Helice $\& \$ y$ nofura auferent \& omnes piftilli, omnia item mortaria noftra ceffabunt.Cord.Défiores ers rorum tenebræ funt, quã ut his prælucentibus quafi cicindulis abftrufam in eis ueritatē inda gare queamus: Alterius tamen, puta Maioris Luminaris autor,Iohănes Iacobus Mâlius nổ ubiq' difplicet, ut diligentior taliürerum fcrutator.Sed fatis de his, tanta mea neq, eruditio, neqg autoritas eft, ut fuper eiufmodi uiros ceu conftitutus iudex cenforiā uirgă ufurpê.Meg. Liberum eft cuiufq̧ iudiciŭ, Publicum ædificium, uarias cenfuras pati oportet Quid aliud agamus, g̈ ut medicide medicisrebus confabu Iemur? Ral.Scripfifti mihi nuper, imo \& in libello tuo de Pleudotheriaca oftedis teuerum amomü deprehendiffe, \& penes te habere: id ut exhibeas, oro.Meg.Id admodum uidere cu pio.Nig. Riferüt te quidă apud nos feioli,cum in eodê libello hrefuper amomo xैba legerët, Cord.More id fuo fecerüt, at rideant me quan rumuis uelint Democriti illi ego uiciffim eos 
Heraclitus defleo, Quod ego a momum credo uobis monftrabo. Videte, côferte, \&ciudicate ipfi num errë. Aperi fcrinium uxor, \& Hieris chütida pfer.Meg.Hierichũtida rofam: Cor. Sic appellăt, unde fumpto noie ignoro. Hắc cu

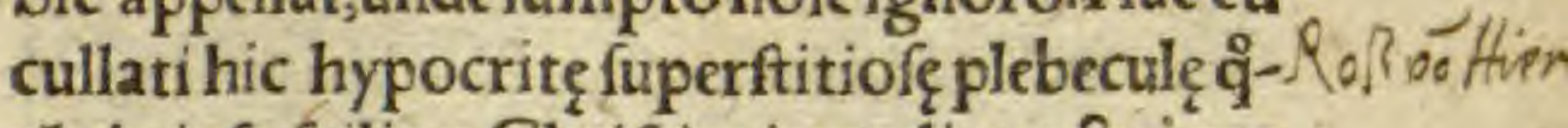
tănis, ipfa filicet Chriftiani natalis nocte, qua fifacrü fpectaculü,adéḉ miraculum nuper ex- 0 , hibuerunt. Quod tum ea fponte fua feaperire $\&$ ramulos furos exporrigere crederetur, cum tamen idfemper faciat, quando madefit.Nig. Papr, qualis planta! RALLA, Quam fuauis odor: M E GOB A C C H V S.Putas hocue rum amomum effe? CORdus. Intuemini, \& Amomi hiftoriam in Diofcoride adhibete. Nonfpero uos eum authe: em reijcere, qui omnium optime \& ueriffime, medicas res, quä tum ad depingendas earum imagines attinet, expreffit, etiam tefte Galeno: Imo huic uni plus fidei habendum quàm trecentis pandectis, omnibus'qz, qui hinc conforipti funt, herbarijs. Adhunc uelut ad facram anchoram confugiendum eft, quoties in nofcendis, fims plicibus fuborta fuerit dubitatio \& contro uerfia. Huic affentiendum contra quantum. uis diuturnum \& receptum ufum ac errane tem authoritatem, ME GOB. Nemo eft hic. 
noftrum, nec erit aliquis fapiens medicus, qui hocneget. Cord.En hic caput de Amomo.Vi detis à principio Amomum exiguum fruticem effe ex ligno uux modo in feipfum conuo lutum.Nig. Simillima huius eft figura \& fubftantia. Cord.Defloribus \& folips qux hincde fcribuntur iudicare nố poffumus, ut quæ forte ante centü annos hic perierint fed ruffefcens li gnumuidetis, \& odoră fragrantiam percipitis. Qux hinc fequütur electionis notæ (nam plura Amomigenera funt) nö facile expediun rur, deprauatus enim \& mancus eft illic uerbo rum contextus, de qua re fubiecta ftatim Mar cellifcholia legant. Hoccertum eft, optimum Amomüdenfo confercto'q3 \& implicito habi tu, rufféfcēte itẽligno, acoptimo odore pbari, qux cuncta hicfunt, Videtis item racemofum intus femen, rarũ tamen fed frequentes, equib? idexcidit,loculos et pediculos:Ral,Quod ego A momumuëdo, huic diffimilimủ eft, nempe exiguum \& fufcúfemen. Cord.Multa alia quę non habetisuenditis, non fine magno xgroru periculo.Quifemen effe poteft, cum ipfum ea, quæ, ut fubricitur,Amomis dicitur,fimili fcilicet plăta, fèd fine odore \& femie adulterarifo leat? Meg.Certe Corde nó temerarium eftiudicium tuum, habet perfuadentemrationem. 


\section{BOTANOLOGICON.}

Cord. Qux in fine capitis uer ba funt opinioni mexe tiam patrocinanť. Vbi Diolcorides docet in huiufmodi rerũ probationibus uitanda effe fragmenta, eligenda' qj $_{3}$ illa quæ ab una radi ceintegros ramos habeăt. Videtis hic ab una radice plurimos ramulos trina femper diuifione multiplicari, donec minimis tădē cirris conuoluant̂̉, \& fingula interualla, maxíe à prin cipio ueluti columbinos pedes referre. Vthine fufpicer columbinum pedem hanc plantă ab Arabe Serapione dici, quanğ tota etiă uua ean dem fere formă affimilet. Ral.Nos aliam herbam columbinū pedẽ appellamus, Cor. Scio, profundi` crenata folia habet, alio quoq; noie Rupertiană dictam. Hincetiam eo deuentum eft erroris, ut congenerem, nempegruina roftra proferentem ac bene olentem ob id'q $q_{3}$ mo fchatam acum diçă herbă pro ipfo Amomo complures medici credant.Meg. Aliud Amomum, ğDiofcorides depingit, Plinius nouiffe uidetur. Cord.Idneq3 me latet, Diofcoridem in hacre, non Plinium fequor, donec quifpiam Plinianum illud Amomũexhibeat. Nifi male profpicio, uideo in pốte Gulielmú Bigotium. Meg.Quis eft ille Bigotius?Cord. Vnus difcipulorum meogy huc ex Gallia pfectus, home

$$
\text { B } 5
$$


græce \& latinenon uulgariter peritus \& $\mathrm{ad} \mathrm{ml}$ raculum ufque in ftudio affiduus, ob id'qg mihi non infrequens falutator, Nig. Siplacet eum accerfe, Cord.Sigallico ingenio pręditum ho minem ferre poteftis, Meg, Affueui Italis, $\mathrm{Hi}$ Ipanis \& Gallis.Nig. Ageuocet. Cord. I puer 8 ftantem in ponte Gallum ad me uenire iube, Ral. Ex Gallia hucueniunt difcipuli? Cor. Imo \& ex Anglia \& Scotia, RAL. Adde \& ex Vtopia.Cord.Ne id breui fiat ueteor, fi iă qua lis incepit literapz contemptus latius graffari perrexerit.Nig. Perpetuis laudibus dignus eft princeps Philippus, Qui tantă labentibus lite ris opê fert, ut nouam fcholă tot ueteribus iă corruentibus erigat, occidētiáđ̧̧ paffim bona rum artium ftudia inftauret. Sed utinăfirmŭ perpetuun'qu fit hoceius tam utile \& necefiarium inftitutum, mentiătur'q ${ }_{3}$ qui id temporaneum direptarū monafticaßł opum pratextü interpretătur. Cord. Syncerior \& magis pius eft euăgelici principis animus, quă ut tăti doli infimularidebeat uel poffit. Imo maior eft ei honeftatis refpectus q̄ut talem de fe famã ad pofteros fuos tranímittat, Meg. Vereor tamē ne fint, non tantum ex equeftri ordine Analphabeti Idiotx, qui magis arma g̈ ingenia fua expoliūt, tantumíg literas quátülituras a mät, 
verum etiam inter proceres aulicos habiti nố infimi uiri, q cú indignante Iuda fecum muffitent, quid hæe tanta in nihili res perditio? Et pium ergáquj doctos nố male affectum principem ab hoc tam Chriftiano propofito retra hant,Nig +Qui id faciunt, ut nó prudentes, ita etiam nổ boni funt uiri, Cord,Pleriqu, hom̌ies non tă ut boni, quă ut diuites fint curant. Qui uniuerfas tũ artes, tum refpublicas periclitari, imo horridiorẽ, g̈ unğ fuerit, barbariê repullu lare finerêt, modo rebus fuis cöfulăt. Nig.Hos utinam in quacunq, metalloge fodina uinctos feruos uerberari potius, ğ in celebri aula cốpi cuos fumoz uenditores coli, adorariqg afpiciam. Ral. Cui hæc principis liberalitas nocet? cui fubditozı non cốmodat? Gals Salue uenes rande preceptor. Cord.Tu quoq; falue multü amate propter ftudium tuum dif́cipule, Quid noui adfers? Gal,Nihil, iuffus ad te uenire, adfum. Cord. Recte factum, accipe \& bibe. GAI. Non fitio.Cord + Nonergo nifi fitiens bibis? GAL.Non temere, nec libenter. Cord,Et me dice $\&$ Gallice facis, utinam eundem morem \& Germani noftri haberent, \& inuēta aliquan do Oenagra, abfqueuino hilariores conuenixent.MEGO. Tali facultate pręditam herbam, memini, Eoban 9 nofter optare folebar. 


\section{EVRICII CORDI}

Nig. Si nancifferetur, multis ille nummis pars ceret, Cord ${ }_{*}$ At Kego pluribus, fi Scythicē Spar taniam, \& Hippicen, \& Latacen habere côttin geret: Nung̈ famerem nec fitirem, imo omniü copia rerum iugiter afflueré, RAL. Incomparabiles adeoque fabulofas herbas narras. Cord. Imo quales Plinius tradit At dicbona fide mi Galle, quam in ponte gallinã opperiebaris? Gal,More tuo iocaris, ad te ibam, ue rumubi te holpites habere audirem, pręterī. Cord.Vis igitur mihi aliquid!Gal,Nihilultra folitum, ut filicet te pro côfuetudine rus peten tem comitarer, aliquotque herbas difcerem. Cord.Quid eft quod te melius quam feplafiarius Thomas Meles docere queam? GAL Egon' ab indocto homine difcam. Cord.Nöne tu eum tibi magiftrum tuum conduxifti? Gal,Iam intelligo quo tendas: Age quis hune ludum tibi narrauit:Cord.Quodfciam audis, fed tu eundem mihi recêfe, ut audiam an recte acceperim. GAl. Adiui hominem, \&, ut gloriofus fciolus eft, interrogaui quid darē ut aliquot me fimplicia, que uocamus, docere $\&$ in pyxidibus fuis, ut cognofcerem, exhibere ue lit. Tum decem à me aureos, \& ut filium fuum in graca Grammatica inftituerem, popofcit. Ego nimium finxi, quicquid tamen 
Burchardus Mithobius decreuerit, me daturum confenf, Eft enim hic familiaris illius cô gerro, Cord,Scio \& experior. Gal,Pactū pla cet, afcendimus fuperiorem exedram, monftrat aliquotherbas, quarum tamen paruam admodum cognitionem tenere eum animad uerti, deinde, cum in tabernã uentum eft,centum mihi pretiofa exotica exhibet. Cord.No mina tantum,Gal,Imo\&res.Cord.Sed non illisnominibus fignificatas, Gal.Id ignoro. Cord.Perge.Gal. Tandem arcanas qualdam receptulas mihi communicare pollicetur, que damq, ut ita loquar, fuperdoetoralia experimenta iactar, quibus, ubi defperantes doctores defierint ipfedeftitutos ęgros curare incipiat,fed omnium maxime quendam efficaciffimum contra lumbricos puluerem, cuius ma giftralem compofitionem chariffimos etiam amicos crelarit, Ral, Tam ne craffe ambitiofus et philautus eft homo? Cord.Nố credipoteft quanti fe reftimet, quàm doctum fe medicum affluentibus rufticis uenditet, quàm nihili me fui refpectu faciat, Tantum abeft ut aliquid ex me difcere cupiat:Interim, pene dixeram, infignis afinus, ne fabas quidē nouit. Ral. Ego Lypfeníes doctores, ut par eft, dominos \& praceptores meos ueneror, fuŕpicio,\& ad- 
26

\section{EVRICII CORDI}

oro, Sciens me eorum effe miniftrum, Idem ne facit eplafiarius tuus? Cord. Tu audiêtem illum feplafiarium meum appella, qui mefamulum fuum uocare folet. Meg, Heiinfanus eft,et indignior, quàm cuius mentio fiat. Relin quatur fuæ ille ftultitiæ $\&$ nos rem noftră tra ctemus,Nig.Quantum ex moribus illius con ajcio, forte nuper monachus fuit. Cord. Rem acu tetigifti, Nig. Quem olim monachi nune nihilo melius (ut uideo) genus apoftatæ perfe quuntur. Megobac. Quinuna omnes tecum Corde, quod Gallus hic cupit, herbas inquifitum imus! Ral. Vt hoc petentibus nobis non recufes, oro. Cordus, Ego facilis fum, \& ea facilior quod fperem à uobis me aliquiddifce re. Niger + A nobis tu difces? Cordus , Quid ni ' cumà uiliffimis nonnunquam muliercuis \& colonis didicerim. Non pudet meuelà, minimo puero doceri, ne dum à uobis doctiffimis uiris , Quando itaque libet eamus, nulla in me mora erit, ego tamen, etiam fi nulli adeffetis, ultro pro confuetudine mea exiuiffem, fampto mecum uno \& aitero libello.Ma xime enim ruri delector, ubi coram uiuas illas, de quibus domilegeram, herbas ad commendatas memorię effigies confero, \& cốtem plor, ipfaśg tum nomenclaturas, tumetiam 


\section{BOTANOLOGICON.}

uires ab obuijs uetulis exploro, dehinc collatis ad earum hiftorias omnibus maturo $\& \overrightarrow{\mathrm{g}}$ fagace poffum iudicio uel decernoluel opinor. Gallus. V tinam imitatus te fuerit Brunfelfius, qui bonam herbarumfuarum partemnon ad hiftoricam fidem fed uulgarem potius indicationem \& opinionem pinxit. Cordus, Qui tu fcis? Gal. Duos eius Tomos legi, \& cum Diofcoride contuli, Cord, Boni confulendus eft conatus, \& prætereunda funt, fi qua funt, er rata, feligenda uero recte dicta. Gal, Quid fi interim Plaufibile opus nouitate \& authoritate fua rudibus adhuc lectoribus imponat, \& euellendi potius ueterum errores radices fuas altius infigant?:Ego tacendū non puto. Cord. Loquere igitur, \& fi placet clama. Gal . Hæc tua potius fuerit prouncia. Cord. Longe indoctior eft Cordus, quàmut hanc difputatio nê,uel cum minima laude fufcipiat: Ambiant eam qui uelint, ego pro tenuitate mea id qquod fcio, \& in quo adhuc hæreo, candide, \& apertis mufarüforibus indicabo, paratus quę mee lius me fcitis àuobis fine pudore difcere. RaI ${ }_{6}$ Quid ftamus? Cord. Da puer leuiorem tunicam, 8 minorem Diofcoridem tecum accipe. Nig. Bene admones, unus hic author fatis eft. Gal. Duos ego Brunfelfij Tomos habeo. 
Cord. Si placet hunc prius hortulum meum, qui domui iungitur, intremus. Meg. Placer, i præ, nos te fequemur, Cord.Deponat qui ha bet cornua, non nifi humiles hæcianua tranfmittit. Ral.Pro mea ftatura facta eft.Megob. Quàm amoenas hic amoenitates habes Corde. Cord . Sed quas aliquando relinquere cogar. Nig. Putabam hanc domum tuam effe? Cord . Princeps quidem, ut effet, mihi dedit, fed funt quidă aduerfarị mei authores, ut rurfum auferať, fic muf̣̂ităs rumor detulit, quod fífiet, alio cốcedam. Nam hrecuniça eft ancho ra, quxe hactenus me in Heffia mea retinuit. Nig.Hoc dij prohibeant, ut tu hinc demigres, propter quem folum hucueni. Cord . Confilia mea, \& quæ me cauffa urgeat nobis amicis meis à cœena aperiam:Iam rem noftram profequemur. Ral.Seuifti uideo quod mifi, fylueftris cucumeris femen, Cord, Seui id tum ftatim, \& magno iă foenore aucta eft planta.Ral. Ita folet, nam fponte fua maturum femen eiaculatur. Cord, Valerius meus ut diligens eft iu uenis, \& f ftudiofus farum rerum obferuator, proxima rftateex multis fructibus uix pau-

? cos Elatărij paftillos côfecit, quos, quia commodú in pyxidula penes me habeo, tibi exhibebo, ut f́iam an bonum fit Elateripha, non- 
dum eo aufusfum uti. Ral. Tale eft $\&$ meum. Cord. Sed iftum colorem Diofcorides impro bat. Nig. Verú eft, illud enim probatiffimum Elaterium dicit, quod candido colore humefcit, quod leuitatem fimul \& lauorem habet. Obidetiam,ut idem ait, Amylo quidă ipfum adulterant. Contra, quod uirefcit, maluni dicit.Meg.Paulus tamen Aegineta id commendat, interprete Albano Torino,ubi de purgan tibus medicinis agit. Cord.Secundum Diofco ridếpraferiptum iddiligenter factum eft, nec alius, quàm quem uidetis, color refultat, fed ex radicibus candidum fit. Ita nefcio analiquid in eo capite defyderetur : Et ut de colore conftet, de bonitate tamen eius, quxe exætate eft, noneadem tradunt authores. Diofcorides bi mum illud ufq; addecennium purgationibus aptum dicit, Aegineta uero quod uno anno nö antiquius eft, probat. Cótra utrunq; eft Theo phraftus, qui omnium medicamētorum diuturniffimum, opportunumiq', quod ueturfiffimumeft,Elaterium fcribit. Nig. Cui ergo illorum credidebet? Cord. Id me doctioribus iudicandum relinquo. Gal. Difficile fuerit mihi medicinæ ftudium, fi multę tales controuer fre occurrant, Cord. Nihil moror,fi humile medicogs uulgus inter fe diuerfi,imo \& ficon- 


\section{$30 \quad$ EVRICII CORDI}

tra antiquos proceres nugentur. Quis enim tunc rationē $\&$ autoritatê non fequatur ? Sed cum ipfa capita \& principes medici contrarijs fententijs diffident, hoc dubium facit com pitum. Ral. En hic Ceruinam linguam, eam tu affinis Corde Scolopendriam effe adhuc ne gas? Cord. Conftantiffime. Ral, At hoceft contra cốmunë fere omnium medicorum cổ fenfum, \& iam multis freculis receptum ufum. Cord,Nihil moror, Ral,Et nifi perfuaferis re giam uiam non deferam. Cord. Vide eius hiftoriam. Ral. Nulla eft in indice Scolopendria. Cord, Quare Afplenố, nam hocetiam illino méeft.Ral.Habeo.Cord.Lege igitur, Ral.Ne fcio quale Scolopendra infectum fit, cui fimilia folia dicit. Cord. Vermis eft multis pedibus, quibus non aliter ac nauis remigio fuo (ue lut Nicander ait ) progreditur, Et fi maxime ignores, legis eam herbam Polypodij modo incifuris diuifam effe, quod de hac lingua $\mathrm{Cer}$ uina dicere nố poffumus. Nig. Vides ob ideti am Pteryga eam Gręce uocari, à pinnis fcilicet quas inftar filicıs habet. Cord. Virgilius tamë Marcellus dum ad Ceruinam Linguam plus g̈ ad Diofcoridx uerba animú fuum intếdit, incerta rei indicatione fic appellari, nihi' $q_{3}$ in $m$ m Scolopendria pinnatumuideri dicit, non ani- 


\section{BOTANOLOGICON.}

maduertens quod inferius alteram Lonchitem idem author fimiliter incifis folins eidem Scolopendriæ comparet. Meg. Credis nunc Ralla Ceruinam Linguam \& Scolopendriam diuerfas herbas? Ral. Facile perfuaderer, fi qua nam alia herba Ceruina Lingua fit, indicetur, \& eo faciliss quod in Maiore Luminare Ceterach ueram Scolopendriam effe, fi recte memini, legerim. Cord. Iam anteuertis me, fed lege etiam qua Simon Genuates in Afpleno, Ceterach, Splenio, \& Scolopendria dicit, \& plane in fententiam meam non inuitis pedibus ibis, Megobac. Hanc Scolopen driam feu Ceterach olim à Latinis Calcifragam appellată in Scribonio obferuaui, quod calculum frangat. Cordus. In Saxonia interrogatus quidam Agyrthes Spicantumnomi nauit. Audiui \& faxatilem filiculam appellari + Nig , Eft huicut iam dixifti fimilima lonchitis altera, quare cautos effe nos oportet, ne fallamur. Cord. Nullum in hocpericulum ef, quantumad curandumi fílenem attinet, eandể enim hic ut fimilitudinem fic \& facultatem habet + Ralla , Tabernæe noftræe noneandem omnes cetarachexhibent: Sunt enim quitenerrimam quandam \& minutifimam, fubtiliffimég incifam filiculam pro ea accipiant, 
uulnerariam feilicetherbam. Cord. Propte rea diligentius confulendam//fpleni hiftoriam duxero, in qua, quia non defcripta fed qua fitunc omnibus nota preterita eft radix, in al teram muris auricula cognofcëda uenit, facta ibidēadillă cốparatione, etenim cü murisaurıculæe radicem digitali craffitudine multis'̧́ f. capillamétis quibratam Diofcorides, dicit ftatim fubiügit in uniuerfum eam fcolopendrio fimilem, minorem tamen, \& maioris quàm il lam lauoriseffe, quod illi (quam dicis \& ego noui) filiculęnon congruit, Ral. Nondum quę ceruina lingua apud Diofcoridem fit audio, Cord.In Nicandro meo, quẽ tibi mifi, ad mar ginem fignaui non legiftic Gal.Petaliten in lin guam ceruinam uertifti.Cord.Eadem Phillitis eft.Ral.Hiftoriam eius legam, Cord.Et fequentia eă fcholia. Ral.Ita me dị bene ament, ut non male omnia répondent. Cord.Afpicis fimilem rumici figuram?'Ral.Quęrumex her ba eft? Cord. Quamuos lapatiú dicitis, cum lapathon debeatis. Ral. Idem fere afpectus, Cord,En natiuum lęuorem, \& pendêtes à ter go uelutiuermiculos. Meg. Et acerbus fapor eft . Nig. Et foliofum potius cefpitem uideo Cord. Nec natalis locus diffidet, in umbrofis enimlocis \& imis turribus, unde \& Pyrgitis 


\section{BOTANOLOGICON.}

dicta,nafcitur.Ral.Vidi \& in opacis fylueftribus fcatere. Hinc colligêtes radicarij agyrthæ uænalem eam magnis farcinis circumferunt, propter fcolopendriæ, quæ creditur, uirtutes expetitam. Cord.Diofcorides eam contra fer pentium morfus, \& inteftinorum tormina, adeoque alui fluores, quos Diarthiamuocant, $r$ cómendat. Nig.Vnus adhuc fcrupulus reftat, quem fi mihi exemeris, tecum fentiam, Cord. Quis ille? Nig. Nicolaus Leonicenus, fi recte memini ineo libello, quem de aliquot medicorum erratis fcripfit, af́plenó quidem feu fco lopendriam negauit ceruinam linguam effe, fed aliam interim putauit, nempe fequentem mox hemionitida, nó hăc phyllitida.Cor.Me quoq, hac eius opinio diu hrefitabundum, ne facile crederem, detinuit \& rorfit, nec libenter à tam docto uiro \& quidem præceptore meo diffenfi,Megob.Satius eft à pręceptore quam tueritate difcedere. Nig. Potiora funt rationis ga authoritatis momenta,Cord,Vbitamë cer uinā linguam adutranç, phyllitidos fcilicet et hemionitidos, hiftoriam cốtuliffem uicit illa, nă hæe nố undiquaqg huic herbæ congruere ui debatur, Maxime quod non lunata folia funt, qualia diftæhemionitidi tribuuntur. Vidi ta men ceruinam linguam talia guodammodo 
folia habere, fed in muro ob nutrimenti defectum \& natalis loci anguftiam potius fic deprauata.At ego Diofcoridem libere nata \& à medităte natura fic perfecta hemionitidos fo lia'defcribere intelligo.Meg.Mirum eft Theo dorum Gazam doctiffimum alioqui uirum hæc non animaduertiffe, qui fimili errore fcolopendrion feu af́plenon ceruinam linguam interpretatus eft. Cord.Cum nimio ftudio au gendæ latin $x$ lingux teneretur, $\&$ omnes in uniuerfum fere medici ceruinam linguam ueram effe fcolopendriam putarent, facilenon profentius rem perfípicienti uiro impofitum eft. Ral, Potuiffent faltem exnulla fplenem iu uandi ui,errorem fuum, utentes phyllitide pro fcolopendria, medici deprehendere. Cor+Cur idem non fecerunt $\&$ adhuc non faciunt in cicutæ femine, quo pro fylueftris rutæ femine, quantumuis doctiores reclament, utuntur, nó fine magno xgrotantium periculo, nedum cum aliqua medendi facultate. Tam indulget fuccedens errori opinio. Niger.Idem in dicta cornicis pede peccatur, quam falfo, (ut fcitis) Diofcoridre adeoque ueterum coronopoda credunt. Gal, Quxe nam huius in hac ceruina lingua erroris anfa fuit Cordus, Forte indem natales \& eifdem uerbis defcripta hiftoriz bo 
na pars, nempe qua utraque, ceruina filicet lingua $8 \mathrm{C}$ arplenos, fine caule, fine flore, \& $\mathrm{fi}$ nefemine indicatur. Gallus. In Nicandro tamen legicaulem fcolopendrix tribui, Cord. Quee non poětis permiffa licentia? Haceadem Virgilius \& Statius dictamno florem affingunt, quem tamen Diofcor ides negat.Ral, Quam in noftra etiam regione radicarin agyrthre dictamnum effodiunt, floret, \& femen nancifcitur. Cordus, Vera nos dictamno carere multa argumenta funt ut credam. Gal. Cum Nicander tot contra uenenatos morfus herbas enumeret, mirz q̊d huius dictamn;, cuius pracipua contra eos facultas eft, nurquam meminerit. Cord. Forte alia in eo hoc nomenclatura latet. Nig. Quam pulchros hic flores uideo, quo illi nomine uocantur: Cord. Hi funt quos tu in Policiani ruftico difcipulis meis Erfordix quondam immortales amaranthos interpretatus es, fic dictos, quod fere nunquam marceicant. Nig. Nunquam, quod fciam, antehac uidi. Ral. Amoris fores nune appellamus, quam autem ob cauffam igno ro.Niger. Forte quod eius fymbolum gerunt, quemadnodũ enim illi in marceffibiles funt, fic $\&$ is effe debet. Cord. Egotamen hanc uero fumiliorem puto, quod qui eos fic primum

C 2 
dixit amaranthum ex amore $\&$ antho, (quo omnes iam uel male latini medici florem Grę cis fignificari fciunt) componi crediderit. Megobac. De hoc nihil curandum. Videndum potius quem in medicina effectum habeant. Cordus. Nullum quem me legiffe meminerim.Gallus,Magnum domine.Cordus, Quem ergo? Gal, Galenus incidentem \& extenuantem amarantho facultatem tribuit, \&comam eius menfes ducere, grumos item fanguinis non tantum in uentre fed $\&$ in uefica foluere, imo omnes fluxiones deficcare dicit. Cord, Non hancille herbamfed aliam intelligit à Diofcoride heliochryfum dictam, quę etiam amaranthus appellatur, quod \& 2 ius immarceffibilis flos fit, Hinc \& noftrates puellix hyemales fibi corollas exutraq, fimul amarantho faciunt. Ral.Nofti ego heliochry r fum:Cord. Omnes eam uos pariter nouiftis, non hoc tamen fed citrinæ ftecadis nomine,

- in qua etiam herba multi herbarij errant,eam cum Seriphio, i.marino abfinthio falfocommifcêtes. Ni. Paulus tamẽ Aegineta duo facit de amarātho \& heliochryfo capita, quafi due diuerfo herbx fint. Cord,Idem in multis alinjs facit,ignoransne, an abunde diligens nefcio. Meg.Ingbus ergo? Cord. Diuerfas forte het" 
bas credit cacaliam à cancano, neurada à pote. rio,echinố ab erino, myarổ à myagro, chamæ drynà chamęrope. Nig.Si hos peccatüeft tüc magnus ille Plinius fimiliter \& quidem crebri us peccat, melius eft de eadem re bis quam nihil dicere. Ral, Putas ergo citrinam ftoccada dietam à Diofcoride heliochryfum \& Galeni amaranthon effe? Cord. Sic mihi perfuafi,licet foliorum ad abrotanum comparatio aliquádiu me retinuerit. Meg.Duplex ergo ama ranthus,purpureus feilicet $\&$ luteus eft.Cord. Vt dicis, ille plane nullo, hic autem nö iniucun do odore. Ral, Hac forte cauffa, quod ueftib" interponitur. Cord.Imo, quodà tineis eas tue ricreditur, ob id etiã tinearia à plerifqaz dicta, Gal. Tineariamego poliü effe in Brunfelfio le gi, Cord.Id non aureä fed albam comă habet. Nig,Plinius aureos quoq; bulbos Heliochryfo fuo tribuit.Cor,Putoillic errari, \& pro bul bis bullis forte legidebere.Meg.Quid fipericu lï faciamus de hacherba?non histantü, quas Diofcorides receêfet, facultatibus, fed \& illo q̊a Theophraftus de ea tradidit, nempegratiam \& uitæ gloriam eum confequutury, qui heliochryfifloribus coronetur, Cord. Falfum hoc uel hinc arguirur, quod multx hic puells hac herba coronatę incedăț \& peffimam interim 
famam habeant. Nig. Imouerum effe Theophraftum conitaret, fi quodibidem quoq; faci endum fequitur, aureo fe illæ unguento infper gant. Cord.At ego aliam hac facultate pradi tam herbă fcio, frusğ reperiri poffit,non enim temere, nec paffim, led maxima difficultate \& rariffime na'citur, Ral.Quod ei nomen?Cor. Virtuti. Nig.Id credere nō eft fuperftitiofi ho minis, Meg. Putabam te antirrhinum intelligere, de quo idē Theophraftus nefcio qd fimi le promittit. Cord. Ei qui illo ungitur, gratiă cốciliari,Nig. Eadem apud Plinium de Polio uanitas. Cord. De tripolio autem id intelligi debere, apud Leonicenü puto uos legiffe. Por ro quiddabitis \& antirrhinum illam uobis in dicabo? Ral.Euge nofti? Cor. En hic decerpe, Ral. Hæc eft quam hodic orant appellamus. Cord.Marcolpho ei nomen indatis, per meli cet,modo res ipfa conftet. Gal.Hrecnon eft he deracei folin fimilitudo, qua quofdam xtatis noftræ herbarios eam herbă deprēdiffe Virg. Marcellus dicit.Cord.Quam \& an ueram antirrhinó deprenderint, nefcio: Certe in hac de inceps adnata uirulina capita, unde \& bucrani onea Galeno ditza,et patulas in eis nares uide tis. Neqg fcio qui hederaceum ei folium cốgru at cum id Diofcorides anagallidi, Theophra- 
ftusuero aparinæe comparet, fed hoc neutram referre, imo lino, (ut etiă quidá dix erunt,) ma gis fimile uidet. Suboritur ergo fúpicio nunquid antirrhinố eadẽ cynocephalex herba fit, à fimilibus fcilicet capitibus, qux eadē \& Ofiri tes, q̊d ofirim, id eft, linariam fere exprimat, di citur.Ral.Ofirim linariam appellas? Cor, Cö fer eius ad hane caput, \& eandê dices, quătum ad figură attinet: Nec obftat quod pauciores ibi facultates de Ofiride ğ recentiores medici de linaria fua fcribunt, inuenias, cü hæe ex illis fluất. Nig Si cinocephalea hrec effet, dudū Ra! la nofter expiraffet, modo uera fint qux Appi on, (ut apud Pliniú eft) de ea pdidit,ftatimf́i licet mori eü gcinocephaleă eruit, Ral.Dị me lius, Cord, Tâleuẽ te efíe nố puto, ut huiufma di uanitates credas. Meg. Tecü fentio Corde, \& hắc antirrhinố effe nổ dubito, Cor,Idut fa cias nốurgeo, imo etiă nolo fi temere \& citra pfuadētē rationē fuf́picari \& opinari uideor. Gal.Sed hæc rotundú,nō anagallıdis, caulē ha bet. Cord.Interim tñ tëpore fuo purpureos $\&$ uiolis ferefimiles flores, atq $\mathbf{z}$ illa, unde nomen, capita, \& confpicuas in eis nares.Meg.Et pro minens inter illas quaficorniculum, ut $\&$ rhino ceron appellari poffit.Nig. Proceras atq, elegantes hic habes roxifmarini plantas. Cor.Pe 
rierunt mihi his quatuor non minores alize fex hyemis iniuria, \& nifi has infictilia uafa tranfpofitas domi tepido aere fouiffem, nullas iam haberem. Gal, Vulgaris eft in Gallia herba. Cord. In Italia quoque frequens nafcitur, ubi ea ruftici uenales lepores infarciunt. Nig. Fructum eius cachryn exhiberi mihi uelim, cuius crebra apud antiquos medicos fit mentio. Cord, Quxe cachryn fert herba ne in calida quidem, (ut puto) Italia, nedum in frigida Germania prouenit. Nig.Putabam liba notida Latinerofmarinum dici? Cord. Dici tur quidem, fed hre alia eft, ei ob aliqualem fo liorum fimilitudinem cognominis. Vera liba notis longe diffimili hiftoria indicatur, nempefceniculaceis fed latioribus craffioriburque \& rotæ modo in orbem circumagentibus fe folins, olente thus radice (unde \& nomen) \& copiofo femine confpicua in fummo unbella, multifqualins apud Diofcoridem uidendis no tis. Quibus parum animaduerfis pleriq,imo omnes fere hodie medici uerze illius libanotidos éxiftentes uires huic coronarię libanotidi falfo tribuũt. Meg. Sed quonomine Diofcori des lauandulă hanc appellat:Nonem̌ tã odori feram et multiiam ufus herbã latuiffe eú credi derim. Cor.Ingenue fateor me ignorare, ego 
quoqgiam olim id fcire cupiens ipfum Leonicenum Ferrariæ idem interrogaui, qui $\&$ hã́c coronarię libanotidos fpeciemi efferefpondit. Ligures adeo'́z, Genuates herbarinpro Celtica nardo eam exhibent. Hinc funt qui Celtică fpuan, \& factum hinc oleum, fpicarum oleum nominent, quod uagi apud nos agyrthæ $p$ bal famino oleo uendunt, miferis' g $_{\text {g }}$ modis credētí id uulgo imponunt. Nig. Sed Celtica nardus longe alia res eft, Cord. Id \& ega ficio. RAL. Qux hre eft arbor:Cord, Quxiam Armenia ca mala ferret, nifi intempeftiuo gelu preproperi flores perịffent. Nig. Sunt ne fructus illi, qs Germanice amarellennominamus? Cord. Sic opinor. Meg. Hxc mala ediffe me Erfordix in hortulo tuo memini, quem nunc habet Iohănes Langus *Cord,Noli me amiffarú de litiarum admonere.Meg. Velis itaqg hunc adhuc hortulū poffidens Erfordixe agere. Cord. Nullubilibentius, modotranquillus effetreipu blicę ftatus, fopitæéq\} ciuium diffenfiones, fublatx item religionum fect $x$, fed ante omnia in ftaurata fchola, \& accitis in omni difciplinase genere profefforibus, Meg. Dolédum eft tam celebre quondá gymnafium iam adeo nutare, neminé'q\}, ne prorius corruat $t_{\text {, dorfun firum }}^{-1}$ opponere. Nig. Eobanum noftrum exNoren 


\section{2 \\ EVRICII CORDI}

berga reuocarunt, Cord, Vna hirunda non fa ciet uer. Ingentes fumptus Erfordianũ fenatũ facere oportet, fihincuel mediocriter freque tem fcholam uelit, qualis iam eft rerum muta rio, \& exofum bonas literas freculum. Meg. Si omnino inductas tenebras uolumus, ipfum qque e mundo, folem auferamus.Nig. Permale res cecidit optime Corde, ,perabamus à nouis theologis ipfam fophifticen \& barbariem era dicatum iri,cum nec opinantibus nobis bonis interim literis inflictũ fit paftinum, ut exiguá admodum fpem habeameas unğ poffe repullulare. Hincetiam longa eis dicta falute exem plum tuŭ fequor, et medicinæ mededo.Cord. Recte rebus tuis confulis, ut idē olim facerem preceptor meus Ludouicus Placenta Melon fingus mature $\&$ diu ante has religionis turs bas admonuit. Meg. Superftes ne adhuc optimus ille uir : Cord. Nuper hic nobifcum fuit, inuifit me fuum olim difcipulum, \& fcholam noftram perluftrauit. Totus quidem canus, ue rum proætatefua fatis incolumis eft.Megob. Perpetuũ optime ualear, fic infignís eius pro* bitas meretur,Cord. Idem $\&$ ego precor pro pter plurima eius in me beneficia: Atqjutină ranta mea fuerit aliquando facultas ut eidem \& Ludouico Chriftiano Fräcobergio cogno 
mine fuo dignifimo diuini y̌bi in patria fua difpenfatori etiam meo quondam pręceptori meritam gratiam referre queam. Ral. Noneft præfens de iftisloquëdi locus, herbas inquifitü ingreffi fumus, tales ad coenamfermones refer uate. Non quod fua tam bonis uiris encomia inuideam, fed ut commodo dignius ea tracten rur tempore. Cord.Egonullas hic herbas tis bi incognitas effe exiftimo. Ral. Qux eft illa, medio inter rumicem $\&$ Saracænicam feu Ro manam mentam folio? CORDVS. Nufquă hanenifi hic Marpurgi uidi. Zinziberinam appellăt,atçea eft, quam Arnoldus de uilla no ua in quodam Fori Iulì căpo iuxta nefcio q̊s muros tantum nafci dicit,piperinæe noie quod acrifapore fit: Et hanc accipiendam docet in quodam Iohănis Florentini unguêto, ubi ille Tapfiam habet, qua tamen nomenclatura $\&$ aliam quandam herbain ferulacea fpecie foeniculateis'́g folijs indicarif́citis. Nig. Quodfi capfia legendum fit, quo quidam nomine cerrum nafturciigenus appellant., Ral. Tantis fo lijs nullum effe nafturcium puto, Cord. Non remere fúficaris, Paulus em Aegineta ubicoxēedicis curā docet, agrefte q̊ddă hiberidi cốge ner nafturcium nố multũ his abfimilibus puta laurinis longe tamen maioribus folìs indicat 
RALLA, Forte Arabum feitaragi intelligit. Cord. Id Diofcoridis lepidion eft, quod mihi Ferrariæ minutiorib? alijs'́, folins indicatum eft. Ral. Eft \& dictum feitaragi Indum. Meg Iam fuccurrit Barptholomzum Mŏtagnană in quodam contra elephantiafim confilio Sei taragi Indum fuccum Tapfix (capfix legi de bere puto) interpretari. Nig, Id mex patrocinatur opinioni, Cord. Auicenna fi non aliud aliter tamen feitaragi Indum deferibit,nempe parua \& fubtilia quafi ligni frufta,fimiles' $q_{3}$ ca riophyllis cortices imo \& aliud quod fructus fit adrubedine 8 nigredinem declinans: Mox tamen quafi diuerfum ab his adiecto articulo alfeitaragi herbam fubiungit nafturcij folìs, qux in eftate plurima fint \& paulatim adeo minorenter ut non appareant, Hinc aliquădo fuípicio fubỉit teā effe, quă Saxones rorippā ap pellant. Verum tamen cum idem author folia eius mox cordumeni cõparet, nihil aufim decernere, Meg. Cardamomo igit fimilia effent folia. Arabum enim cordumeni Græcopy cardamomum efféficitis, Cord, Imo herbă à Nicandro hordeilon, à Diofeoridetordylon, ab Aegineta uerogorgylonuocatā, hoc eft Creticumfereli pandectarij medici fic nominant, Quam olin Leonicenus mihi Ferrariæ often 
dit fimilibus putato melilotouerũ minoribus \& in circuitu minutiffime crenatis folijs, qualia neq\} nafturciü (cui Auicēna alfeitaragi fuū affimulari dicit) neqz dicta Saxonib? rorippa habet, cuius folia nifi ualde exilia effent ad fumariam potius accedere uiderentur. Quę pau latim pereuntia ramulos relinquüt nudos $\&$ fe mine in filiculis nafturcij faporeplenos. Sed hæc nihil ad hane fue piperină fiue zinziberinam pertinent. Ral.Vt ex uerbis ruis intelligo neq; uerum melilotum habem', dicebas enim putato meliloto.Cord. De hoc non folus ego imoplures mecum alij dubitant, Obidà Dio f́coride exactius defcriptă eius hiftoriā uelim, Vbi in Italia effem,exhibuit mihi' Vincentius Caprilus hofpés meus in empris ad equi pabu lum graminibus, pro eo herbă quă hic bernklehe id eft urfinum trifolium dicimus. Hæc hactenus Serapionis alchilelmelich hiftoriä exprimit, quod floribus fuis quafi in femicircu lumpofitis, regiam coronă referat, \& pofteos exiles rotundas'gु filiculas habeat, in quibus minora finapis granisfemina. Sed hrec admo dum infirmo, imo quafi nullo eft odore, qui tà menegregius meliloti eft. Neque liguftici folia habet, qux diofcorides meliloto cóparat. Sunt qui herbã, quam Saxones narts appeliăt 
46 EVRICII CORDI

foeno Græco feilicet fpecie $\&$ odore fimilem, nifi c̊d nố in corniculatis fliquis fed echinatis capitulis femen fuum fert, melilotum putent. Qux huic hiftoriæe eius parti refpondet, quan ex Diofcoride Serapion citat. Videlicet effe meliloti genus, quod foeno Gręco affimiletur, quæe tamenuerba in uerfo per Marcellum Dio fcoridenon leguntur.Idem Serapion ipfotan tum femine una cum filiquis fuis utendum do cet, quod non ex Diofcoride colligitur, qui to tam plantam medicinæ accommodat. RAL. Vtcunq, fit, quia dubius relinquor, ufitato haCtenus meliloto me uti oportet, donec uerum cognofcere \& habereliceat Cord.Quam pro ximam uidetis theriacariam hic uulgus nomi nat hanc magis puto hiftoriæ Phu g̈ dictam ualerianam refpondere. Meg. Grădiora funt hæc g̈ ualerianæ folia. Cor + Talia effe oportet fi ceruiocello comparari debeant. Nig. Concauum etiam \& lęuê tenerum'q́a ac in purpura albicătem caulem cernere licet. Cordus. Effo deradicem Ralla \& \& uidebitis hanc quoq hiftoriæ refpondere. RALLA. Eanciem figurä eundein'q3, quem ualeriana, odorem habet tătum maior eft. GAL. Sed ubi funt fimiles nar ciffo flores? CORDVS. Vbiijdem in ualeriana.' in qua plura quàm in hac defunt, que $\mathrm{Phu}$ 
hiftoriam perficiant, NIG. Iam nonuerum effe uideo, quod Brunfelfius ait, $\mathrm{Phu}$ fine controuerfia noftram effeualerianam. CORdus; Quod ego hic decerno hoc tantum eft, hane theriacariamualerianæ inuiribus ubertim re fpondere, finon eam fuperat. Quod autem qui dam hic docti eandem theriacariam Gallicam fpicam effe putant non facile nec temere credo, difcrepante hiftoria, NI G. Tenerum ne hanc foeniculum an anethum dicam? Cor. Audiam quo eam nomine RALLa nofter ap pellet. Ral, Nos meuuel ut nos dicitis meum uocamus. CORdus, Scio at ego Creticum daucum effe leui teftimonio perfuaderer. Con ferte huc utriufque, mei fcilicet $\&$ dauci picturam, $\&$ ipf iudicate num temere opiner. Gal ${ }_{6}$ Qui Germanico fermone appellatis: Cordus, Behrvurt5.Nig.Si peregrinum acranum olim nuncuero nullum in Italia meǔ eft, ut Virgi. Matcellus ait, non id in Germania inueniri pu tarim,GAL. Hanc tu nigellam effe quondam aiebas at Brunfelfius longe alia eam figura $\mathrm{ex}$ hibuit. Cord.Forte in eius manu nố fuit quæ cuiq, herbę facies deliniaret, quanğ non uideo qui defendi poffit cum ex uulgari indicatione Germanicum nomen, radam fcilicet, adiūxerit. Ral,Ego tibi credens, ab eo tempore qु me 
admonuifti, hăc nigellam habeo, fed funt quidam qui non credant, quod non promifcue in pratis,fepibus, hinitibus'q $q_{3}$ ut Virg. Marcellus nec inter frumenta ut alij medici dicunt, fed in hortorũareis fata \& culta nafcatur.Cor, Qua finon alize apud nos herbæ uix diligenti cultu ra proueniant, quaalibi fua fponte fcatēt.Quã illinigellam accipiant uiderint, ego hanc ueram nigellă effe fcio uel à uulgo perfuafus qui, contra deftillationes femen hoclintheolo ins clufum olfacit, Hanc enim nigellæ facultatem omnes medici tribuunt, quod humidum cere brum exiccet. Meg. Videăid \& guftem idem \&'fapor \& afpectus eft illius nigellæ, qua Pata uini \& Veneti mediciutuntur. Nig. Hic iudicium tuumexpecto Corde, qua hos flores no menclatura prifci herbarij indicarint. Cord. Ego quoq, tecü hæreo, multǘq, ac diu fed fru ftra laboraui, ut quod tu me interrogas fcirê. Legi quę multi multa de hisfcribunt, fed ad pa latum meum pauca faciunt, fubferibo his qui artificio quodã factos illos flores, \& antiquis ignotos fuiffe exiftimant.Meg. Inter eos certe \& Manhardus nofter eft, RA1, Nos caryo. phyllos à fimili fcilicet odore, dicim' \& apud Iacobum Manlium maioris Luminaris noftri autorem de eislegiffe me recordor. Cord. 
Hunc inter ueteres non côputo, nec quicquam ille certi, imo ignotum fibi nec ufquă apud aus tores lectum eorum nomë dicit. RaI. Sunt qui herbam tuniciappellēt.Cord,At magnus Me diolanenfis in quodā libello quod fanitatis regimeninfcripfit,ubi de prohibendo uenæno agit, herbam tunici ait effe quam Diofcorides polemonium nuncupat.Id ego ut non negare fic nec affirmare poffum. Gal.Brunfelfius pole moniam fylueftrem rutam dicit.Cord.Dehis qua nefcio non iudico, idem hiberida uincitoxicum interpretatur, an recte, admodum fcire cupio.Nig. Eft ne hrec tithymalus? Cord, Sic appellatur quidem hodie, Diofcorides tamen extra feptem illa tithymalorum genera feorfimponit, \& lathyrida appellat, pro qua in $\mathrm{P} \overline{\mathrm{a}}$ dectis Latua \& inferius alio capite letura legi nur quafi diuerfe herbze fint, cumuna et eadem fit quametiam cataputiam minorë dixit. Sed catapotia Graci plurali fcilicet numero, proferunt, intelligunt'q3 quas nos pilulas dicimus. Pro his enim utentes Italogy ruftci huius her bx fimilibus fructibus hoc ei nomē indiderüt. Ral. Maiorem cataputiă fimiliter nofcere me uelim. Cord.Eamfemel in Germania uidi,nê. pe Caffiliz in horto Iohảnis Rui Nordecij, qui harumetiam regs non parua cupidine tenet.

$$
\text { Mo.Bot. Garden, }
$$


Vocant Germani hăc plantã Vuundelbauin;, Latini ricinü, Gręci crotona \& cici,Arabes ue ro cheruă, Ral, Hinc igit oleü de cherua, cuius tam frequës in receptulis ueftris mêttio fit, exprimiț? Cord,Maxime, cicinü \& ricininü etiä dictum. Sed miror cur illud noftrates medici tam frequent f́ribãt, cum hic nô habeaț, $\mathrm{RaI}_{\text {* }}$ Ego illo \& omnibus quę nố habeo,carere me, ingenue fateor, ut fcribêtes mihi doctores q̆ $^{3}$ uelint fuccedaneas medicinas fubftituăt.Cor. Multa huiuf modi exotica funt, quę magno hic emim', gbus tamể nullo defyderio carerem?; exiftentibus apad nos fimili facultate praditis alïs non difficulter, imo gratis acquifibili= bus. Qualia zinzipha feu ferica, quas iuiubas, mixæ feu mizxe quas febeften, rhos, quem fur-. mach dicitis,ut alia plura taceam. Meg,Tales multi fumus medici ut religiofum putemus à præfcriptis Arabum receptulisuel latũ pilum. recedere. Cord. At femper inuentis uti \& nihil inuenire, nihil mutare, augere, \& minuere audere, id miferi \& cecutiêtis eft ingenij. Quãsquă receptularì illi medicaftri in maxima iă xftimatione fint, \& ad omnes foli ægros uocentur, contemptis interim multis qui nó tans tum laborantibus hominibus melius g̈ illi,fed ipfi quogi medicinæ mederi poffent. Megob، 
Cur \& illi non impoffibilia promittunt, magnifica mentiuntur, \& egregie imponunt? Nig. Id boni \& doctinon faciunt, \& fi uelint, nequeunt. Cord. Iam ego uiciffim à uobis difcere cupio, qua hac herba fit, Meg.Nifi exfo lani generibus fuerit ignoro, Cord.Opinaris ut ego. Niger.Halicacabum forte intelligitis? Cord.Halicacabus eft, $\dddot{\mathrm{g}}$ Arabes et eosimităs medicorú uulgus alkekengi nominăt: Hæc ỳo herba altis \& craffis caulibus furgit, ๆ̊s cernes retis, nifi huc nuper tranflata uixdú coaluerit, folio quali uidetis, halicacabo quide frmili,fed maiore: Floribus ferrugineis apollinaris feu fymphoniacz, id eft, hyớcyami flores imagie referentibus unde tandem fimiles cerafijs acini nafcuntur, quibus paucis uefcentes paftores fomnü conciliant. Hinc etiam Germanicüeis nomen, q̊d fchlaffbeehr i. fomniferiacini $\&$ ipfa herba, đ̊d infaniă faciat, tholkraut i, maniaca uoceț,$R a l$. Forte lunaria eft feu faba inuerfa, fic em̆ fomnificü folanü, nifi male intelli go,Iacobus Manlius nofter appellat, Cor ${ }_{*} \mathrm{Vt}$ id credă fomnifici folani hiftoria non patitur. Plura quæ de furiofo folano indicantur, huic herbæ conueniunt, inter qua illud præcipuum eft quod huius radix miras \& ut ex eajaccipien tium geftibus ac moribus liquet, nonillepida. 
52

\section{EVRICII CORDI}

rerum fpecies \& imagines reprę̧entat, cuius rei multa exempla f́cio. Solent enim quidă hic medicaftrihanc radicem arthriticis ęgris, quä recte autem nefcio, propinare. Nig. Forte eadem radixeft, cuiusego infigne experimẽnum fcio. Coquus quidam hanc in puluerem lauigatam multouino mifcuit, $\&$ omnes id biben tes ridiculis gefticulationibus infanierunt.

Cord. Quam tuintelligas, nefcio, hrec candida \& craffa eft radix,nafciturnon tantŭ in montanis locis, ut de furiofo Solano Diofcorides ait, fed imis etiam uallibus, ut in Renhardina fylua ubi maxima eius copia eft, uidi,Megob. Erucęadeo'qza acanthi, quam pæederata uocăt, folio folanum furiofum à Diofcoride pingit, Cord, Eundem acanthum Ferrarix uidi imis folins quafi dictæ urfinæ brancæ fimilibus fed longemaioribus, hinceum qui indicauit, bran cam urfinam Rocautr. Gratumprebuit mihi fpectaculum uel ob id, quod Virgil. eius in Bucolicis meminit. Ab hac tamen hiItoria quod huius herbx folium uidetis, diffidet: ob id aliquando dubitarefoleo, numuerum illi opinentur qui nuper eam contemplati mandragoram effe uoluerunt, Perfuaderi tamen nequeo, quod uterque mandragoras Diofcoride autore nullum habeat caulem, qui 


\section{BOTANOLOGICON.}

in hac non unus $\&$ quidem altus affurgit. Item quod haec non ouorum uitellis, ut mandragoras, fedcerafinis ut dixi fimilia poma,eaquenigra ferat. Nifi malim Theophrafto \& Plinio credere, qui mandragoræe caulem \& minutü acinum tribuunt, Gal.Egoplurimos mandragorasuidiuendentibus eos circumfo raneis agyrthis plane humana effigie. Cord. Age tu fictitias illas imagunculas ueras mandragorx radices putas? GALLVS. Quid ni? cum tales eas natas cöfpexerim anthropo morphinomen repręfentantes, Cord. Nolo tecum de friuola referius contendere. Tu Ral. la eas imagunculas pro mandragore radicibus uendis: RALLA. Nequaquam, fed quas ueri efie mandragorze credo, Cordus. Putaram te Galle uel ex ipfis fcholijs, que Virgilius Marcellus mandragorz capiti addidit, certio rem factū huiứmodi nugas \& fuperftitiones ridere. At forte more tuo etiam rem aliter fciens contendis. RAL. Ad alias herbas pergamus,Qui hancapellas? Cord. Chamzcy: pariffum. GAL. Eft igitur cupreffina latinis dicta. Cord.Id nefcio, lego tamen chamxpytin, id eft, aiugam fic dici, quă ignorantes cha mępytin effe medici iuam mofchatam hodie nominant. Megobacchus, Veram habetno- 


\section{\$4 EVRICII CORDI}

menclatură chamæcypariffus hæc, fimillima enim facies eftcypariffo arbori,Cord.Similis quoq3 facultas etenim ut Nicander cupreflum fic hăcetiam herbã Plinius contra Venenatos morfus commendat, ut alias interimeius uircutes taceam. Nig. Humilem atque ualde exiguum fuiffe oportet Aenex filitum Afcanium quem auia Venus fub hac non alta herba, ut Virgiliunofter canit, occuluit.Mego. At funt qui eá non aunaracü effe putët, Ral,Nos maio rană dicimus. Niger. TuCordequid cenfes, Cord. Galenus non hanc fed aliä herbă amara cum appellat, eă fcilicet quă hicnaf́ci uidetis. Ral.Hæc autē matricaria noftra eft. Cord. Et Diofcoridę Parthenion, quă oculīfolis Marcellus interpretat́: Cognominat́t tamë \& ipfa amaracus, quêadmodü $\&$ hoc, q̊d tu Niger in dicas, famlychon, RALLA. In libello tuo de p feudotheriaca amaracon, quæ̇ paftillos Alin daracaron, id eft, hedicroi ingreditur non $\mathrm{ma}$ tricariamíed dictam hodie cotulam foetidam appellas. Cordus, Vt fic errarem Virgilius Marcellus author fuit, qui in fcholins parthenion feu hanc amaracon chamemelo tam fimilem pingit ut legentes fallat, \&uirofo effe odore dicit. Imo \& ipfum cautę (unde cotula deducta) nomen in eiufdemparthenị hiftoria 
mihi impofuit. Cum etiam fuprema excreti coriandrifolia quibus parthenion Diofcorides comparat, non admodum diffimplari uidiffem confirmata eft hrec mea opinio, donec alios quofdam Nicola. Florentino fubferibere, \& hane matricariam hodie dictain Galeni amaracum et Diofcoridis Parthenion ac Aui cennze emeruchit afferere uiderẽ., Quibus facio le dehinc credidi poftă eam herbă nuper nata coriandri folia plane referre aspexiffem.Meg. EtItali medici quorum diligens has res obfer uandi ftudiū eft, parthenion fuue amaracū hắc matricariă effe affirmant. Nig. Miror q̊d Galenus hanc herbă, ut iniu, de cốpofitis libro ui dere eft, Romę difficilēacquifitu dixerit, cü hic paffim fcateat. Cord.Id cü \& ego legerem, fta tim opinioné meă à feetida cotula retraxiquę adhucuulgarior $\&$ copiofa fere ubique herba eft. Nig.Albanus Torinus in träflatoà fe Pau lo Aegineta amaracum \& famfychon unoeo dem'q3 maioranæ nomine appellat. Cord.Ma le, quemadmodú \& melian quæ fraxinus eft, Perficana,Nig.Vtină hi foli in hoc opere erro res fint, in multis eũ alins maioris momêti hallucinatū aiüt. Cor.Inueni etipfe nốnulla ̣̂̉ mí etfigręcas lías nô calleă nố pbe interp̆tata uident.Ral, Cuperẻ nouosillos tranflatores qui 
ita expectationem noftram fallunt, uires fuas, priufquam impar onus fubeant, perpēdere ac metiri. Meg. Vtoptima fide omnia tranftule rit,tamennimia fua affectatione lectorem abs fterret. Cord. Illius uitij per amicos eum ad. moneri uelim hominë alioqui de medicina nö male merentem. Gal,Quam bene autem non facile intelligo, ut qui fua ifta, quă ficut omnibus inuifam ita merito Megobacchus taxat, affectione adeo larciuit, ut uerendum fit, ne, dum tanto elegătiam oftentandi ftudio indul get, uel plura uelaliter quam autor ille, quem interpretatur, forte habet, quędam etiam minus expreffe acpropriealiquando dixerit. Quod ut alibil leue nonnunquă uitium fit, certe in'medicis libris immane femper piaculum d eft, in quibus, ut cü Rabelæfo meo loquфir una uoculauel addita uel expuncta, quin \& apiculus inuerfus aut præpoftere adfcriptus multa hominum milia haud raro neci dedit. Niger. Quid ergo fiet fi quis tam profunde hallucine tur, ut pro glăde balneü, pro parte medimnü, alia'qz his non minus abfurda inuertat: Cord. A duobus me non leurbus dubijs expedis, quo rum primum eft, qd incapite de podagra \& arthritide ad uehementem earüdem paffionü dolorẽ tantum cataplafma defcribit, quätum 
ad decem parietes deliniendos fatis fit, utpote quod ex foeni Græci medimnis tribus, loliatę̧ et cicerum farinęuniufcuiufqg, medimno uno conftet:ubi, utiam audio, partes intelligend $x$ funt Alterum quod colicis nimio dolore oppreffis ex melle, cymino, nitro, alinfqu fimilib? rebus balneum adhibendum uerterit: ubi glä demprocul dubio intrudendam Aegineta do ceat. Meg. Facilis eft ex balano in balineum la pius.Nig.At debuerunt eum defcripta ibidem fimplicia faciend $x$ balani admonere. Cord. Multa adhuc alia fimiliter mihinegotium faceffunt non tătum in hoc Aegineta fed in alijs etiam, quos uertit, authoribus, quæ, quia non funt prefentis inftituti, inter coenandum, qui intelligenda fint, inquiram, iam coeptum noftrum profequamur. Ral, Prius ğhinc pergamus fcire cupio quxe maron fit, quoniam Aegî neta inpaftillis hedychroi, ut Torinus interpretatur, maron proparthenio feu amaraco pofuit, Cord.Doctioribusid diuinandum relinquo,Meg.Manhardus origami feciem pu tat. Cord.Ob id etiam à Diofcoride origanis dicitur. Quam legitimum autē hoc caput ma riapud eundem authorem fit, hine pater quod in antiquiffimis exemplaribus nó reperiatur, neqg fuifie credendum eft, quod neq, Galenus 
58

EVRICII CORDI

neque fimius eius Aegineta in medicre materix cenfu moron ufpiam pofuerit. Quro magis miror quod in dictos iam paftillos receperit. Nig,Aliud parthenion Pandulphus Collinutius nefcio quo genfemini nomine depingit, fed quia uehemens eft is preceptoris tui Leoniceni infectator, forte nihil quæe dicit moraris.Cord. Sic preceptoribus meis \& quibufq3 authoribus addicor, ut emergenti indicatréq ueritati potius affentiar, Eam quicunq demố ftrarit me fuum habebit affeclam, Id an Colli nutisis ille fecerit, nolo meü hic iudiciü profer re. Multa quidem, quæ coarguti Leoniceni 88 defenfi Plinị quandam præe fépeciem ferant, anxie collegit, omnem que lapidem mouit, ut Talua tanti uiri authoritas ac fides perftet, que tamen non uno lapfum errore liquet, fed interim facili dignum uenia, ut cuius tanta tam ua rix materix, totgl grauium officiorum mole oneratus animus non potuit nố aliquando la bare.Meg. Si Pădulpho illi credimus, tum fua uem adeoq3 gratum, unguentis'́g a ptum parthenijodorem dicemus, ut uel ob id etiam my ralium quafi unguentaria \& pelecynus, quod eadem odoris fuauitate nos pelliceat, dicta fit. Cord. An pelecyni nomen à pelliciendo deueniat aliorum efto iudiciŭ, hoc tătum hic dico, 
grauem odorem huius fiue parthenij fiue ama raci à Diofcoridenominari, cui Galenus quo quefubfcribit, qui idem eandem amaracũ qua finon boni odoris unguento cuidam nequag̈ mifcere uoluit, tantum abeft ut ex ea, quod idê Collinutius putat, preciofiffimum \& fuauiffimum illud amaracinum fieret. Nig. Hoceft er go quod dixi non hanc feilicet ipfum fed aliam parthenion intelligere, quam uulgus genfeminum appellet, Meg . Forte iafmini flores funt, \& hinc corruptum hoc nomen inualuit. Ral. Scepe mihi recipiëdum nunciefeminum, nunc gêfeminü oleũ fcribitur, at ego hactenus id habere, necquodnam fit, et qui fiat, fcire po tui.Preciū ergo operæe feceris mi affinis fi hoc iầ à te didicero. Cor.Et ego in eadê tecú caligî necẹcutio, Megobaccho tamē fubfcribo, ggē feminos iâ dictosiafminos effe flores nô teme re exiftimat, q̊s egoaliquădo ppter hiftorię fi militudinë eofdé effele leucoñ̄s putaui;fed cüuideã Serapionê feorfum à cheirii eft leucoins il lis, de his, capitefcilicet deiefemin \& Zäbach, fcribere, nô ab re hæefito. $M e_{*}$. Diofcorides quo que diuerfis capitib? de leuconjs et iafminis flo ribus agit. Cord.Iafmini tmŭungëti meminit, nihil tri dubito, ex iafminis idfloribus olim fie rifolitū, idemqg effe g̊det fambacinü hodie na 
minatur, fed an habeatur, nefcio, Gal,Puto id effe quod A egineta Iaton \& Palladius uiolaceum dicit.Cord.Nequaquam,nam id de his, quæ propriæ fic appellantur, uiolis conficieba tur. Ral.Violarumnomine nigras illas uiolas iam intelligimus, quęueris initio iuxta muros 2 inter dumeta non ingratoetiam odore pro ueniunt. Cord. Verum eft, at latius id olim pa tuit, ut etiam iafminos \& leucoia, quæ uos, ut prius iudicatum eft, cheiri dicitis, comprehen dat.Meg.Pandectary autor capite iefermin $\mathrm{Ga}$ lenũ ex fexto \& feptimo fimpliciü libris citat eorüdē, ut credo, iafminoßx cognitas uirtutes recenfentē. Cor.Quxexfexto,repetit de nullis funt iafminis, fed ipfam ammeos hiftoriä exprimunt: Qux uero ex feptimo, nominatim leucoijs tribuit, qux eadem iafminos flores interpretatur. Gal.Si leucoia interpreteris albas uiolas dixeris, at cheiri croceo funt colore? Cor. Vno hoc nomine omnes uidelicet, luteę, purpureæ, \& albæ,fpecies intelliguntur.Gal. A melioribus ac potioribus forte defumpta eft adpellatio: Cord, Præferuntur in hoc genere lutę̨:In hoc inquam genere, nam murarię ill ̨̧ \&propriæ iamuiolædictæa alia familia eft, cố traria his tum qualitate num facultate, ut errët hiqui uno omnes fafciculo côftringunteteas- 
dem eis uirtutes adfcribunt authore fuüMattheum Syluaticumimitantes, qui uno capite de leucoijs \& nigris uiolis comprehenfim agit, licet aliud etiam caput de riffé leucoījs ponat, ignorans hæc ipfa cheiri effe + Sedfatis in his moratũ eft, pergamus. Meg. Alter, uideo, uel Ariftomachusuel Phylifcus colëdis apib? delectaris. Cord. Placuit femel poft tot caffa uota bene inftitutam aliquam rempublicam, $\&$ bonos mores uidere.Nig. Quafi in nullis illa ciuitatibus fed in folis iâ aluearijs fint, Gal. Pape funt iftę apes!'frpe de eis legi, fed nunquä uidi.Ral.Id tibicredamus Gallæ? Gal,Sic eft. Cord . Et ego dubito num ueræ hæe apes fint. Meg.Quid audio? Cor.Nă quas gratas apib’ herbas legi eas potius hre fugere uidêtur, ut in hac prope cófita dietta meliffa iam aliq̣t annis obferuaui, Nunquam enim uel unam huic apê infidere uidi, cum tamen hrec eadem meliffophyllo feu meliphyllo creditur, quã apes maxi me appetere eag, fummæx delectari Nicander, Diofcorides, Virgilius, Plinius, demüomnes herbarij teftantur, adeo ut, fi ea aluearia côfricentur perunganturue, detentŭ in eis examen non fugiat, unde $\&$ facta herbæe nomina, Nig. Fortedeflorente herba intelligunt. Cord. Id certum,fed \& ipfos flores non fectantur, qui ta 
men rari \& non fimul exeunt, lutei cum adhuc niuent, dehine ubi aperiuntur $\&$ hiant, albi. Meg.Non puto mutatam effe, qux ubigg fibi fimilis eft, naturam. Cord, Aut igtur hæe non ueræ funt apes, aut hoc non uerum eft meliffo phillon. Ral. Nonfacile credo omnes in uniuerfum medicos noftros falli,alias uidendum dicerem num hacuera meliffa fit, Cord.Nullam hic lanuginem uideo, quam ei Nicander tribuit, modo fit quam lanofam feu hirfutam (Lonicerus tamen afperam uertit) apium her bam nominat:Nec admodum fimilem citrijs odorem fentio, à quo \& citraginemuel citrariam appellant, Nig.Fœedus hiceft potius quä gratus odor, forte igitur non de hac herba in telligendum eft, dum meliffophillon propter fuauitatem fuam in coronamenta quondam ueniffe legimus. Cord. Aliud adhuc eft, quod me furpenfum tenet. Ral,Quid: Cord.Quod Nicander bis meliphyllon illud etiam marrubium appellari dicit. Gal.Recordor iam eo rum quxe in eo authore fuper hos locos dictafti: Alterum fcilicet effe oportere aut ut idem meliphyllo marrubium fit, aut commune dua bus herbis marrubij nomen. Niger. Forte igitur non male Palladius, tubi apum meminit, aliudà citragine meliffophyllon intelle- 
xiffe uidetur:Cord.Nefcio, communem omní um uiam, licet furpenfis dubijfque pedibus, fequor, donec me alio monftrans Mercurius re uocarit. Meg: Hanc herbam nouifti Ralla? Ral. Noui, cardiacam appellamus. Cord.Eam ad aluearia plantaui: Non enim credi poteft, quanto examine, quam fonoro murmure, circum hanc florentem denfre apes fufurrent.Et niff incifa folia, qux meliffophylli hiftorizenon refpondent, aliter perfuaderent, id ipfum effe putarem, Ral. Si tu nihil in hoc decernis, ego minus poffum, Cord.Agite quam hanc herbain effecredam? Ral, Illudis nobis; \& more tuo iocaris, nam hyffopum te non nofcere monftrum foret, Cord. Scio quidem abomnibus, fic medicis appellari, uerum, eft \&chic quod me dubium facit, \& fufpédit, Ral Legam ergo hiftoriam eius apud Diofcoridem, ut, quod non congruit, indices. Dutum, inquit, generum eft hyflopus, montana altera, hortenfis altera : Probatiffima quæi in Cili cia nafcitur \& cretera, Cum nulla eitus hic pictura fit, quid eft quod te turbat ? Cord. Verte folium \& origani caput lege. Ral. Origanon ait, Heracleoticam funt qui Heracleam, qui conilam, Romani cunilam dicunt \& origanum. Folia habet byffopi, non tamen 
umbellam, hyffopi modo rotæ figura, \& in or bem circumactam,fed multifidam \& ueluti di uifam. Cord.Satis, nihil hicuides, quod, ut häc hyffopum effe dubites, fuadeat: Nig. Quam omnes fere medici origanum indicant longe alia quam hęc, folia habet.nullam item, huius qux hyfliopo tribui uidetur, umbellam,fed fpi catum potius florê uideo.Cord,Hoceft quod \& me dubitare facit. Gal. Audiui ex te nuper cum Nicandrum prælegeres, hyffopum famfycho fumilem herbam effe, Cord. Sic Nicandrifcholiaften \& Serapione eamindicare admonui, id quod dubitationem meam adeo nó minuit, ut augeat potius. Siquidem ut Diofco rides ait, famfychon tenuifoliz nepetæ fimilia circinataque folia habet, qux figura creditæ \& dictæ nuncubiqz origano accedere uidetur. Siue ergo origano, fiue famfycho cỏpare tur pralens hęc noftra hyffopus, magna eft di fcrepatio, cum longa hæc 2 gracilia foliola habeat, ne quid tributam eiumbellam, \& corymbaceam (ut in Chryfocomeuidereeft)co mam, quarum neutram hicuidemus, imputë. Accedit \& aliud, quod in diui Iohannis euangelio legitur Chriftum in cruce potatum ace to, quod impofita hyffopo fpógia porrectum eft, multo ergo longiorem \& robuftiorē eum 
cauleme effe oportuit, quă hæc herba, fi ad hũe ufum accommodus fuit. Nig. Eft dignus uindice nodus.Meg.Duplicēe ef́e hyffopü audiuimus, quid fi hac altera fit? Cor.Idutnefcio fic nō affirmo, fed quid tam diu taces Ralla, Ral. Fruftra meditor quid tibi refpondeam, Nöleuiz deijcienda ftat Diofcoridis autoritas, Cor. Imo ueluti Marpefia cautis. Ral. Nec inuetera tam omnium medicorum opinionem temere deferuero. Cord. Ego quod foepius dixi, cui uis erutam ueritatē docenti inclinato femper animo quamlibentiffime fubferibam, atqz uti nam tanta mea fit facultas ut patrocinari quo que poffem. Meg. Dolet nunc mihi quod non maiorem norcēdis fimplicibus operam in Ita lia nauauerim, Cord. Solent \& illic plarique medici harum rerum ftudiofos difcipulos deridere, quafinö ad eos fed folos feplafiarios in quifitio et fcrutatio illa ptineat, fed longe, meo iudicio, fallütur. Cum enim tria fint circa qua tota medicina uerfatur $\&$ abfoluitur, nempe corpus, morbus $\&$ medicamentum, cunctors" eorum æque neceffaria eft medico cognitio. Contra periculofa gro ignorantia.Quis aliquem unquam morbum curauerit, (ut de me dicamento tătum hic dicam) cum inftrumencumillud, quo ad hoc opus eft ignoret? Ridi- 
66

$$
\text { EVRICII CORDI }
$$

culus ille faber fuerit, qui domum ædificant: rus pro bipenni feu fecuri perpendiculo, pro runcina gnomone, pro ferra terebra, pro afcia celte utatur? Nouiftis quales \& quam non omnes tui fimiles Ralla feplafiarij fint, fed qd bona eorum pars non multum ultra analpha betos idiotas fapiat. Atq $z_{3}$ his tantis afinis tam difficilem prouinciam commiferimus? $\mathbf{F} \propto$ licius olim cum medicina noftra actum eft, ubi magni non tantum medici fed \& reges hanc curam fufceperunt, $\&$ ad fcrutandas herbas per altos ac difficiles montes, per denfas fyluas, ac uepres repere non durum nec indecorum putarunt, Quos ego libenter imitater fi haberem huius non dico laboris fed uolupta tis doctiores aliquor comites, quibufcum fusper his rebus, ut aliquid difeerem, conferrem \& cỏmentarer. Nunc folus hic fum, adeoque nemo hoc ftudium meum adiuuat, ut plæriq3 fint qui derideant, feque non cornicum oculos configere uelle, fed per præceptorum fuorum manus acceptis fimplicibus contentos fore di cant.Quo nomine etiam non parum mihiapud fimplicem \& indoctam plebeculam nocent, cui inculcant poëtico me ingenio nouam quandam curandi rationem quærere, diuq in maximo honore habitos medicos reijcere, g gd 


\section{BOTANOLOGICON.}

non fine magno agrorum periculo fieri poffit . Interim meam illi meffem fecant, ac belli congerrones in ferotinis cốpotationibus pra xim fuam Cordinæ theorefi preferunt. Nig. Vbique boni medicifuos Theffalos habent, tu nihilo fecius labora ut teftata illa tum eruditione tum experientia nos difcipulos tuos iuues. Ral. Si ita in fingulis alips moremur quando exibimus:Cord Quota eft hora:Gal.Prima.Cord.Quinta coenabimus,Meg. Eüdum eft,fi tempeftiue redire uoluerimus. Cordus. Venite ergo, claude poft te fores puer, ne uicini mei quid portent, quo poftea caream. Hoc male me habet quod tam longum fuburbium nobis permeandum fit, tam angufto lithoftrato, ut non bini queamus, fed finguli ire cogamur. Tu tamen Megobacche propius accede, nam habeo quod tibi feorfim dicam. Megob. Dudum aures arrigo. Cordus, Solis etiam illis clam concredo arcana hæe mea . N. N. N. N. N. N. Intellexifti? MEGOBACCHVS. Optime, fed nonopti ma Deum immortalem quanta hominum in uidia, quales item technæe ac uerfutix. Puto te ad ferendas iniurias \& aduerfitates natum. Verumtamen hactenus cum cucullais tantum triconibus, nullis cum doctis 
68 EVRICII CORDI

huiufmodi tibi res fuit, Imofemper illorum optimiquique propēfo tibi animo fauerunt. Cord,Fauent, \& adhuc fpero uidebóque ut in pofterum quoque non inuideant, Quod fi qui dam occulticum complicibus fuis lurconibus aduerfentur fufq, deque feram. Nolo tamen in hac fimultate diutius uerfari, decreui enim non ita longo poft tempore hinc alio concedere, ubi rebus meis forte melius ğ hic confultum erit.Nam poftg̈ eo laboratum eft, ut reti nendre domus mex facra illa anchora refecta fit, non potui,ut manerem, animum inducere, quantumuis liberali ftipēdio meream, Et bona quidē fpes eft, ut femper folitam, fic \& $\mathrm{mo-}$ do inuidiam me promoturam, Meg.Quoergo demigraturus es? Cord, Bremenfi me fena tui obftrinxi.Meg.Dijbene uortant, ut tä pro pitios medicinx, quam hic funt iniqui, homines ibi reperias, certe opulenta urbs eft. Cord. Vtinam hinc profecto mihi fuccedas, \& $\mathrm{ad}$ uerfariorum meorum ordinatæc chartæ turbë tur., Me. Egóne dign' uideor, qui tibi fuccedă? Cord, Quid ni? cum alius hanc prouinciä ambiat, qui tam terefert, $\not{g}$ murca cicadam. Imo iam dudum eam fe naçum $\&$ mihi prẹlatuin apud fuos gloriatur. Fauerem eum huicffholæ, fitam doctus, quamíe putat, \& arrogans 


\section{BOTANOLOGICON.}

elatufq, eft, effet.Me. Forte idem ille eft, de quo prius. Nig. Quam lutulentum \& foedum fuburbium habetis . Cord. Nonalia eft, ubi por- ci uituunt, mundicies.Ral.Graffata eft $\&$ hic, ui deo, rufticorum furia, memini has faxeas ima gines magno olim fumptufieri, \& huc poni. Ad quid nunc attinet huiuf modi opera $8 \mathrm{r}$ mo numenta tam mifere confringic Cordus. Tali pietate egregij hic Chriftiani fumus. Megob. En uocatam uermicularem in hoc muro. Cord. Vt hocilli nomen concedam, quam tamen frigiditatem medici noftri tribuunt ne go,figuftui, quod Galenus precipit, credidebet. Nig. Hei quàm acer fapor eft. Cord. Atque is eam calidam arguit. Gal. Qui Germanice nominatur. Cord,Mauerpheffer. Gal. Hocfemel oratum te uolo, uenerande preceptor ut Germanicas illas herbarum nomëcla turas, quoties occurrunt, interpreteris. Cord. Sonat hoc quafi murarium piper dixeris, facta hinc appellatione, quod longi piperis fimi lem aliquatenus tum figuram tum etiam faporem habeat. Nig.Quid fi aliam alijuermicularem intelligant: Cord. Nihileft quod cerce de hac herbula ex uetuftis authoribus dicam.Ad uulgares uos herbarios remitto. Ral. Cum Francobergæ iam apud patrem effem 
uidi in cautibus, qure lacui ibidem incumbunt, item $\&$ in muris \& macerijs nafcentem non adeo abfimilem plantam, nempe dodrantali altitudine $a b f q_{3}$ ullis folijs, fed habentern interim numerofa quafitritici grana. Cord. Eam \& ego diu antehac obleruaui, putóq; menofcere, \& effe quam Diofcorides tragum appel lat, Guítaui, \& adftringētem ei ${ }^{9}$ uim fenfi, qua cam facultatepræedită idē author indicat. Eius nomen à mulierculis inquifiui, quæ hunerberh.i.gallinarias baccas adpellari refponderunt,Meg.Hic quid cenfeas audiam, eft hęc ca pillus Veneris? Ral.Dubitas? Qui tribus et ain plius annis in tam docta harum rerum Italia fueris. Meg. Non abs requęro. Cord. Eft quidem, fed ea fpecies quæ trichomanes dicitur. Meg . Forte muraria rutha altera adianton. Cord, Id nefcio, foepe enim id, an haec fit, expe rirer, tentaui, fed fruftra. Meg. Quomodo: Cord, Irrigaui \& afperfi eam aqua ut feilicet an ficca maneretnomen' $q_{3}$ furum tueretur, uide rem, fed ęque ac alix herbæ humecta maduit, Hine diu hxiftaui, neceam pro adianto accipientibus affentireuolui . Quam meam dubitationem infirmam fam opinionē uertit $\mathrm{Hu}$ bertus Barlandus in eo libello, quem contra quêdam Louanienferm medicum fcripfit, Aur 
BOT ANOLOGICON.

eennę lui acrem affertorem, ubi faluiă Vitam, quam murariam effe rutham autumo, aliam ab adianto herbam conuincit. Ral. Cum ergo accipiendum forte adiantum fit, quid accipiam? Cord,Hoc ipfum trichomanes, nẩ eaíde uires habet, $\&$ ob id alterutro utrunqz nomine uocatur, Ral, Quxuero polytrichon, \& callitrichon herbæ funt? Cord. Exdem adianto, Ral, Cur tune quidam mediciomnia hæe nomina fimul una eadem'q3 receptula fcribunt? Cor.Id ab illis nõ à me quære, ut q plane ignorẽ.Meg. Habeo quæ uolui, nã in I tralia eandē fu per hac herba cốtrouerfiă audiui. Nig. Iam có modú in pëtaphylló incidimus, de qua magna eft inter medicos controuer fia, Tu nobis Cor defententiam tuam aperi, fit ne uerum ea pen taphyllon:Cord. Effode \& radicem contemplare. Nig. Feci. Cord.Ad hiftoriam confer, $\&$ anrubeicat afpice. Nig. Nullum hic rubo. rem uideo. Cor. Id priusğ effoderes f́iebam, tametfiuero pëtaphyllo tam fimilis fit, ut me foepe fefellerit. Ral. Nunquid quinqf folium intelligitis? Gal,Nihil aliud hæe gręcis uo x figni ficat. Ral, Tm̌̀nego Græce quantüfturnus calleo,noui tamë quordam qui quinq̧foliüà pêta phyllo differre putarint. Cor.Auicēnęfui erro te forte feductinő uerum interim quinq̧ร 


\section{EVRICII CORDI}

norunt, Ral, Si hrec non eft, ignoro \& ipie. Cord.Ignorans tameneam nouifti fcio. Ral. Qui eandem rem ignorem \& nofcam fimule Cord,Nofti ne tormentilla..Ral,Noui.Cord. Hrc eadem pentaphyllon feu quinqzfoliūeft: Idquodignoras, Ral. Hactenus certe. Nig. Hoc expectabā nam funt qui idē uelint multi. Cordus. Scio 2 inter eos eft preceptor meus Manhardus,Gal.Comes quoq; ille, neício qui cognomen proferam. Cord. Neuenarum uis dicere?'Gal,Recte,Manhardo fubicribit, quan quameum remoratur Marcelliuerfio, quod ea quinq, ${ }_{\text {foli }}$ florem in pallido candidum depingat, magis'́; Ruellij interpretationem pro bat, quaxinluteo pallidum habet, Cord, Ego duos illos idem dicere puto, fubdit enim Mar cellus auri modo flauefcentem, quibus omnibusutriufque uerbis optime expreflus flos ille uidetur, qui licet luteus fit, plerunq, tamen in pallido candet, atco id interiore fui parte, ut foe pe animaduerti. Alrud eft quod me fufpendit, quod filicet Diof́corides menthe, Theophra ftus uero uitigineü ei folium tribuat, cum neu trum conueniat. Et nifi omnes uires qux pentaphyllo adícribuntur tormentillam dictam habere certofciremuideremq; recēs effoffam eius radicē rubefcere, poftuero cum auruerit 


\section{BOTANOLOGICON.}

nigreffere, diuerfas omnino herbas decernerë. Mego. Oportet ut in alterutro autore uitium fit.Cord.Sinon inutroq3, neutrum enim foliū tormentilla, neqgetiam hre pentaphyllon pu tata refert.Pluribus huiufmodi mendis oblitū effe Diofcoridem reperitur, ut inerratico papauere uidere eft, cuius foliñ origano erucæure aut cichorio aut thymo fimile dicit. Sideriti dos item folia marrubinfaluiz \& quercus figu re comparat. Sic $\&$ fatiuam cannabem malo, quxe omnia nullam inter fe fimilitudinem habët.Meg. Theophraftus quoqzeodem capite quo uitigineum pentaphylli hederaceum etia adeoq rotüdius rubię folium defcribit,eam'qz graminis modo humi ferpere tradit', qd ego nufquă uidi, imo indicatăa Diofcoride hiftos riam repręéfentare, ut $\&$ hic mendum fúpicer. Nig. Legitti procul dubio quem in hac quoq3 pentaphyllo Plinijerrorem Leonicenus tuus offenderit.Cord, Legiuna cum his qua cốtra eum Collinutius, ut Plinium fuũ tueretur, mul ta effudit. Ral.Inquo iginur Pliniŭ erraffe Leo nicenus credidit? Cord, Quod pentaphyllon ille fraga gignere dixerit. Ral, Hocneqg dicta tormêtilla, neq hacten' nobis putata quinq3. folium facit, Cord, Imonec ipfa, quancunqs ille uêdicat pentaphyllü. Ral. Trifoliă femper 
74

quinquefoliam uero herbam nunquam fraga proferre uidi,Gal, Dicit tamen Collinutius fe Venetijs herbarium librum uidiffe in quo admodú affabre depicta fuerit quinq; folins herba cum fimillimo fragis fructu, faniculam $\mathrm{La}$ tine, Germanice uero fanyckel appellată, Eam ueramille pentaphyllūexiftimat, méq\} plane in opinionem fuam traxit, Cordus. Miferefed fruftra tamenfe hoc toto capite torquet ut ali quid refpondeat, Si in alijs fimiliter, tunc nihil egit.Aperi tu Brunfelfij tomos \& eiufdem faniculae egregie expreffamicona confíce. In quinqj partes diuifa quidē folia habet, fed quæ in fupremis coliculis coaceruata quafi capitula apparent, nulli fructus, fed herbacei coloris mufcofi \& à fragis plurimum differentes flos res funt, quos uiua herba melius quam quauis pietura exhibet, ut forte aliquando uidebis. Magna enim eius copia non procul hinc in fyl ua ifta nafcitur. Meg. Quo nomine putas hăe faniculam apud Diofcoridem latere? Cord. Nefcio an infit. Multæ enim huiufmodi, uulnerarix prefertim \& ex folidaginum genere, herbse poft illa tempora repertę funt, quemad modum \& hær quam hic cổmodum uidem? Germanicekleyn beynvuel appellamus. Gai,
Potes interpretari; Cord. Sonat quafi minus 


\section{BOTANOLOGYCON.}

fymphyton dicas, nontamen eft quod fic Dio fcorides appellat. A cruribus formata eft no. bisnomëclatura maioris fymphyti, q̊d fracta illa confolidet, Putaui aliquando hăc Beinbel lă effe polycnemon Diofcoridx, propter mul tas fcilicet, quas in ea uidetis, furas fed nö und qua'qj refpödet hiftoriz. Egregia eft ad entero celas herba,cuius facultatis multa ipfiexperimenta uidimus. Eifdem uiribus laudat $\&$ alia quędă quă uulgares herbarīi pfoliată, Germani uero non multü abludē te noie durchvuahs appellắt. Gal.Illì duas effigies Brũfelfrus exhi buit. Cor.Sed neutră uerä. Nafcit q̊q ${ }^{3}$ in flumi num ripis fruticola herba falicis folio unde \& Germanice Vueiderich q̆f falicaria dicta,flore luteo, uulneraria côfolidătéq; \& \&́iṕa ui, acer bo fapore, quă lyfimachiá quá Leonicen' corneolâuocat, putarê, fímordax \& mufcas intex ficiês hinc fumus, dŭ uriẗ, exhalaretur, Imo \& quę hic ferpit \& nouis femper radiculis propa ganur, binideinceps đ̆fi circinatis folijs,flore lu teo, fimile côglutinandi et cốfolidădi uim obti net. Ral, Chirurgi Vuilde poley i. fylueftre pu legiü uocant.Me.Iplefa por qui hic acerbefcit, geffifit, oftëdit. Gal. Ad pentaphyllóredeo, qw

céfes ergo accipiendă pro eo tormètillä: $\mathrm{Cor}$. Cêleo, donesfragiferälllam Plinijinueneris。 
76

EVRICII CORDI

Nig, Miror undetantus uulgaris alioqui herbxe error irreplerit. Cord. Non aliunde quam quod in plerif́ç Italiz locis tormëtilla ifta nő quing, ut hic, fed feptem folijs nafcatur. Facilis igitur inclinatio fuit ab illa, ad hanc, quam hic effodimus, femper quinque folips confípicuam, adeo'g fereeandem, ut me, quod dixi, fæpe fefellerit non effoffa, Nig. A quinqffolio ad trifolium, quod hic uiret, difputationë noftram conuertamus. Ral.Quid in uulgari \& omnib? nota herba moremur? Nig. Scio quid quęram Cord. Quid fi uerum trifoliñ ignorare te conuincă: Ral, Id quod hic calcam? Cord,Quod Diofcorides alī' ${ }_{\beta}$ medici intelligüt. Multa \& egouulgaris \& pratenfis illius trifolij genera noui,fed ualdedubito an eorum aliquod medicinam faciat.Ral.Vtimur tamen illo omnes quos ego noui,feplafiarï, \& in uulgaribus iftis herbarijs mira id poteftate præeditum laudat. Cord.Quam recte \& digne, et an aliquam eius uim experti fint, uiderint ipfi, non eft de qa antiqui fcripferunt, tantas'q̧ ei facultates tribuunt. Ral.Qui hocf́cis. Cord.Quia ueri trifolij hifto rix non refpondet. Id hirfuta \& acuta folia, ut alia multa taceam, habet, \& nondum excretä rutam, mox ut ad confiftentiă peruenerit, bitu men olet. Sic Nicäder, fic Diolcorides, fic Scri 
BOTANOLOGICON.

bonius, alriq'; complures teftantur ${ }_{*}$ Afpice $\&$ olfac, funt talia hęc folia,fentis aliquem fatu di gnum odorem? Ral. Nullum nifialiquatenus fubdulcem, qualis neq̧ rutę neq̧ bituminis eft. Cord. Non etiam ita temerenecubiqg nafcif. Scribonius enim in nullis Italiz regionibus,ni fi in Lunæ portu, cum Britanniă peteret, trifo lium illud fe uidiffe dicit, củ hoc ubiq, fcateat. Sed aliud eius nomẽ dică an eo forte noueris. Cum tibi doctores tui herbam flauram accipiendam fcribunt, quid accipis? Ral.Id an un quă factum fit, nelcio, quodfifiat ingenue infcitiam meam fatebor, Cord. At eadem herba flaura, quam \& plantam leonis appellatis, trifolium illud eft, Ral.Ergo $\&$ andachucha? Cord. Andachucha quidê trifolium, fed non illud, uerz qux lotus Diofcoridi eft, dicit'. Nig. Harc dudum expectaui \& libenter audiui, quo enim uolebam recta tendifti. Ral,Sed an recta in hortum tuum, quẹ petere deftinauimus, ten dam' nef́cio, putabam eũfub Glafcoppo fitũ, nune nos ad crucem \& gabalum ducis. Cord. Hactenus non aberrauimus, ad dextram tamen per uuias has fepes declinemus.Nig.Magnus eft, uideo, heffiaticarum uuare prouétus: Cord. Vt inutilium omniüregefolet, Ral,Nö inutilia prunella ifta funt, quantüuis auftera, 


\section{8 EVRICII CORDI}

nam acatiam hinc noftram facimus . Cord. Beneueftram dicis, quia ueram non poteftis. Ral.Nonne hęc acatiæ arbor eft: Cord.Minime dices fi Diofcoridi credideris acatiam defcribenti Aegyptiam fpinam \& cădidum eius, ceulupinos, femen in filiquis inclufum, exquo fuccus ille eodẽ noie appellatus exprimatur: Vbi tale hic femen? ubi claudêtes id filiquas uî des? Meg. Duo acatiæ genera legi,forte hoc al terü eft. Cord, Nequağ, nam \& illud cốiunctis fimul folliculis femē fuũ trinü, quadrinumue lenticula minus fert, nulla ad hunc fructum fimilitudine: Et ut fortius períuadeam hanc nő effe acatix arborem, quxro an unquam ex ea def́criptum à Diofcoride triplex illud gumuni fluereuideritis? Primum lumbricorum figura \& uitrea tranfpicuitate pellucidum, optimum: Secundum candidum, minus bonum: Tertium refinofum \& fordidum, plane inurile: Quorum nefcio an primüuel fecundum, uti namnon tertium Arabiam gummi ueftrum eft, fi Serapioni credimus, qui illud acatix lachrymam effe dicit. Nig.Galenus \& alijueteres medici fimpliciter commi(fic eñ eis gümi dicitur) nulla Arabici adiectiố pronunciant nec arborem, unde colligitur, defignant. Imo congelatamid concretamig lachrymä, quam 


\section{BOTANOLOGICON.}

arborum trunci producant, defcribunt,anidê cum Arabicogummi, ignoro. Cord. optimü tamen gummi à Plinio ex Aegyptia f́pina, nimirum acatia, laudatur, Meg. Diofcorides \& alĭ Graeci huic opplendi \& obftruendi tătum uim tribuŭt, Arabes uero Arabicum fuũ gum mi magno ambitu pluribus facultatibus prexditum efferunt, ut tragacanthă, fi non fuperet, certe zequet.Nig. Si uera eft uulgiregula pluris mũuinifutura nobis uindemia dabit, grauida eft acinis fambucus illa, Eadẽ eñ eius \&uinea rum fertilitas effe credit. Ral. Iă rurfus fuccur rit, q̊d cü id pri' ubi de Leucoijs ageres, interro gare te uellë, propt aliǔ incidentē fermoné ex cidit, nêpe q̊̊d Hieronymus Braufuicëfis Argë tin $^{2}$ herbarius, cui ${ }^{9}$ magnă ubiq ${ }^{3}$ autoritatể ce lebrät, häc arborē, fi eă fic appellare licet,à grę cis leucoia uocari,eiufque tres fpecies tradit. Verbaipfius funt in capite holder(fic Germa ni fambucūnominant) Gal, Scripfit Latine? Ral,Nö,fed germanice, Gal.Latine ergo refert Ral.Sambucus, inquit, frutexnon herba eft, à

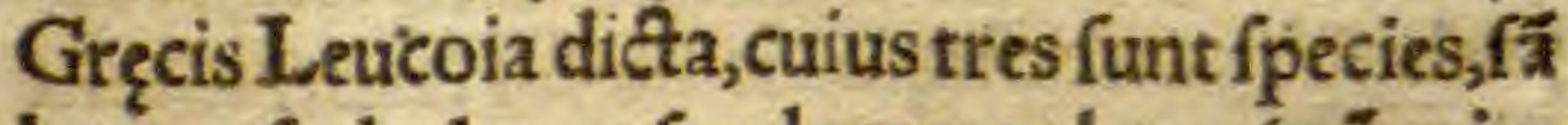
bucus, $f_{+}$ebulus, et fambucus rubeus (nó mine eum in grammatica peccafle, cum plane anal phabetus idiota fuerit) quamuis aliqui doctores deagrefti feu fylueftri fambuco ícribăt. 
Cord. Scio quid rudiliterarum homini impo fuerit,Legit fambacum Arabum, nempeiefeminum, trium effe fpecierum, album, luteum, \& rubeum, \& quia lesiona totidem tum fpecie bus tum coloribus indicantur, putauit fambu cum fambacum, nominis fcilicet uicinitate de ceptus, \& fambacü idē leucoijs. Contingit ma gnos medicos fimiliter errare, qui pro famb2 cino, id eft iafmino oleo, fambucinũ fcribant, 2 intelligant. Vtină idem Hieronymus æqua lem habuiffet tanto harum repy ftudio cruditionē,præftitiffet forte quod quidă ei tribuüt, Nunc quod crcuscrecos fecutus eft, una cũ eis in foueam erropy cecidit, quopy catalogum hic recenfere ut nó libet, ficetiă non uacat. Id ideo loquor, nonutbono uiro detrahă, fed ut lecto res, qui toti ab eo pendent, admoneam. Omni bus eñ qui tali conatures medicas iuuare ftudent, impenfiffimo animo faueo, fic tamë, ut, filli errent, magis ueritati. Similes ego uices mihireddi cupio,fiin aliquib?, ut humanüeft, hallucinor, humaniter \& ueritatis amore reprehendi non refugio, Sed de his fatis, Nouifti Niger hunc fruticế: Nig, Vbi tu dixeris, Cor. At in Virgiliano Bucolico dícipulos hüc me os docuifti. Nig. Qui quod ignoras alios doceas? Cor, Hoctamé pleriqģ literatores folêt. 


\section{BOT ANOLOGICON.}

Liguftrum eft,Meg. Similia olex folia habet. Nig, Longe aliam eius idæam cốcepi, nempe quam pręceptores mei indiderunt, Viticularis ac circumuoluentis fe in fepibus herbę, referc̄tibus ferelilia floribus. Cord, $\mathrm{H}_{2}$ c quæedā helxines eft fpecies, quam Gręci ciffampelon, La tini conuoluulum uocant. Meg.Sic ex Leoniceno \& alins didici. Ral, Refpondet hoc liguftrum lectæ hiftoriæ uideo, Cord, Redolentes flores tempore fuo fert, ex quibus olim non in elegans $\&$ utile medicinx ungentum fiericon fueuit,cyprinum dictum, Cypros enim Gręcis liguftrū eft, Arabibus uero tuis alcanna.Nig. Cur hodie non fit: Cord. Cur ignorant: Ral. Hanc arborem audiui, cum adhuchic agerem Germanice Rein vueyden \& mundtholts, id eft Renanam falicem, \& , fed non pofium latine dicere. Cord.Stomaticum lignu, forte quod oris aphthas, quas Arabes alcola uocant, curet, Sunt etiam qui hardtriglen Germanice appellent, nonrecte tamen, fi, quod HIEronymus dicit, hardtrigle alni folia habet.MEGOBACCHVS. Venit in mentem cuiufdam apud Columellam uerfus, quo in hortulo fuo contra Virgilium nigrum liguftrum dixerit. CO RDV S. Virgilius ad flores, Columella forte ad maturas eius baccas refpexit. Nifi 


\section{EVRICII CORDI}

quis ibidem liguftrú pro purpurea e leucoijis uiola interpretari malıt,nam huiufmodi uiole quondam à Romanis etiam liguftrix dici folebant. Nihil tamen certi habeo. NIGER, Qux alba Virgilij liguftrafunt noui, utinam \& nigra eiufdem uacinia noflem, Ralla. Sylues ftres illi mirtilli funt, quos Germanice heydel beehr appellamus. CORDVS. Vanum hoc ludimagiftrorum commentum eft, fif fire uoles hyacinthi caput apud Diofcoridem \& quxe illic Virgilius Marcellus fcholia addidit, lege, $\&$ longe aliam eius hiftoriain, quam poëtr fa bulantur,comperies.Niger.Non ergo regum nominib? infcriptus ur Ouidius canit, flos eft. Cord, Siid credendum cenfes, crede etiă quod is ex traniformato puero factus fit RALLA. Hos berberes feplafiarius tuus non colligit. CORDVS, Dum rancidos ueteres habet, nö opus effe putat. Ralla. Vellem me eos Lypfixe habere,MEGOBACchus. Eft ne hac f́pina quam Diofcorides oxyacantham appellat? COrdus. Eft. MEgobacchus In Italia crifpinam quandam nefcio an hanc dici audiui, qua fi acrem, id eft acutam fpinam, id quod \& Grę co uocabulo répondet. CORDVS.Egotamen id non ut acuta fed acida fpina fit, inrelligendum puto, utrunque enim acre figni- 
ficat: Nam abfurdum uideretur ab acuto acu leo, qui omnibus fipinis eft, hanc proprie dici. NIGER. Placet mihi opinio tua, etenim perquàm acidus foliorum eft fapor. Cordus. Porro quam Itali crípinam uuam appellant diuerfum ab hac genus Barbarus feparat, imo \& alium fruticem æque fpinis horridum \& topiarium pufillzeque uitis folio ac rubẽtis uux fertilem, nec in Italia modo, fed in Germania quoque illi uifum indicat, Quifnam hic apud nos frutex fit fcire cupio, quemadmodum $\&$ hanc fpinam quonam ab autho ribus nomine uocetur, MEgobacchus. Quam intelligis? CORDV S, Hanc candidis aculeatifque ramis lapidofis item ac in maturi tate rubentibus mitique carne efculentis baccis forti admodum ac duro ligno. GALLus. Ego cornum effe puto. CORDV S, Cornus longe maior ac f́peciofior arbor effe dicitur, cuius fructus oliuam æquat, cum hic nedimidiam eius quantitatem. NIGE R. Vifam mihi Viennę cornum exiftimo, efféç eam cuius fructus dirlas appellant, GALlus. Quod huius ergo fpinæ Germanicum nomë eft CORDV S. Nos hagendorn appellamus, quemadmodū $\&$ hacproximă curuatis \& tenacibus aculeis rofarum fpinas fimili fas 


\section{$84 \quad$ EVRICII CORDI}

cie repręlentantem $\&$ eandem fere, nifi quod agreftis eft \& non tắ multifolias, imo quinq\}folias tantum rofas fert. Ral. Nos fpinamalbam dicimus, Cord. Sed magno errore, cum ea longe alia fit planta, hæc uero illa quæ Gręcecynosbatos, \& Latine caninus rubus feuut Theodorus uertit,canirubus nominatur. Gal. Eadem igitur cynorhodo. Cord. Id non perindeaffirmare aufím, nă alia ab hac cynorhodos uidetur.Meg. Imoplures ac diuerfas plan tas uno hoc cynosbati nomine fignificari,fiea quę Theophraftus fcribit,perpendantit. Is foliú cynosbati humano ueftigio, fi recte memini,fimile dicit.Cor. Columella amerinę falici, Nig.Plinius quoqz nigram uuam deferibit, in cuius acino neruus fit, unde neruus paffus dis catur.Cord.Idem hanc noftră hagendornam cynosbatinomine graphice depingit \& harü, quas inea uidetis, fpongiarum meminit, easq3 egregiam contra calculum medicină laudat, cui ipfam etiam experientiam non uno exem plofubfcribere fcio. Nơ femel eñ uidi his ipfis fpongiolis in puluerem leuigatis fortiffimas urinæ anguftias folui, quin repertos in eifdem uermiculos maius ad has prafidium effe qui. dam affirmant. RALLA. Ipfos quoque fru* ctus eadem facultateualere audio.Niger.Iam 
fubit in Carolario Barbari me legiffe cynorho don à cynosbato non roleo flore, quem uterq: fert, fed fpongiolis diftingui, quas cynorho* dos habet, cynosbatos non habet. Cord. At eas in hacfpina uidetis, cynosbato certe, quod etiam nomē huic, qux uere batus, id eft rubus eft,fpinę cốmunicatur.Megobacch. Vidi\& ol fect in Italia nó abfimiles his äs hęc fert, rofas, longe tamen meliore odore, uergenteque aliquantulum ad luteum, colore, atque in ipfo autumno, nefcio an hacuel fimiline fpina decerptas, Cord, Non omnes res ubique fimiliter \& exedem proueniunt. Duarum hancfpecierum effe conftat, eftenim \& minor, fuauiter redolens rubeicente rofa, quę eadem fuas etiam fpongiolas fert, R A L L A, Noui qui eafdem fpongiolas pro Bedeguardt accipiất. Cordus. Hoctam reete faciunt quàm eandem fpinam, albam fpinam exiftimant, fic error ei roremparit. GALL V S, Nulla in hac terra aipalathos nafcitur? Nam \& hac forte fimilis eft fpinz. Cord.Calidarum regionü hic fru tex eft, ex Syria ex Rhodo petendus, Ral, Hine ego non feram. Cord, Sed unde ferunt, g apud uos ueram theriacam componerefe iactant.

Nam hanc afpalathos ingreditur, eft'q; quam darfíahan appellắtfed iuxta quoq̧ ignorant: 
86

EVRICII CORDI

RALLA. Quëadmodum alia, quibus carent; fic \& hanc in eam mifcent : Nam quantumex tuo de peudotheriaca libello didici, nufquam hodie uera theriaca fit. Cord.Id ego non folus fed doctiores, quàm ego unquam futurus fum. plures alij dicüt, \& ante me admonuerunt, ut non iftam in unum me inuidiam rejpcias. Ral. Certe non bene à circumforaneis illis agyrthis in proximis nundinis Francofordi audiuifti, CORDV S. Sic illiuicifím à me + Nihilimpoftorum \& nebulonum maledicta facio,ut à bonis bene audiam conabor, Mego. Iohănes Manhardus, afpalathon fanda torum fpeciebus adnumerare uidetur. Cord. At frigidum eft fandalum, calida uero arpalathos. GALLVS. Qux ifta arbor latis aculeatis'́f, fo lijs, forte paliurus? Cord, Eam effe literatores quidamuolunt, \& crederem ipfe, quantum ad eius apud Diofcoridem hiftoriam, attinet, fed cum Theophraftus paliurum femen fuum in filiquis habere dicat, ab hac opinione refilio. Nam hæc fpina nudas 8 non trinas quadrinas'q\} fed plurimas baccas inter ramos fuos $p$ fert. Neque etiam adigi poffum $\times$ Gerharda Nouiomago fublcribam, qui holfam (ficeñ Germanice hanc (́pinam appellamus) taxum arboremeffe publice difcipulos fuos docuit, 


\section{BOTANOLOGICON.}

eam'qgin hac noftra terra minime tuenenofain admonuit:Cum tamen à Nicandro $\&$ Diofco ride taxus magnitudine $\&$ folion figura abies ti æqualis fimilis' $q_{3}$ defcribatur.Mego. Vulgaris notaque omnibus in Italia taxus eft, an apud nos unquam uiderim nelcio. Niger, Non in fyluis tantum ut Virgilius ait : Sed etiam in hoc horto pulcherrima fraxinus eft. Ral.Ne obliuifcar afcendam continuo \& fruetus decerpam, ut his pharmacopolium inftruam, iamdudum nullos habeo.Cordus, Quid agis? mane, puer me' fat is colliget. Ral, Velle \& cor ticis eiuss aligit me pondo habere, Năcrebro mi hi adf́tringêtribus ac côfolidantibus medicinis mircêd’ is fcribiț. Cor, Sed neutră hars imo ab fterforiâ ei facultatë ab antigs tribui uideo. $R$. Serapion nŕ,ut in pådectiscapite Dirdan uide re eft,utranq; hancipficerte arbori adicribit, quin \& corticis decocto pituitam expelli docet.Mirum ctiam idem extenuando fpleni prę fidium eft, tefte, qui ibidem citatur Galeno. Cordus. Non eft is, que citat Galeni liber, imo nec caput illud de fraxino eft, Ral.Hoctín eius initiü legi Dirdan girce, Arabice luzach, $\mathrm{La}$ tine vo fraxin?. Cor. Hallucinat more fuo.Me lian Greci non dirdam fraxinü dicunt, Quod fi quis idem caput ptelex, id eft, ulmi hiftorix 
apud Dioícoridē conferat, eandê ei diudăfens ? ut Serapion habet didar,cóperiet. Nefcio etiă quam reete fraxini ligno pellendi uenenú uis detur, cum pota eius ramenta lætalia fint, $M c_{\text {e }}$ Folia certe, foliorǘq\} fuccus, illa illita, hicpotus uiperarum morfibus fubuenirecreduntur. Cord, Tefte Diofcoride. Nig. Arbuta ac forba quoqz me nofcereuelim. Cord. Neutră hic arborem uidiffe me puto. Ral. Nonne forba funt qux agreftia mala? Cord,Longe aliud eo rum genus in Italia uidi, ut quod ibi, quëadmo dum hic matura ac mollia mefpila, ediť,Meg. Verum eft, Arbutum uero unedonē appellat. $\mathrm{Gal}$. Nonuere, nam hoc nomen epimelidi $\mathrm{Ga}$ lenustribuit, cuius, nefcio, an Diofcorides, më tionem fecerit, Cord. Fecit, fed inter mépila retulit, \& quia fere fimilia poma, fimiles uires habent,nổmin fi eodem etiã nomine appellës tur. Hoc ex te Megobacche fcire cupio, an usg̈ in Italia arborẽ, quam nos hic tiliấ noiamus, uideris? Meg. Quatenus ego peragraui, quod fciam, nufquă. Cord. Sic \& ego. Ral. Ergo nō eft tilia ut audio, quæ nobis fic dicitur? Cord. Diffimillia figura Diofcorides eam depingit, nempe olex folijs, lêtifcino fere fructu quafíqz racemofo, \& adittringêteui,Meg.Magis ergo iam monftratüliguftrü,ğnoftratē tiliä referr. 
BOT ANOLOGICON.

Cord. Ob ideriam fope mecum hrfitaui, an hæe Diofcoridis tilia frutex Ille fit, quem liguftrum uobis indicaui, uerum tamen liguftrum effe odori flores perfualerunt, qui nef́cio an fimilıter in tilia redoleăt. Ral, Ex ea, quam nos tiliam appellam', arbore, iucundiffimo certe odorefunt, \& egregiam medicinam humido frigidoq3 cerebro faciunt, fielicita ex eis aqua propinetur. Cord. En hic hortum meum.Ni. Ingens rus uideo. Cord. Quatuor ferme funt iugera.Meg. Virgilij tui præecepto aúfcultans, ordinibus indulfifti. Cord. Nonplacent, quia non iucundum prabent afpectum temere difperfe arbores, Nig. Qux aduiuam hancfepé prima fe offert, quo nomine uocatur. Cor. Diuet ipfe quęfiui, nondum tamen fcio, nifi qp uulgo eam hochmut id eft fuperbiam dicant. Me. Cum tali natura comparat? homo fis ut omnibus fuperbis femper reftiteris, quifit ut ipfam nunc fuperbiam foureas: Cord. Si effet qux dicitur diu eruncata hinc facefferet. Ral. Omnium ferme colorum in Italia monachos effe audio, ad quem ergo eorum ordinem $\mathrm{Me}$ gobacche hane ceruleo fuo cucullo referendă cenfes:Meg. Tales etiam flores alterum aconi tum, dicta hic vuolphs vuurtz id eft luparia, haber, nifi quod illi in albo flauefcant. Cor "In 
ter eius fpecies \& ego eam refero, nam \& fimi li eft folio + Ral, Magis tamen, minutius' z $_{3}$ id incifumeft. Nig. Vbi cucullatam uiderem, ftatim \& malam eam fúpicabar, Gal, Eadē ma net, etianfi cucullam abiecerit, modo quoldă apoftatas imitetur, Cor.Adhuc mihi non cre dis Ralla, hăc ueftram agrimoniamuerũ eff́e eupatorium?'Ral. Cü tot, qui hinc interim pro dierunt, authores, tibi fubfcribant, amplius reluctari nequeo: Sunt tamë uel apud nos, qui cö ftanter negant. At crederent fortaffis, fi aliă eis agrimoniam indicaueris. Cor. Diofcoridem. confulant, \& qualem ille depingit, inquirăt, ne pe agrefti papaueri fimilem, incifis anemones folips, puniceis floribus, oblongo \& in fuperio re fui partelato capitulo, quale in erratico $\mathrm{pa}$ uere, quod rhceada uocant, uidetur: Rotunda radice, qua diluti aqua croci colore, liquorem ex fe remittit, \& acrem faporem habet, Quid fimile in hac heriba, quod eam agrimoniă, (fic enim Diofcoridis argemonē nominat) putēt? Nig. Duas ille argemonas defcribit, quarú alte ram à Romanis argemoniā ait nominari, for re hanc ipfam. Cord. Sed \& huic omnes prioris uires tribuũt: Etnefcitur, quă legitimüalte rius caput fit in eo authore, \& fif fuerit, tamẽ ea dem eft foliorü figura, quę huic non congruit, 
pro terreftri hedera indicata eft.Ral, Chamę ciffum nos dicimus. Nig. Sed idem fignificante Grreco nomine. Cord. Gaudent Gracis \& Arabicis uocabulis medici noftri. Nig. Quxe tamen interim mifere corrumpunt, Cord.Pu tatur quidem et ab omnibus iam herbarijs ter reftris hedera accipitur, fed multa funt quę ani mum meum, ne eo inclinet, retrahunt.Primü, quodueræ chamæcifí, \& fi fimilia aliquatenus hederæ longiora tamen tenuiora'ç; \&, ut Virgilius Marcellus ait, faftigiata funt folia, qux in hac herba rotundiora \& in circuitu incifa uidentur. Secundum, quod flos neq; figura neq, colore refpondet, qui in Chamęciffo albę uiolæ fimilis, feuut alijuolunt, luteus eft. Tertium, ut parum de colorereferat, quod is fecŭ dum diuerfas regiones in eadem foepe herba mutatur, tamen fapor qui fallere non poteft, diffidet. Is in Chamæciffi flore gregiæamari tudinis eft, huius autem herbæ tam dulcis uel faltem adeo non ingratus, ut acetarijs mifceatur. Gal. Veri igitur commentarij funt, quos Brunfelfius citat, \& chamæciffum Afclepiademinterpretari dicit.Cord.Neq 3 id affirmo, nam ut aliæ notx congruant, non tamen graue olentem necrofx fimilem, qualem Afclepias, florē habet, Nefcióq̧; an unğ pelecini.i,fecu 
ridacx femine fimile femen proferat, Nec in montibus, ut illa, fed decliuibus frequenter, \& humidis locis, ut hic, iuxta fepes \& dumeta na fcitur. Ral. Germanicum tamen nomen non adeo à terreftri hedera abludit, quo grundt reben quafi humi repentem uiticulam dixeris, appellatur. Corruptum tamē paulatimid eft, ut iam grundelreben dicatur. Gal. Sic nullam hrec medicinam facit: Cord. Id ego non inficior, fcio quidem omnes fere equites, quoties fibula dicta peftis equum corripuerit, hac con tra eandem herba efficaciter uti, \& quis dubitet plures eam facultates habere? Gal. Phuch, quă ingrato \& plane alliaceo odore huius her bre contrita folia foetent. Ral.Quam herbam oftēdiș Gal.Didodrantalem illam folio fubrotundo nifi quod iuxta pediculum, ut in hadera introcedit,flore albo. Cord. Hanceff́e pu to, quam pandectarius rimam marinam, alliariam,\& pedem afininü appellat.Meg. Vtinam fcordium.i.paluftris tixago fir, quam cö traferpentes adeoqzi ipiam peftem commendant. Cor.Valde dubito, nam rubefcentiflore f́cordiō depingiț, qui hic albefcit, Ral.Vt hinc apparet nô eft fcordiō, ğd nos accipimus fylue ftre alliū. Cor. Sylueftre alliū noftrates hicpa ftores rampumappellant, cŏqueruntur'q̧ eius 
94 EVRICII CORDI

paftu tetrum lactis odorem fieri, tametfifunt qui eodem delectentur. $\mathrm{RaI}_{+} \mathrm{Neq}_{3}$ hoc dico, fed aliud medio inter allium $\&$ porrum odore. Cor ${ }_{+}$At hocfcorodoprafon eft, nifi forte ampeloprafon.i.uineale porrũ intelligas, Sed has herbas uos noffe \& exacte diftinguere poffe deceret, Ral.Curuos, qui domini \& precepto resnoftri eftis, medici non docetis? Cord. Recte refpondes, \& merito, qui hanc nihilad nos curam pertinere credimus, iftud à te fcomma referimus. Ral. In hac reuos foles noftrieftis, cốtra minora nos fydera onnne quod habem? à uobis lumẽ accipimus. Cord.Sin Maio adfuiffetis, eodê hoc uliginofo loco minus chelidoniǔ oftendiffem, plancea, qua apud Diofcoridem indicatur figura.Nig. Quo abiit:Cord. Statim incipienti ęftate euanefcit, hinc Germa nice meykraut.i.herba Maij dicitur, quod tan tum in eo mêfe appareat, Ral, Hiftoriă eius legă,an forte nouerim. Eadēe eft quă animo con cepi,fcatent ea omnes fere tunc horti.Et firecterecordor Hieronymus eam feickvuartzen kraut ideft hemorrhoidum herbă appellat. Cord. Saxones uero fchorbocks kraut, g̊d for te morbo, quem illi fchorbock nominant, me deatur.Meg. Quod hocuocabuli monftrü eft? Cord,Nifiadftomacaccen referat, nefcio. Nä 
ḋentes eo malo excidere \& totú os affici dicút. Ral,Alia hiftoria Serapion meniten i. chelido nium minusdepingit, nêpe altis \& gracilibus ramis, cum hrec fine caule fit herba. Cord $+N$ ä hoc authoris fed interpretis forte eft uitium. Nig. Ariftolochia quoqg rotúda quá hic holvuurtz.i. concauă radicem uocắt nố diu appa ret, nunğg enim in æeftate eam uidi, Ral, De hac herba magnă Corde controuerfiam mouifti, ineo, quem de preudotheriaca feripfifti, libello, ubi teuehementer deea, an uera ariftolochia rotunda fit,dubitare dicis. Cord.In eadê opinione hareo omnes'ç appello, qui uocată hanc ariftolochiam rotundam ad hiftoriam, qua uera ariftolochia rotunda defcribitur, contulerunt, an abfque ratione fufpicer. Ral.Eius hic caput habeo, Cordus. Lege itaque. Ral. Duo funt eius genera rotundum quod fceminam uocant, habetque hederæ folia, cum acrimonia odorata modice rotunda, tenera, pluribus ab una radice erunipens tibus germinibus . Viticula' illi longz funt, flores candidi,pileolis fimiles, in quibus quod rubet graui odore fentitur \& catera . CORDVS. Nunc aperi Galle tomos Brunfelfin \& dictx ariftolochiæ rotundx, quoniam uiuam imaginem uidere nequimus, graphice ex- 
preffam icona monfrra, Nũ hrec figura auditę iam hiftoriæ refpondet? Rutæ potius quam hederæ fimilia hæc folia funt. Meg. Radix tamen in globum, ut dehinc hiftoria habet, rapi modo rotundatur, \& forte in defcribendis folins per tot fecula commifius eft error. Cord. $V t$ id non credam author eft Nicander, qui \& iple hederaceis eă folijs in carmine, cuius metrica menfura comprehenfęuoces non tam fa cile deprauari poffunt, depingit, \& grauisillius odoris, qui ex ipfis floribus exhalat, meminit, quem ego tamen nung̈ in his percepi, quëadmodum nec odorata folia, nec illam, quae cis tribuitur, acrimoniam. Quin iṕé Diof́corides alibi foldanellam hederaceis adeoquariftolochiæ rotund $æ$ folins indicat, licet, quod eadem longiffima ibidem, tenuiffima' $q_{3}$ dican tur, nonnihil mirari me faciat. Meg. Vbi meminit Diofcorides foldanellær? Cord,In capite de braffica, eft enim marina braffica, fi Leoniceno credimus, Ral, Nó diu fciui brafícam hoc olus effe quod caules hodie dicimus. Puta bam enim caputium fic appellari,Cord.Atq; id inter eius genera numeratur, eftg ( ut mea fert opinio) quod Cumanum \& feffile Plinius dicit, quod folioet capite patulum conípiciat. Nig. Ariftolochiă noftram repetamus, delö- 
BOTANOLOGICON.

ga nihil eft quod dubites eandem effe quam omnes iam medici fic uocant? Cord. Si purpureos inea flores, \& eos quoque grauifime odoratos, fi in his dehifcentibus fimilem pyro fructu, unde melocarpos dicitur, oftenderint. Meg. Forte ergo hęc tertia fpecies eft quę clematitis.i.farmentaria cognominiatur. Cord. Similia minori fedo folia hic quoque non re fpondent. Ral.Nullam uideo, nobis ariftolochiam relinquis? Cord, Nullam furripio tantum admoneo, ut intentiore eas diligentia cô templemur, uideamusíg ne erremus, Meg. Vnum miror, quod, cumomnium ariftolochia rum contra medicamentorum noxas acuene natos morfus debiliffimum antidotü farmen taria illa prabeat, prac cateris tamen una theriacr mifcearur, Ral. Ingreditur \& rotunda, Cord. Recte Megobacchus dicit, una, debet enim ariftolochra clematitis pro una herba, adeoq, tertiailla fpecie ibi intelligi, quam dun quidă in duas feparant, non mirum fiauctior fimplicium numer ${ }^{9}$ refultet. Ral.Id memorix mädabo. Gal. Plurimú hyperici hic nafcitur. Cor.Veră tamë hypericum uidere mihi nunğ licuit. Ral.At nos eam fic appellamus. Cord. Et Diofcorides hypericum cognominat, cum primum aclegitimú ei nomen fit afcyro.Ral, 
Perforatam etiam à trăfpunctis fcilicet folins, acfugam dęmonis, quod dęmones fugare cre daț,appellant. Nig.Meticulofi pufillanimefq3 admodum fint dxmones illi oportet, qui tantillam herbã fugiất ac formident, Gal,Germa nice aūt qui uocatur:Co d.Harthau.i.durum fcenum, \& C Runrath quafi Grece thrafibula in quiburdã etiẩ locis unferfrauen bedtftro.i.dominæ noftrę ftramen. Nig. Audiui eandem \& androfemô dıci, à fanguinolētofcilicet fucco, quo côtrita folia digitos inficiunt. Gal. Illud, per oés mufas, faciunt. Afpice ut rubeăt. Cor. Eft tamen hoc nomine proprie infignita alıa herba,ob eandê cauffam, ftatim poft ueră hypericon \& hāc afcyró à Diofcoride defcripta, ut uiribus duabus prioribus nốabfímilıs, fíc cố muni earundem appellatione etiā hypericum dicta. Meg. Nolim diras ac imprecationes illas, quibus procul dubio uxor tua hanc cufcutam, ut lino fuo, dominatam peftem deuouit, in caput meum uertere. Ral,Irafcantur $8 \mathrm{rma}$ ledicant ei muliercul $x$, quantumuis uelint, bene interim à medicis audit ob egregias multis zgritudinibus medendi uires.Nig.Miror tam utilem herbam tam diligenti harum rerum obleruatori Diofcoridi prẹterită. Cord.Sinô plus ęquo audaculus cốiectator uobis uiderer, 


\section{'BOTANOLOGICON.}

qux mea fit opinio dicerem. Meg. Dic audacter libere funt coniecturæ. Cord. Puto eă androfaces apud authorẽ illum effe. Gal.Scdandrofaces in maritimis Syriæ tantum nafcitur. Cord. Dicıt tm̌́r Ral,Non,fed fimpliciter, nafcitur. Cord. Quid prohibet ergo quo minus $\&$ in Germania nafcatur? Videte candidă.inô adeo uirdem herbam quę fine folijs tenues cir ros, 8 in his continentem femina folliculum habeat, guftate item \& attributam ei amariciem deprehendetis. Ral.Paucis abfoluit paucas eius facultates Diofcorides, nempe quod copiofam ducat urinam \& fubeuntibus cutem aquis profit, CORDVS. Hinc alia, quas alncufcutæ attribuunt uires emanant, quxenim urinam ducunt ipfum quoque, qui in hepate ac renibus hæret, humorem expediunt, obftruchafque uenas aperiunt ac emundant. MEGOBACCH V S. Vnam habereriaturam dicitur, quam tibi, fi in ea ut in hominibus deteftaris, nam placere fcio, quod fcilicet eam, cui adhæret, plantam referat, inuififfimum enim corum genus tibi conftat, qui eodem nunc ore calidum nunc frigidum efflant + CORDVS + Et interim tamen integram in eo farinam continent, quam 
me uelim difcerem, quidem prudens habitus uir mihi fruftra confuluit, ex quo plane indocilem eius difcipulum effe me fentiam. Nig. Eadem rationeetiam odiofa uernilago fuerit quod \& ipfa eius, cui inhæret, foli colorem induat, \& hic nigra, illic uiridis, alibi crocea, appareat. Ral. Quam hoc nomine herbam intelligis:'Nig. Quam uos cum Grecis chameleonem dicitis. Cord. Sed in demonftrando longeà Diofcoride iuxta diffidetis, pro albo (nam duplex eft) ingentem illum carduum, quem mareien diftel grandia \& albis maculis uariata folia habentem, pro nigro uero nó minorem, imo féfquialtera nonnunquam hominis ftatura confpicuum alium, que viehdiftel appellamus, indicantes, cum prior chamæleon nullum prorfus caulem, fed echinatum tantum in medio caput habere dicatur. Alter caulem quidem fed nonultra/dodranta li longitudine furgentem proferat. Ral. Quae tunc, duo illi cardui, herbæ funt: Cord, Priorem nempe Marianum carduum, nefcio an Diofcorides defcripferit, in nullius enim cardui piêtura albæ iftę maculę quas non prætermiffifet, legütur, Alter puta pecuarius carduus nifi fcolymus fit (de quo tamenualde dubito) una cũ tot alijs carduogr generibus, qure ubiq 
fcatent, à meignoratur. Noftrates tamen mulierculas imo \& nonnullos medicaftros collecto eius femine contra pungentes laterü dolo res inteftinorrǘq ftrophos uti uideo, quafi acu ta herba,acuto quoq3 morbo medeat.Ral.Ex eifdé quoqa carduis efíe puto quæ bedeguardt \& fuchahadicuntur? Cor. Hanc Aegiptiă feu Arabicam fpină, 11 lam albam fpinā Diofcori des nominat, \& præter hanc alia eft alba f́pina per compofizionem leucacătha dicta, cum pri or acantha leuce duabus uocibus proferatur. Nig. Ex hac igitur alba f́pina Ianalis uirga, de qua Ouidius in Faftis, fumebatur ad arcendas fcilicet à foribus noxas prohibëdalqg ftriges? Cord. Ramnum ibi poeta intelligit, qux eadē etiam leucacátha Græecis uocatur, \& nefcio an eadem fit, quă nos Germanice Stachdorn appellamus.Meg.Dum de aculeatis f́pinis fabulamur, offert fe commodum fimilis herba, quă Itali reftam bouis, quod altis fcilicet \& duris radicibus in agris aratrum remoretur, appellant.Cord.Obidelegantiore uocabulo remo ra aratri diceretur, inueni tamë in ueteri quodă herbario acutellă eă nô male ưocari. Quod fi nulla harum uox arrideat poffumus eă cum Gracis ononin feu ononida nominare. Nig. Eft hasc ononis? Dir eam nofcere optaui, 


\section{2}

quod contra calculuin laudetur, cui,quoniam obnoxium fore me uereor, aduerfas ei, quafcunque fcire poffum, herbas colligo . Cord. Abeadem urinaria ui equites eam ftalkraut, id eft, urinalem uocant, potandumqz eius decotum meiere nequeuntibus equis offerunt. Alia tamen eft ab ea urinalis, quam prius lina riam dixi, quamuis fint quidam herbarij, qui linariam \&urinalem quafi duas herbas duobus capitibus magna incuria difiungăt. Meg. Habet ne hre ononis aliud adhuc Germanicum nomen? Cord. Audio eam $\&$ hauhechel appellari.Gal,Si patitur, interpretationem ad de. Cord. Hau nobis feenum, \& hechel inftrumentum illud fonat quo mulieres linum carminant, \& à craffiore ftuppa expurgant. Gal. Congruum rei uocabulum audio, horretenim crebris inter folia aculeis. Cord $\mathrm{H} x$ quo que qux Grace dipfacus, Latine labrum Veueris dicitur inter fpinofas herbas refertur. Ral. Nos labrum Veneris marianum illum carduum, de quo iand dixifti, appellamus , \& hane Virgam paftoris maiorem, uel carduum fullonum. Cord. Ille quo fullones utuntur huic quidem congener eft, ignotus tamen ut reor Diofcoridi fuit. Nufquam enim quod talem ufum prabeat memunit, fed alips eum dua 
bus herbis nēpe hippophai et hippophęto tri buit. Credo in hoc hamatos cultura fieri aculeos \& e ufdem fere utrunque facultate ualere. Meg. Verifimile eft. Cor. Cum facta fit aculea tarum mentio, cupio uiciffum à uobis difcere quifnă terreftris tribulus fit, fiuerum eft quod Virg.Marcellus ex Theophrafto dicit, eã plă tam priuatim \& alio nature ordine fuos non in foli $8<$ caule aculeos, fed ipfo fructu. i.peri carpio ferre, quod ut in aquatico tribulo uekz eff́c uideo, (eius fructus aquaticas nuces uocamus) fic in terreftri indicari mihi uelim,Meg . Etçdă lappa minor,et Germanice bettlerfleu E/t fe dicta, quę oblongas et aculeatas fructuú the cas fert, quid fi illa fit:Cord Hăc xanthiũ poti us crederê fi maiores illi fructus eflent. Debët eñ olituas pilule iftæ, iuxta hiftoriă, fuperare. Ral.Quid audio, ipfos etiẩ tribulos uulgarem agroß* peltẽ ignoramus?Nig. In meo tñ Theophrafto terreftris tribuli fpinofa folia lego, ait enim:Duo eius genera/,unus eñ folio ciceris exit, al' f pinofus foliatus conftat, ambo ter reni, atq, multifidi funt, feri' germinat $q$ fpino fus folns eft, \& apud (epta uillap is folet erũpe re. Cor.Vt aculeata cốcedấ,ubi ciceris, ut The ophraft', uel portulacæ ut Diofcorides ait, folia in noftro putato tribulo funt. cuil etiă ter- 
reftrisunum tantum genus ab eodem Diofco ride ponitur. Meg. Referuabimus hane quæeftionem in proximá aliquă quodlibeticam me dicorum difputationem. Cord,Imo te affinis

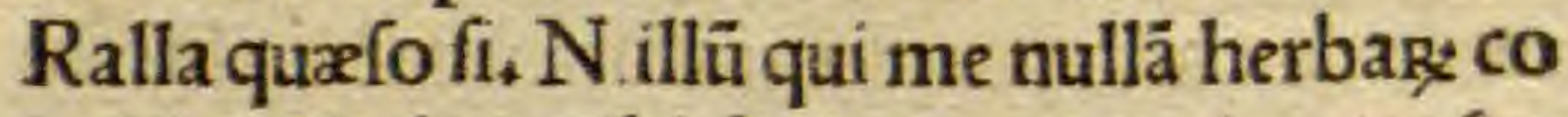
gnitionē habere tibi dix t, conueneris, eum fug hac re confule, \& quid decernat referibe. Nig. Sunt qui $\&$ in hac uulgari herba dubitent, qui bufdă aparinē, alijs alyffon effe uolêtibus. Ral. Nos rubiă minorê uocamus. Gal, At Plinius alyffon rubix comparat, \& eandem fere dicit, nifiquod minoribus folijs et ramis fit.Cor.Sic alios quoq; herbarios dicere fcio, cótrarıá ta* men cóparationem Pliniana x̌ba oftendunt; quxe hæc funt. Diftat, inquit, erithrodanus ab eo quę alyfíon uocatur, folins tantum \& ramis minoribus, hic Plinium minora rubiæ folia, minores item ramos tribuere intelligo. Neq3 uideo quonam pacto hrec etiam figura depiéto apud Diofcoridem alyffo congruat, quă ser circinata habere folia dicit. Nifi forte circinata quafi in circulum difpofita quis inter pretari uelit, Niger. Hoc Graca lectio forte non patietur. CORDVS. Et ut de folins confter, in ipfis caulibus magna eft diuerfitas, qui multi funt aparines, alyffi uero fingularis eft. Alyfion quidem hanc uelim, utpote 
egregiü illud cốtra rabidi canis morlum antis dot im, fed inagis mihi aparines hiftoriă exprimereuidecur, maxime tenaci afperitate \& fim libus umbilico fructibus, unde $\&$ factum omphalocarpi nomen. Gal. Brunfelfius aparinen apud Italos grapellam uocariait: fi forteMegobacche hanc illic nomenclaturā audie ris. Meg. Nó animaduerti.Cord.Collinutius alıam quandain, utcredo, uidelicet lappariam herbam fic appellarifcripfit, qux fere mercurialis folia, \& afperum retinax' $q_{3}$ femë habeat, $\&$ à Plinio inter Parthenijgenera numeretur. Modo mercurialem eam nổ intelligitis cuius Brunfelfiani tomi effigiem oftëdunt, \& $\mathrm{n}$ nefcio quem bonum Henricü appellant, cum illa potius ea fit, qux Germanice kuhevurt5, id eft, uaccaria, uel ea (fi me pietura fallit) quæ miftmilden, ideft, fimetaria atriplexdicitur, Ral, Mercurialem omnes alia figura nouimus, illius folia hæe non habet fed multo graciliora. Meg+Sit ergout \& ego puto hęc aparine, Gal. Germanice qui eã uocatıs? Cord. Klebkraut, eft em̃nnobis cleben quod Latini tenaciter inhærere dicunt. Ralla, Eft huic aparinæe fimilis alia quædam herba nulla tamen afperitate ob fita que in muris \& macerijs peculiariter nafcitur. Cordus.Eam quidam afpergulam effe 


\section{6}

\section{EVICIICORDI}

putăt, quidăă ue o gallium, Mego.Sed gallium odoratos flores habet, \& eam effe credo, qua aparin $x$ quide fimilis, fed multo minor ac hus milior eft, imo \& copiofiorib' caulib' e terra exit. Cor. Tibi fubfcribo atq3 eccă eam in pro ximo hoc cliuo, Gal Germanicum eius nomẽ audire expeto. Cord Nondum, q̊d íciă baptifata eft. Nig. Hac ratione forte anabaptiftę cu iufdă catechumena ples fuerit. Cord, Tunc cô feftim eam tã grata eft mihi anabaptiftąy fecta,Meg. V tină ad extremam ufqu Thylê hoc hominum genus relegareț, ut pelíma omniũ bonanz artium adeóg; facrasz Iterazy peftis \& pnicies. Cord. Adde \& publicæ tranquillitatis feditiofi cõturbatores. Ego omnes huiuf modi fectapz autores phanaticos adeóģ atribilarios hoies credog nihil aliud inuentis fuis placitis efficient, uereor, gुg ut uera tandem religio a mittať. Nig. Hăc quoogz non ùeră millefoliū effe quidá contendunt. Cord, Inter eos \& me effe noueris, Nä cum tres herbæ fint huius nominis, prima Achillea, fecitda ftratiotes terreftris, tertia peculiariter millefolum dića, hanc terreftrê ftratioté puto, an errorẽ iud cate ipfi poftğ trium has hiftorias côtuleritis.Gal. Quia Germanica noia pugilla ribus excipio, cupio \& q hăciplam nominetis 


\section{BOTANOLOGICON.}

fcire,Cord, Garbă audio dici, Saxóes relicam uocant, utroq, non patiente interpretationem uocabulo. Sunt etiã qui fthaffsreibe, id eft, outnan coftam appellent. Nig. Non adeo pericu lofus error fuerit, fi \& hæc pro uero millefolio accipiatur, nam eadem fere éft omnuū harum trium, nempe uulneraria, uis. Cord.Herbarij ueftrifimilem huic philipendulă quandam indicant, hae quænam fit, $\&$ an hic uipiam nafca turf cire cuperem. Gal,Brunfelfus eam Difco rid s oenanthen effe putat. Cord. At eam non ftratiotis huius, fed paftinacæe folins idē autor depingit.Nig.Licet hic Virgi, Marcelli,nefcio incuriam ne an obliuionem dicam, admirari, qui de labrufcæ flore, qui etiam cenanthe woca tur, agens nứquă fe in Diofcoride de cenăthe herba, quam ex Aegineta citat, Jegiffe dicit, cú tamen eius caput in codem autore interpreta tus fuerit et adiectis quoq ${ }_{3}$ fcholins dilucidarit. NIGER. Vtimini etiam ifta in medicina her ba? CORDVS.Vterentur multi fi cognofce rent. Nig,Quxeft igitur. Cordus. Diofcorisdis erigeron, qua latine fenetio interpretatur. RALLA, Aterigeron carduus benedietus \& fenetio creffon ab herbarijs'noftris dicitur. COR D V S. Male, legefenetionis hiftoriam \& hancherbamgraphice depingi uidebis. 
108

\section{EVRICII CORDI}

En exigua folia erucx modo in extremitatis bus incifa $\&$ longe quam erucæ funt, minora, cuius etiam lutei flores cito poftğ enata eft, de hifcunt, \& in pappos abeunt, Nolui tamē huic tantum fimilitudini credere quin colligētes eă anus nonnung̈ interrogaui ad quemnam mor bum ea uterentur: Quę ad reftinguēdas inflămationes refponderunt. Nǔcubi Diofcorides fenetioni refrigerandi uim tribuat fimilifque in hac figura appareat, quid prohibet fenetios nem credere? Ral, Medici tamen inter calidas herbas fenetionem numerant. Cord. Alterü fcilicet fy fy mbriü puta cardaminen, id eft, na fturciariam, quam crefonem quoque dicunt, falfo intelligentes.Nig. Creffonēlauer,adeo'q; fium effe quidam autumant. Cordus, Cogno minatur quidem frum, fed uerü frum q̊d idem lauer, herba eft quam Germanice pungen, \& à natali loco vuafferpungen uel bachpungen uo camus, Saxones lemmicain, cui adraodum fimilis alia, fed non odora, ut nefciă an hæc non odoratum lauer fit, quod tamen nomen Leonicenus creffonietiam tribuit, Certe odoralo fio feu lauere chirurgi quidam ad uulnera \& hulcera curanda utuntur, ut hinc etiam aquas ticam anagallidemà Diolcoride appellari pu vem:Verum ad hanc fenetionem reuer 


\section{BOTANOLOGICON.}

tamur Iohänes Manhardus quoqg erigeronta nõ carduum benedictum fedaliă herbam ef̂́e teftatur, quam, quod in muris nafcitur, petrels Jam ab Italis uocariait. Nafcitur quidem \& hæc in muris fed fimillima quædă alia, maior tamen $\&$ ramofior frequentius, Illa uidelicet quam Brunfelfius pro altera uerbenaca exhibet, candidioribus quam hæc, \& aliquătulum lanuginofis folins. Gal.Hanc fenetionem Germanice mihinomina. Cord, Kreut;vurts, id eft, cruciată herbam à fimilibus fcilicet folins. Ral.Si reste uerba tua accipio nonuera effigie apud Brunfelfium hanc uerbenacă monftrari furpicaris? Cord. Imo neutram, fi quxqg ad hi ftoriam fuam referatur. Ral. At herbarijno ftri utramqg fe nofcere non dubitant. Cordus. Nonenim tamlata \& eo modo ferrata prioris, ideft, rectx yेbenacę folia hicuideo, ut hine gallinacea crifta (fic enimuerbenaca etiam di citur) appellari uel debeat uel poffit. Nec memini anung in aquofis eam locis nafci,uel aliquä cũ colübis (unde perifterionis nomê) ami citiā habere compererim. Dedodrantali quă hrec ter fuperat, altitudine nihil dico, quod nô eandem omnibus herbis ubi'g, proceritatem efféfciam. In altera qux profupina \& foemina uerbenaca hic pingitur, hoc me fufpendit, 
quod luteos flores habere foleat, $g$ fupinæ uer benacæ purpurec colore apud Diofcoridé ine dicantur, ut al as, quibus non refpondet, notas præteream. Gal. Ipletamen Plinius, ut eî hic Brunfelfius citat, fupinã uerbenacamluteis flo ribus defcribit. Ral. Id audire cupio.Gal.Eft, ingt fimilis uerbafco herba, q̃fępe fallit pro ea capta, folns minus candidis, cauliculis plurib?, flore luteo, Cord, Male iungit haec uerbenace uerba, cum feorfim aliam alus herbæe nempe blattariç hiftoriă conftituant, Gal Reçe, nam fic eă Rònæuocari mox fubdit.Niger, Aliam quandă herbă latis fcabris'q̧̧ ac grauiter fpirătibus folijs centrunn galli, quo etiă nomine uer benacam uocant, appellari nonnunquã audiui Cord. Verum, fed magno interim errore.Me. Scarleam hodie dictă intelligit. Cord, Hanc ip [am, antiquis nimiz medicis, ut puto ignotam, Gal. Verbenacam putatam Germanice qui uocis: Cordus. Ifenkraut uel Ifernnhart. Quaififerrariam dicas, NI GE R. Gręcorum forte fideritis fuerit: CORD V S.Sicuerbenacam fupinam quidem à Diof coride cognominari legimus, alla tamen eft uerbenaca pro prie dieta fideritis, ut Pandectarius errarit, pro eadem hanc intelligens.MEGObacchus, Hac quxe eft eadem ne illi quam beinbellam 


\section{BOTANOLOGICON.}

prius appellafti. Cordus, Non, fed tamen admodum fimilis, præterquă in florib", quos hic quafi in umbellam difpofitos puniceo colore iucundum afpectum præebere cernitis, Saxóes aurinam inaiorem uocant, Ral.Ergocentaureum maius eft, aurinam enim eadê gens centaureum nominat: A quo etiă Germanicun nomen quo in Heffia noftra appellat́t non mul tum abludit, uocant enim hic eam taufent gul den, quafi mille aureos quis dixerit $\&$ ad centaureum (quod quaficentúaureos fonat) refpexerit. Cord. Centaureum maius aliam ha bet hiftoriam. Nig. Eam apud Diofcoridem legi fed ipfam herbam uidere cupio. Cordus. Ego quidem uidi Ferrarix nontamen maioris centaurijfed Rha Pontici nomine indicatam. Eodem \& uos eius radicem nouiftis quă fcilicet uagiagyrthæ nobis pro rhapontico uẻ dunt. Etenim uerum hanc raponticum effe non facile perfuadeor. R A L L A. Ergo \& ue ro nos thaponticocarere putas? Cord. Imo fcio:Interim tamen Rha Barbarum, quo Ara bes proeoutuntur, habetis . Licet \& hocuel euanidum uel adulteratum adeóg; factitium plerunque afportetur, que iam mercatorum-

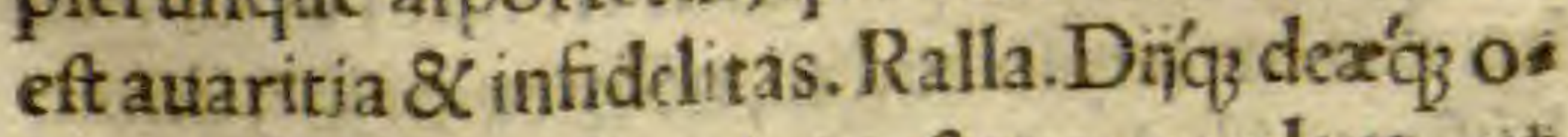
mnes falíarios illos impoftores perdant, ute 
fyncera tandem fimplicia, quantumuisetiain cara, nanciffi liceat, Nullis ego nummis,nulli certe fumptui parcerem, modo humanę faluti confuleretur. Cord Chritiani hominis egregium animum audio quem utină nulla cupidi tas paulatim, cum ditef́cere coeperis, có́cutiat. Multis aliogł exemplıs didici, quăta fit in auaritiā pcliuitas quätus itê dehinc iuftitiæx, acæ $q$ tatis contemptus Ral, Curabo ne ditefcă exq̊ hac opes uitia fecum trahunt. Cordus. Taceo quod nihil auaris miferius fit, \& magis impiū minus mifericors.Meg.Scio quid aio iă conci pias, dulcem nimize carică. Cord. Imo acerbif fumum arbutum. Ral, Sunt qui Rha Barbarü idem cü R ha Pontico effe, notum'qu ueteribus etiă medicis fuiffe putent, inter quos $\&$ Paulus Fezerus eft, qui hancopinionem publica difpu tatione defendere promittit. Cord.Non adeo inficior, fciës præceptorem meü Leonicenum fimiliter, ut apparet,opinari, cui tamen Iohãnes Manhardus, quafi dubitet, imo diuerfas efferadices credat, in quadam epiftola fcribit. Et idem præceptor meus eft, utneiciă utri ma gis adhęreă.Meg. Refpondit huic Leonicenus longis literis et refponfurus eft eidē rurfus $M a ̆$ hardus, ut exipfo audiui, nố breuiorib?, duo'q̧ hi fimul libelli alıguädo prodibunt in publicü, 
runc ex hisquafi collifis pyritidibus emicantemueritatem uidebimus. CORrd. Plures ta les uiros fuper his rebus committi, \& conueli tari cuperem.Nig.Magnam huic herbæ iniuriam facimus, quæ cü multis nominibus celebretur, \& uarias in fe uirtutes habeat, eam tamen pedibus noftriscalcamus, CORDVS. Id cum bonis ac doctis omnibus uiris commune iam patitur.Gal. Quam eam dicis? Cord.Po lygonon fiue polygonatum proferpinacă, fan guinalem \& corrigiolam, alia alibi nomina ui de.Gal.Cum Nicandrum prælegeres aliă poly gonatum herbă dixifti, nempe eam qux figillü Salomonis hodieuulgares herbarij uocant. Cord. Recte, fed quid obftat quo minus et huic nomen fuum, ut plures aliz quoq, herbæ folêt, cốmunicetr Ral.Polygonatü illud ut Diofcorides, feu figillum Salomonis ut nos dicimus, Germanice vueifvort5, id eft, alba radix nominatur. Cord, Sunt quidam erroze caligine adeo caci, ut eandem radicē pro alboueratro accipiant. Meg.Sirecte memini legi aliquădo figillum, Salomốis ne an Marię nef́cio, fecacul effe. Cord,Apud Iacobum de Manlins. Gallus; Sic et Brunfelfius quofdam uelle teftatur. Ral. Eademergo eryngo polygonatü,namfecacul 
\&Ceryngus imo \& centum capita erdem her barins noftris res funt. Cord. Non aufim crede re, fi uerum eft quod Serapion, ut idè Iacobus citat, in feptimo de conditis capite ait fecacul fcilicet fimilem zinziberi radicẽ effe \& exIndıa afportari,\& nefcio quid ex recenti ea fieri, Quę an de credito à me polygonato queant in telligi nefcio. Hoc autem conftat quod idẽ aus tor de fimplicium temperamentis capite, fibe ne memini lxxxix. fecacul deferibat, nullumq̧́ Diofcoridem citet, g̊d procul dubio more fuo feciffet fiillud ex eo caput tranffumpfiffet. Nö tamen admodum nec pertinaciter repugno. In eiufdem capitis lemmate nố bene eryngore fit mentiofufpicor + Quemadmodum \& ubi aftera atticum, id eft, inguinalem, bubonium $\&$ alibium (omnia hrec idem nomina fignia ficant) defcribit ${ }_{*}$ Poteft forte $\&$ after attio cus Grecorum \& centum capita Arabibus dici, non tamen continuo illa eryngi fpecies eft. Quam quia eodem centum capitum no mine appellaretur, ftatim ibidem, ut à prios redifcernat, diuerfa hiftoriadepingit, $M E$, GOB A CCHV S, Aliud à f́cecacul $\&$ cen rumcapitibus, erynginnomen apud Serapios nem in cuiufdam herbx tranffumpta ex Dios fcoride hiftoria legiffe me fcio, fed iam non 
fuccurrit. CORDVS. In montana nardo id obferuaui, quam Diofcorides ramulisfo. Iijfque eryngio comparat. Vbi Serapion loco eryngi i Darfahane habet, quodut f́citu dis gnum in codice meo fignaffe me recordor. NIGE R* Videntur quibufdam eryngium \& centum capita diuerf $x$ herbx, CORDVS. Certe Plinius duo de his capita fecit, \& uarias eryngij fpecies indicat: Imo \& ipfam cen tum capita unam earum nempe albam effe af firmat, RALLA. Omnes quotquotíe eryngium nofle putant, carduum iftum indicant, quem Germanice vuallen difteln, id eft, aggerum carduum uocamus: Eidem \& centum capitum nomen admodum congruit, quod plurima filicet capirula fpinofa \& quafi ftell ta gerat. COR DV S.Sed hrec nullum, quem ego obferuaui, effatu dignum odorem habet, qui tamen à Diofcoride \& Plinio eryngïrradi ci tribuitur:Imo \& centum capita Plinius raram inuentu,tradiq́; radicem eius alterutrius fexus fimilitudinem referre, dicit, quare fape mecū cogitaui an forte carduus panis, quē uul goebervurts dicim? aliqua eryngin fpecies fit. Niger. Huncego aliquando alterü chamaleo. nem putaui, Cordus, Perlapideum Iouem in 
eademetiam opinione fui, fed hoc me reuocauit, quod cubitalem huius cardui caulem esfe, qui eam effodiunt, dicant, quo albus chamaleon prorfus caret, quem tamen hunc effe oporterer cum alter qui caulem habet perimens uenenum fit : Nunc cardui panis uocati radice homines libenter uefcuntur, \& multis incommodis medentur, hac tamen infamis ea facultate male audit, quod uefcentis quis dem uires augere, fed iuxta uerfantis'auferre dicatur. R AL L A. Siuocatus pacis feu panis carduus (utroque eum nomine roftrates feplafiarijuocant) quædam eryngijifpecies eft, \& uerum id quod alterutrum fexum referat, tum quotq̊t ego huiufmodi radices uidi focmi nx erant quandam fcilicet rimam oftendentes: Vtinam uiderim \& mafculas, CORdus, Certe, aliquid dicis, quod tamen ego affirma re non aufin, fiuerum eft quod quidam dee ryngij radice tradunt, effef́cilicet eam tantze longitudinis utraro integra $\&$ femper fere ab rupta effodiatur. Id quod neque apud Diofcoridem, neque apud Pliniumlegiffe me re. cordor. Relinquo igitur hęc doctioribus pro piusperipicienda + ME GOBA CCHV S. Interea dum alio rapimur, huius polygoned 
noftri obliuifcimur, CORDus. Nihil habeo quod ultra ea quxe $a b$ alijs de ea traduntur, addam. Megobacchus. Fceminam fanguinalem nofti? Nam dux eius fpecies funt. Cordus. Variant authores, quidam hanc ma rem, \& alteram foeminam : Contra, hanc foe minam \& alteram marem nominant, fictamen utfemper maiores huius uires celebrent. NIIGE R, Fuit cum hane non polygonium fed agroftin putarim, CORDVS. Putarem \& ego, nifi aliter, qui multi iam fcribunt, herbarij perfuaderent : Quandoquidem omnes uocatam hanc Germanice Vurgegrafs uel vuegedryt Polygonium effe contendunt. Megobacchus, An alteram quod quxefiui, fan guinalem nofeas nondumrefipondifti. Cord. Non affirmo, fuípicionem tantum habeo, qua proferre non aufim. Megobacehus. Quid obftat: Cordus. Vereor ne me derideatis, ne" ue, quafi omnia ad lubitum turbare uelim, male audiam. Dicam tamen ied hac protefta tione quod leuiter fufficer, non decernam. Nouiftis omēes herbam puto quam hippurim id eft, equinam caudam feu equiferum effec cre dimus, Germanice daubennrock uel kannen kraut distam. GALLVS. Neutramuo- 
118

EVRICII CORDI

cem intelligo. Cordus. Prius nomen quafico lumbinam colum fignificat, alterum à ftanneis uafis, quod ea hac afpera herba munden tur, abfterganturque, factum eft. R ALL. A. Quid fi nofcamus hanc, num alteram fanguinalem efle putas? CORD + Non omnino foeminx tamen fanguinalis hiftoriam putato equifeto illi fere congruere uideo. Ait em̌n Dio fcorides eam fingulari caule, exiguum \& tene rum fruticem effe harüdini fimilem, continua ris geniculis, \& in feipfos tubarum modo faretis, \& circa illos fimilia picex foliola in orbë exire, herbam in aquofis locis nafci. R A Lla, Quxe equina cauda creditur in ficcis etiă agris inter recens enatam auenam conficicitur. Cordus, Frequentius tamen \& foelicius, utpo

- te maior $\&$ firmior, in aquofis, maxime que à noftris Schaffthau 8 loecher dicitur, gratŭ \& falubreequis pabulum + Quanquam alteri equifeto hrecipla planta congruit. NIGER. Caulis concauitas harundinem utcunque refert \& continuata genicula non multum abludunt,'quxe plane infeipfa tubarum modo far ciuntur. Ip ra quoque foliola picexe fimilia circa eadem in orbem exeunt. Quantum etiam ad uires attinet, uideoei eandem etiam facultatem nempe adftrictoriam tribui, RAL. Si 
foemina fanguinalis mafculær refpondet, neceffeeft Rafim noftrum errare qui corrigiolä calidam effe \& fluxum ciere dicit Cord.Muls tre funt herbx qux uiticulis fuis corrigiolx usfum prebent, quis fcit quam ille corrigiolă ins telligat, Mego, Perge Niger, Niger. Non minus tamen $\&$ fux equifetum noftrum hiftorix, fil legeris, conuenit. Cordus. Iamdudum legi,\& eft inea quod menon parum dubitare facit. Niger.Id audire uelim. Cordus. Quod in altitudinë augeri herba \& propinquas itirpes afcendere \& exillis circumamplexa nigris equinamíq, caudam referentibus comis pendere dicatur. Quam nosequinam caudam ap pellamus fingularem caulēerigit, fuáç ${ }_{3}$ ipfius firmitate furfum nititur, nec ufquam inclinat, proximum aliquid afcendit circumamplectiturue, Meg. Vrges quidem fed non tam gras uiter ut opinioni tuæ fubfcribam. Ego quod equifetum dicimus uerum etiam equifetum puto atque hoc argumento cum nuper in Is talia forte deambularem reperi primum equifeti rudimentum diuque quarnam planta ef́et dubitaui,tandē poft aliquot dies admira tionis caufa eandem af́picere ueilem factumequifetum comperi. Id admodum his quæe Virgilius Marcellus in equifeti fcholijs feribit 
conuenire uidetur: Ait enim, fiurdeat nafeen tem aliquis equifetum herbam, exeuntemque ex terra aliquot diebus çontempletur, nunquam unde futura fitequina cauda in ea intel liget tam breui, nudo, concreto oritur afparago \& fcapo. Nullibidiffimiliorem natura fi nem quain in hac planta à fuo principio fecit. CORDVS. Hæc \& egolegi, quemadmodum $\&$ quod Hermolaus Barbarus in Corolare dicit, equifetum in pratis nafcentem $\&$ ob id inuifam fonifecis herbain, quafíq; aliquem rerræ pilum effe: Sed magis ad Diofcoridęuer ba répicio, qui equinam falicem arborifque nomine equifetum appellari dicit, quod non multumidiffert ab hoc quod Græcorum aliqui hippurim nigricantem folins pinum nomi nent, MEGobacchus, Tu in tua ego in mea manebo opinione, Cordus. Nonlibenter à re diffentio nedum à communi omnium fenten tia, licet id citra graue periculum fuerit, fiquidem fimiles fere utriuffo facultates funt. Videre tamen cupio, ubi hoc equifetum nofrrum, falicem utcunque referat, propinquas ftirpes afcendat, circumamplexetur'q 2 \&inc nigris comis propêdeat haetenus non licuit. RA L L A, Spontefua an plantata hic afinina hrcungula coaluit? CORDVS. Plätata. 
Ral.Mirabar eam in hoc folo, qux longealio, petrofo nimirum gaudet,enatam, Meg. Eandem hăc Græcorum bechium \& antiquorum Latinorum Thuffillaginem effe uolunt.Cor. Id difcipulos meos iam olim docui. Nig. Iam uideo cur $\&$ ogiros ac chameleucedicat , pla ne enim populi folium refert. Cord. Eadem cauffa 8 farfarus appellatur, quo quondam uocabulo, ut apudPlautum forte legiftis, populus indicata eft. Ral. Hinc forte nobis eius farfarellęnomenclatura inualuit.Gal,Albam populum magis quam nigram affimilat, nem pe albicấtiexaltera parte folio, fed hunc ei co lorem fuperne gua coelum fpectat, contra alio rum foliorum naturam, ineffe Virg, Marcellus ait, quum hic contrarium uideamus, Cor. Scepe hoc me fufpendit, quare diu foepeque animaduertianufquam uidere poffem. Tandem ergo certo quodam tempore in fuperna ifta foliorum parte teneram quafi lanuginem albicare inueni, quam facili leuiqg pollicis attritu abfterfi. An hanc Diofcorides intelligat nef́cio, Gal.Etiamfi maxime id faciat, non tamen aduería parsuiret, ut idem \& Diolcorides 8 Virg.Marcellus tradit. Nig, Confulam Gręcum Diolcoridem meum, an forte aliquir fubfit error.Gal.Germanicume eius nomen au 
dire cupio.Cord.Efels huff.i.ut Ralla uocauît, afininam ungulam. Ral.Iacobus à Mălins pro equina ungula adeoqz nenufare, quâ uos nym pheam dicitis, hanc Tuffilaginem feufarfarellam interpretatus eft. Cord.Male Ral.Di- $^{-}$ citur et Germanice brắdtlattich.i.uftilaria lap pa,quă autẽ ob caufam nef́cio, nifi forte uftioni medeatur, Cord,SEed hæe propior uero eft, quod eius folia quondam uri, \& nidor in pulmonem trahi folebat, nổ leui ad f́piritus difficultatem auxilio. Nig. Id \& iam fieri poteft, Cord. Hanc quoq; Angelică hodie dictam, ex Miffenio per duodecim ferme miliaria noftra tia allată huc tranfplắtaui.Ral.Magna eft eius hic \& fere ubig, in humidis locis copia. Cord. Sed non $æ q u e$ bon $æ \&$ redolentis, Meg.,Mirü quod ueteres medici fi modo recētioribus her barīs credendum eft, nullā de hac mentionem fecerint. Cord. Quid fiNicander, Theophraftus, Diofcorides, Galenus, Aegineta, plurefog tum Greci, tum Latinialijeius meminerint? Meg. Agequo nomine Cord.Smyrnin,quă Theophraftus eam hippofelinon, quod olufa tri nomen eft, appellet : Anacteó uero coptiü. Commodum eius radicem hic habeo in eodẻ monte effofíam.Meg.Quădo in eo eras!Cor. Proxima feptimana cum principēnoftrü $\mathrm{Al}$ - 
tendorffiü $\&$ Efchuegăfequerer:In eüitunc me ducebat Iuftus Hybernus herbariæ rei cupidiffimus etiă fectator + En eă olfacite \& guftate. Meg. Certe odorata eft. Cor.Stringe \& cõ prime eă fortiter, \& uidebis fentiefqz illiü myc xhæ odore fuccü, quē Theophraftus ei tribuit, Vnde \& nomen. Ral, Idē fere odor.Nig. Ergo tu uerã myrrhă olfecifti ¿ Qua Măhardus nos carere dicit. Ral,Quă ornes alì feplafiarị myr rhă habent, eandem \& ego habeo, an ueră nefcio,atq3 eius hic eft odor, Gal. Eft \& grata in guftu acrimonia.Hem, hem, hem, ferire ceruicem, fuffocor,Quă pene perinflem. Cacodęmo nica non Angelica eft, Imo nec Smyrnium, q̊d difficultati anhelitus, \& non nifi recta ceruice fpirantibus medetur, tantü abeft, ut ftrăgulet. Cor.Id \& mihi nuper Altendorffij in Iuftinis xdibus accidit, dum maius ęquo fruftum fum pferă,atqzi ideo magis perfuafus fum Smyrniũ effe, nam id in cibo fauces ledere Diolcorides dicit.Dum tamen in uentriculo confectum \& ad pulmonem ufq, diftributum eft eas, quas ia dixifti \& idem author ei tribuit, facultates exhibet.Meg. Ohê Galle quă male iă cucuriebas. Pene eo tecum uentum erat ut nullis unquam gallinis ufui fuiffes, Gal. Vbi iocus \& rifus, ibi nullum eft funus, Megob. Nifi forte nouerca 
124

aut peffimz uxoris. Ral. Hippofelinum illud, quod olufatrum iam interpretabaris, ufpiam hic nafeitur?Cord. Si quam ego intelligo fuerit, copiofe \& ubiq, atq3 ecce ipfum ad hoc du metü non tamen adeo grandeut in umbrofishortis, alijs'q, humidis locis, ubi plane nomëclaturæ fux refpondet. Ral, Hanc etiă quidam hic Angelică effe putant. Cord.Longe eft debi lior radicis tum odor tum acrimonia. Meg, Cócauum,celfum, \& ueluti lineis interfectum caulem uideo. Cord. Vidiffes etiam dum florefceret denfam \& corymborum modo concretam comam ex inuolucro quodam erumpentem. Gal. Germanicum eius nomen $æ$ de. Cord. Nelcio, nifi quod nonnulligladeroeren .i.læuem cannam feu fiftulam appellent . Ral. Similis eft ei aliquatenus quæ gierfa uulgo no minatur. Cord. Hanc ego rufticum feu paluftre apium aliquando putaui. Meg. Effodi alteram illam, quam dicis, Angelicä, \& nonuerum hippofelinum feu olufatrü efféfúpicor,al ba enim apparet radix, qux hippofeliniforis nigra, intus candida eft. Cord. Hoc unum haEtenus et me fúpendit.Meg. Quod etiam in hi ftoria eius legitur, elixos coliculos edi, magis iam à Ralla dietæ gierfæ conuenit, qua recenti homines uefcuntur. Cord. Vringenue fatear 


\section{BOTANOLOGICON.}

turbant me multiplicia tam uariæ defcriptorum apiorum genera. Vbi enim fatium illud eft hirfutofolio ? ut ex Theophrafto Virgil. Marcellus citat.Nig,Nefcio quàm bene interpres is ibi uerterit, nam Gaza denfum non hir futum tranftulit. Cord.Scepe hrecuox in alijs quoq3 folins me offendit, quibus omnino non congruit . Sic puto \& à Lonicero meo in Nicandro melliffophyllum afperum interpreta tum. Ral. Ingreffum autumnum uideo, autumnales uocati flores prodeunt. Gal, Hos atq3 martios nominatos flores Brunfelfus narciffos putat. Cord. Sic \& alius quidam ualde do ctus, in alihs tamen difciplinis:At meo iudicio toto errant coelo, nifi Leonicenus, Manhardus, $\&$ V Vincentius Caprilus me fefellerint, qui bus præefentibus $\&$ affirmantibus Ferrariæ in Marianorum feruorum coenobio frater quidam eiufdem fodalitij doctor Iacobus uerum mihi narciffum oftendit longe alia, quam utri que hi flores habent, facie pedali feilicet altitudine furgentem cauliculum, quem liliacea, fed multo minora folia ueftiebant. Opertum adhuc folliculo feu inuolucro florê uidere non licuit, quăuis in ultima fere eftatis parte. Qui martij feu februarij illi flores fint in præfentia rum nihil certi habeo. Verum hic autumnalis 
126

EVRICII CORDI

flos agreftis bulbus antigs Latinis appellatus eft, Gręcis uero Colchicü, Nig.QuodDiofco rides defcribit:Cor.Idipfum.Nig,Ergo uenenum eft:Cor.Præentiffimum, utuefcens illo, eodem die quafi malis fungis ftrangulari dica tur, unde \& ephemeron appellatum. Conferte huc Colchiciillius hiftoriam \& in fententiam meamultro ibitis, Meg.Hac defcriptione her modactylum quidam indicant. Ral. Serapion certe in capiteSurugen hanc Colchici hiftoriä. exfcripfit. Et interpres hermodactylüin lemmate prafixit. Sed hermodactyli noftrinon has radices referŭt, neq̧ etiam uenenofif funt, ut quibus in articulari morbo foepe nos uti fo letis, Meg. Quid fi proxime fequens ephemes ron nêpe agreftisiris hermodactylus fit: Cor. Id ut non facilecredă facit, quod ipfum longă \& digitalicraffitudine radicem habere legam: Dehinc quod neq, Diofcorides neq ${ }_{3}$ Galenus quicğ de purgatoria illa ui prodat. Imo quod Aegineta feorfim à colchico \& ephemero her modactylü inter fimplicia fua reponat, eumq3 p fe, ac elixationẻ eius ad purgationes ualere, maximeeop\&, g in articulos decidút, humos: Eadē \& Serapiố ex Galeno citat, fed nondũin eius authoris fimplicibus hermodactylü inue ni,ut credă poft Diolcoridis \& Galeni tëpora 


\section{BOTANOLOGICON.}

hanc ipfam medicinam repertam effe. Ral. Re ticto uenenofo Colchico ad falubres herbas pgrediamur, Quxe eft ifta alto caule, magnis, rotund is, \& in circuitu laciniofis folins: Cord. Non dicam nifi tu que malua fitdoceas. $R a l_{\text {, }}$ Dijboni quid audio, uulgarem $\&$ notiffima omnibus ubiqg herbă te doceă:Cor. Indica er go mihi, quę tă grădem caulem habeat, ut baculi ufum prębere poffit, quēadmodum Theo phraft' de malua tradit. Ral. Tantă nunğ uidi. Cor. At hac in area ante duos annos tă ingeng creuit, ut arborécens caulis nouẻ meopł pedú lógitudinē, brachinuero craffitưdinể æquaret. Atqg hrc illius neptis eft.Nig. Credo hortula nă effe maluam.Cor, Rhomană hic maluă ap pellant. Meg.Nefcio an usg̈ in Italia uiderim. Simile eft malure femini \& illud, fimilis $q^{q} \xi_{3}$, ut ita dicam, lubricitas, Eam omnino fuiffe crediderim, cuius cibo Cicero inteftinop leuitatem contraxit: Non enim fylueftrë $\&$ incultis locis uaria fpecie nafcentem illă edendo fuiffe dixerim.Ral.Vbi L ypfiam retuerfqquid Marpurgi egerim interrogabor, me, qd malua fit, didiciffe refipondebo. Cor.Deride me ut libet, ego fi quid ex te didicerim magnam tibi grati am haberem. Ral.Liceat mihi tecum ut more tuo fic iure quodam meo iocari.Meg.Iam ixi- 
deo cur \& murina cauda nocetur.Gal.Imma. nis fit, ille mus oportet, cui fua hæc cauda refpondeat. Meg. Dum caulis ftringendo trahi tur inftar murinæ caudæ deglubitur. Ral.Pæo niamne hanc an pioniă uocem? Cord, $\mathrm{Ab}$ inuentore Prone, proniam. Ral, Tunceft quxe Germanice minvuenvuurtz dicitur \& altera Pionia in qua grana illa qux benonien korner appellamus nafcuntur. Cord.Nullăego Pęoniæ à Pionia differentiam fcio. Ral. Vulgares tamen herbarij quafi diuerfas herbas diuerfis his nominibus, adeoq? diuerfis etiam capitibus, imo \& uiribus diffungunt. Cord. Vna eft Proniænomēclatura,fed duo eius genera, ma fcula fcilicet \& foemina, ut in Diofcoride hic legitis.Qui \& gd utraq; poffitenarrat. Quod fi platearius aut alius quípiam ex recentioribus Pioniam dicat, \& plures expertus ei uires adícribat, non continuo alia eft à Diof́coridis pęonia.Multos tales errores inuulgarib. illis herbarijs comperi.Sicn.uiticellam à bryo nia, chamædrynà Gamandrea ( liceat eorum uoce uti) irin cuius genitiuus ireos ab iride cu ius genitiuus iridis, urinalem à linaria, ut prius auditum eft, feparät, ut plures, qux iam non fuccurrunt, herbas prætereă. Nig. Quæe autem illa pronia eft quam A puleius in Creta nafci, 


\section{BOTANOLOGICON.}

\&à paftoribus inextrema facula inueniri dicit, mali granati magnitudine, qux noctu, quafilucerna lucet? Cord, Quid his uerbis atthor ille uelit, fiue is Apuleius philolopus fiue alius quilpiam fuerit, non affequor. Pluribus huiufmodi abfurdisalip [q $q_{3}$ erratis fcatet quantumuis ab Albano Torino quafi alterum Altgix ftabulum repurgatus liber, propterea etiam mihi ftudiofe præteritur. Quis unquam ui dit nymphęam, id eft, ut hodie cum Arabibus dicimus, nenuphar, fimilia cichorex folia habere? Atfere in eadem id inibi pagina legitur. Ral. Quam recte hęc muris auricula uocatur, enut fimili tum fpecie tum lanuginenomen fu um repręententat.Cor,A Germanis quidē meufohr, id eft, murina auricula nominatur, non tamê ea eft, quã gręci myofotida \& ideoßy no më interpretãtes Latini muris auriculă uocắt. Errant'q3 ob id qui hăc pilofellam (fic enim à Latinis nominatur) cum auricula muris confundunt, \& eafdem facultates habere tradunt, Nig . Græcorũ myofotiseadē eft quæ alfine ut quidă uolüt. Et qua alfine à fyluis deriuațt,forte hec fuerit quă germanice vualmeifter. i. fylua nă uocamus, Ral, Nos matrem fyluiam, Cor, Nihil hic decerno, quoniam nổ uideo qui eius, matris fyluiæ fcilicet folia, muritumauriculas 
\& helxinen imitent, qux ftellę modo circa cat lê quadruplici ferme ordine deinceps difpofita longáç \& tenuia funt, \& facile defcriptu hi ftoriā herba ipfa p̧buiffet, fi eă Diofcorides de pingere uoluiffet, Gal.En fimillima figura effi giată \& forte eandê herbă Brunfelfius caprifo liúab authorib? appellari dicit, Cord. Nố fine graui errore, ueruntamen fcio quid alioqui di ligenti homini impofuerit. Periclymenon, qd idē caprifolio eft, etrẩ alfine, fed maior, $82 \mathrm{ma}$ terfyluiauocatur, Cor. Et hic grauem errorë uulgariū herbarroge obiter attêdite, qpericly menó, id eft, caprifoliü, cü Lycio mifcent. Ral. Eft ne periclymenô feu caprifoliü q̛d latine in uolucrü \& Germanice lienẽ bloumê feu fpeckliliêuocamus? Cor. Ita audio \& lego. Leonice nus tn̆ de liguftro agens idipfum ab Italis cae prifoliú appellari dicit. Nef́cio quod ille liguftrum intelligat, non enim id cypron, $\mathrm{fed} \mathrm{cy}$. pron fimilem ei fruticem effe tradit. Meg. Id cốtra Diofcoridê Pliniúaliof Hel xine ne illa cuius prius meminifti, dicta iă parietaria eft:Cord.Maxime.Ral.Germanicerant Peters kraut,i. herbamfancti Petri, \& tagund nacht.i. diem \& noctem appellamus, quod filicet bicolores eius flores nēpe partim lutei partim quafi purpurei fint, ut purpureus 
eofor noctem \& luteus diem referat. Cord, Et hic toto erratis ccelo, quotquot hanc herbam pro helxine feu parietaria accipitis. Vis ueram parietariă nofcere, in ædes illas $i$, quas nuper hic cuculliones dicti fratres inhabitarüt ubi magnameius copiam in imis muris inuenies. Ral. Vt difcă certe ibo, modo tu meus in eas dux fueris, ignot' ibifum hofpes, Cor. Et egouereor ingratiffimus. Nig, Quis tunceas incolit:Cor.Sebaftianus Auguftus, Nousenus Habraicaky literan profeffor et Gerhard ${ }^{9}$ No uimagus in docëda hiftoria Bufchïnoftrifucceffor, uterq; Tauciffauts, hic Hollädus ille Flä der. Nig. His tanti habitis hic uiris ingratus eft Cordus qui omnibus bonis ac eruditis hactenus placuit? Cord, Cogor hic tacitus labra mordere, \& multa, qua ind igne patior, deuorare, ne meü in me Veiouem, quem illi fibi pro picium habent, amplius exafperē.Nig. Vt non e literaria rep. fic \& inhonefta ueftra profeffio rum eft fimultas. Cord,Nifi idipfum répicerem,hosego,fed praftat motos cốponere flu ctus. Ral. Cớfulte\& pie facis đ̣̂duehemétiam tuă cớpefcis, modeftiem̌net Chriftiani hois eft illatag iniuriaz oblinifci, deo uindictam com mittere, inimicos fuos diligere, bona pro mar lis reddere, Cor. Durüet quafi captu impoffi- 
152

EVRICII CORDI

bile mihi dogma narras.Nig.At author illius Chriftus ingum fuum leue docuit. Cord. Cur ergo tam pauci hoc fibi accommodăt, etiă ex iftis qui affidue, ut, id faciamus, in facris cổcionib? nos adhortant', cur ipfi, quoties leuiter eti am offendunť, quaficalcati angues fibilăt $\&$ re mordēt:Ral.Abeăt illa \& rem noftră agam? Meg. Parietariam illam etiam uitrariâ feu ui traginem imo et urceolarem dicunt, q̊d uitrea uafa \& urceoli hac herba propter abfterforiă, quă habet,uim,emundari foleăt, Ral. Oportet ut ingentem hăc ferpentariæe copiam mecum diuidas iă dudum inanis eft eius titulo notata pyxis, Cord. Omnem tibi quam hichabeofer pétariam do, fednullă, fcio, etiamfi Argus fue ris, inuenies. $\mathrm{Ral}$. $\mathrm{Neq}_{3}$ hancueram effe ferpen tariam putas? Meg. Bitortameam à torta fci licet radice etiam appellari audio. Cord. Hoc ei facilius quă defcriptę apud Diofcoridem fer pentarięnomen permifero. Ral.Omnes tamé feplafiarì fic eam nominắt. Cor. Omnes etiam medici, uerum uni Diofcoridi plus quam cunctis his credo. In quo duplicë dracunculü (fic Grzecopz dracốtia feu dracontiū a Latinis etiă diciț) legitis, fed neutrŭ intorra \&, ut hæc eft, fubrutila imo rotunda bulbofa candidaç radice.Nig.Minor tamen Dracunculus, ut hic 
indicatur, longam, quia raphano fimile radi cem habet. Cor.Puto raphanü ibi non radicu lă fed eã quæ apios eft, fignificare, cuius rotun dam inftar pyri(unde \& nomë)radicë fortele giftis. Nig. Interim fimile rumici foliū hęc bi torta oftêdit, quali Diofcorides dracontiă fuam depingit. Cor. Sed non racemofum nec in maturitate croceü puniceumq̧ femê, imo neq 3 bicubitalem,neq, lęuë, neq3 purpureis maculis uerficolorem caulë,Meg. Hermolaus Barbarus tí à fubrutila $\&$ intorti draconis cauda, id eft, utego interpretor, radice dracunculü etiä appellari putat. Cor. Fateor, fed fic communi oim fere medicos authoritate perfuafus. Gal. Ino fui etiă Plinij. Cor.Fideliorê Plinio in his ducem Diofeoridem fequor, quang̈ idem plinius lib.XXV.cap.ji.Diofcoridx dracunculá, quaten' fupra terră extą, graphice defcribit. At quiauideo Ralla te zgre hic mihi credere, rem tibi ob oculos ponā, effode radicem. Nig. Non facile à fentētia tua dif́cedo, noui quă nó temere pronunciare foleas, Meg. Qui authori tati \& rationi innititur firmius obfiftit. Ral. En eam , Cord, Guftate \&, quis fapor fit, dehincrefpondete. Nig.Adftringens. Megob; Aufterus, \& fere qualis dictæ tormentillę. Ral. Ob id esiä cius fpecies à pandectario ponitur,

$$
\text { I } 5
$$


154

EVRICII CORDI

Cord,Eft ne \& acer? Megob.Nullamacrimo niam fentio, Cord,Quam ergo ex eo qualitatemiudicatis? Nig. Frigidam \& ficcam. Cor. Sed ueræ ferpentarix acris, \& ob id calida eft radix, hinc illæx, quxè̀ Diofcoride ac Galeno tradütur, cius facultates funt, quibus plane côtrarias hắc bitortam habere crediderim,$R a l$. Si id uerum tunc magna effet medicorum inconfiderantia, qui hanc bitortam proferpentaria etiam adhuc utuntur. Cord.Ego eos fal li,fi pateris, perfuadebo. Guftaftis ne aliquans do noftras arum? Gal. Nefciф quàm egregic nuper eo mihiilluferis ? Perpetuo me illud gu ftafle meminero, tam acres ac diutinas in lingua puncturas excitauit. Cord. Sed fuperior. eft eo ferpentaria. Megob. Id uerum effe hic in ari hiftoria uideo, ubi ficlegitur, Candida if li radix ad dracunculi radicem accedens, qux quod minore acrimonia eft elixa comeditur: Galenus quoque fecundo libro de alimentope facultatibus acriorem aro ferpentariă his uer bit innuit. Huius (de aro loquitur) plantæ radix rapi modo manditur, Quibufdam in locis acrior nafcitur, ut dracütio fere fimilis fit . Sedapertius fexto fimplicium libro fic, dracuntium, inquit, quiddam aro perfimile obtinet tum folins, tum radice, caterum illo tiun 


\section{BOT ANOLOGICON.}

acrius, tum anarius, ac proinde calefactorium magis, \& tenuioribus partibus, Gal. Nullum ego dracuntium aro ueftrate mordacius puto. Cord. Tutamenid in primo caliditatis gradu effe contendebas, quodut falfum often-. derem guftădum dedi.Gal.Id non mea fed Ga leni authoritate dixi.Cor.Scio quidem Galenũ fic tradere, fed uidere oportet quale nă aró intelligat, non enim ubiqz æqualiter acre nafci tur, ut $\mathrm{ex}$ iam citatis eius uerbis liquet, pofe qua, \& mox inferius. Cyrenis, inquit, contra quàm in noftra regionearumfe habet, namil : Irc minimum medicinæ, minimum'qu; acrimo niæ præefefert, adeo ut uel rapis utilior habeatur, idcirco radicẽ quoq; in Italiam comportant, ut quæ, abfque ut putrefcat aut regerminet, longo tempore perennare poffit. Illud ita que comportatū in Italiam arum, quod forte, intelligit, non adeo, ut noftras, calere confenta netumeft. Ral, Vt hincuideo, non ita magnus error fuerit, fi quis aro pro ferpëtaria utatur? Cord. Imo nullus, \& ut id facias omnino con fulo, noneŭ multo inferiorem ea uim arum noftras habere putarim. Ral. Quid fi medici noftrinolint? Cord. Si quem erroris fui per me admoneripuduerit, $80 \mathrm{ob}$ id in falfa potius opinione fciens perfeuerare uoluerit, libe- 
156 EVRICII CORDI

re poteft, ego neminem cogo. Gal, Audiui iä cădidam effe Ari radicem. Cor, Nontalem \&

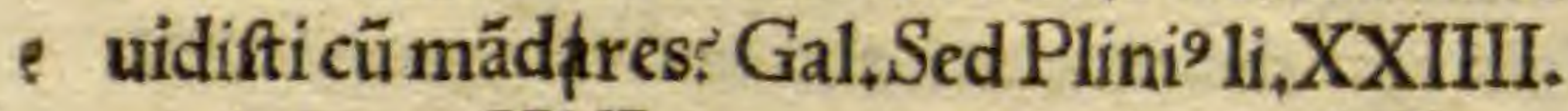
capite uero XVI. eam nigram depingit, Cor. Quamirecte autē nefcio. Defendat hic aliquis eum Collinutius, ego non habeo quod dicam,ipfa resfac experientia Diofcoridi patrocinatur. Nig. Nuphsg in in hac Germaniæ parte uerá ferpentariam prouenire putas? Cord.Ego ha ctenus reperire non potui quăuis ut id poffem laborauerim, Sed te Galle proculdubio in tua eam patria non femel uidiffe, ac optime noffe, fi admoneare, credo. Reuerfus enime Lutecia filius meus Philippus narrauit mihi confpectam ibidem fibi herbam quam ad tabernas fuas pro fpectaculo feplafiarij fufpenderant, fere fimilibus rumici \& fibi inuicem implicitis folins, uerficolori \& quafi anguem referente caule, in cuius fummo purpureum fuerit inuolucrum, fedà nemine, quod eius nomen effet, expifcari potuiffe, imo fe, quoties interrogaret, irrifum fuiffe. Quam picturam, cum animi oculis intuerer, ftatim ferpen tariă fuiffe conieci, memor eopł quę Virgilius Marcellus in Ari fcholijs de dracunculo dicit, nempe habere eum,non, ut Arum, pallidü feu herbaceum, fed purpureum, quo femen claudi 


\section{BOTANOLOGICON.}

tur, inuolucrü. Gal. Iam memini $\&$ noui, fed nullum aliud apud uos nomen hæc bitorta ha bet:Cord, Legens herbarios uulgus, dracuntium \& ferpentariam interpretatur, \& drachë vurt5, nottervurt5, fed idiotæ ruftici,fchlippen appellant,Meg. Anufpiam apud Diofcoridê latet: Cord. Ita quondam opinatus Britannicam effe putaui, quod ea fimilibus rumicin:grioribus tantum folins defcribitur, \& aditrictoria eifacultas tribuitur, quæ huic bitortæe non male conueniunt.Meg. Quid ab hacte opinione nuncretrahit?. Cord,Quodetiâ hir* futa britannicæ folia defcribuntur, qux hic rugofa apparent. Meg. Quid fi \& hic interpres pro hirfutis denfa trăsferre debuit: Cord. Ta men radix hæe non britannicæradici, qux tes nuis breuis'gz eft, refpondet, licet id non admo dum urgeat, cum huius etiam bitortæe dum ad huc tenera \& recens aliquo plantata eft, talis fit, Ral .Pandectarius bitortam $a b$ antiquis bardoniam, Ideft, lap̣pam minorem uocată inquit. Cord, Hoe nomine alix herbæ indican tur, nec quicquă hic uideo quod retinace afperitatelappam referat.Aeque errant qui altepge eũ catanances genus putantreclamante hifto ria,Meg.Illuduehementer miror, quod cum pandectarius ipfam draganteam (ficdracon- 
138

EVRICII CORDI

tiam uocat) proprio capite feorfim à biftorta defcribat, recentiores tamẽ herbarì), qui oëm fuam hinc fcientiam habent,eandem dragans tez bitortam ponant. Cordus, Erratur \& in afphodelo, pro quo bulbofam quidem fed lon gealiam, quam afphodelieft, radicemuéditis, ex humili collectam herba, cum afphodeluso mnium, qux bulbos habent, plantarum maxi muin caulem proferat, ut hinc etiam regia ha fula uocetur. RALla. Oportetnos tabernas noftras non uacuis, fed finonuera faltem fuc s cedania medicina plenis pixidibus inftruere. CORDVS, Si hoc fieret tollerabile effet, nǘc contraria contrariis frequẽter fuccedunt, imo aduerfantur et obuiam occurrunt. NI GER. An hęc etiam herbula aliquam medicinam $\mathrm{fa}$ cit? CORDVS. Egregiam, ut mihi quredam anus nuper retulit, qua contra tormina efficaceremedio fe hac frepe ufam affirmauit, utids circo rodekruit feurhorkraut, id eft, torminas lem dixit, hinc ego centunculum eameffe opinor, refpondentibus alips notis. Videris enim tenuia, mollia, ac alba in ea folia.Megobacch. Tota albicat ac mollicula eft herba. Cordus. Fidemetiam facit omnium qure de gnaphalio Vergilius Marcellus ait:uulgarisubiq; fca tet, pingui folo præfertimíg; marginib' itiaeps, 
$\&$ in hortis \& inter uites, nung̈,quod ego uidi, in quiefcenti \& gramine obducta terra nafcis tur, Gal,Sedubi roftrata $\&$ ad fimilitudinem capitis penularz effigiata funt folia? quibus ce $\vec{e}$ tunculum fuum Plinius indicat:Cordus, Non Plinianum fed Diofcoridę centunculum exhi beo. Ralla. En maiorem hic confolidam feu, ut recentiores dicút, folidaginem. Gallus. Hoc nomine eam index non habet. Cord. Quare fymphytum altę" Argallicum etiă apud antí quos dictum in Calio Aurelianolegi. Gallus. Non refpondet flosy color, quem nuperinea albicantem uidi, cũ Diofcorides hiceũ luteum dicat. Cord,Id nihil me fúpëdit, cumnó ubiqz fimiles, q̊d prius dıxi, etiam earundē herbarú florès fint. Vidi nuper apud Bretinêfes hocfym phytum purpuldọflore. Aliud eft quod in eius ? hiftoria me remoratur, quod fcilicet idem cau Jis nune leuis, nunc angulofus dicitur. Imo ne fcio quàm funili effigie huius flos rutę fiorem referat. Qux tamennon tanti momenti funt, ut hocuerum fymphytum effe dubitem. Gal. Eius Germanicü nomẽ grofs beynvuel in cos dicillo meo prius notatum lego. CORDVS.

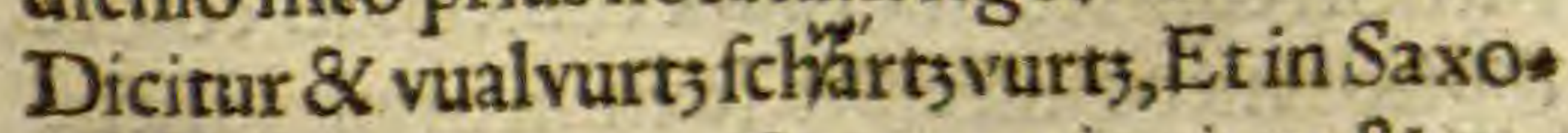
nia Schmervurts quafiaggeraria nigra \& unctuofaradix - N I GE R, Qux autem illa 


\section{EVRICII CORDI}

non adeo abfimili huicfolio:Cord,Mifit mihi huius herbæ femen Chriftophorus Tonfo- : rinus Caffilianus ciuis, \& Camerarius fcriba. Verumq, id recentiorum bugloffum, ideft, ut quidam uolunt cirfium, affirmauit. Crederë et ego, nec libenter à tam charo amico diffentirem prefertim cum earundem rerum nonleui mecum ftudio afficiatur, fi purpurea hæecca pitula ferret. Gal.Purpuraicentes \& quafi caruleos flores habet. Cord. Sed qui non in pap pos, ut Diofcorides de cirfio ait, euanefcunt. Ral. Noftra plurimủ ab hac buglofia differt, qux purpureos flores habet, Cord, Sed interim multo minora tenuiora'q folia, quàm ut hinc maius bugloffum, ut de cirfio legimus, uo cari queat. Hicuos dictam hodie boraginem habitum antiquis bugloffum meminiffe opor tet.Multas feio buglofías à Germanis feplafia rijs monftrari, quarum nulla maiora quă borago folia habet, preter hanceidem admodü fimilem \& cirfin hiftorix, refpondentem, Exce ptis poft florem pappis.Idcirco quandam an chufær fpeciem fufpicarer, fi experiêti mihi per meffem contrectata radix rubicundo colore digitos meos infeciffet. Id enim omnes anchu fr faciunt, $\&$ ob id olim cognitiffim $x$ mulier thilis radices, ut quibus roleum faciei colorem 
illz inducerent. Nig. Mirum ergo hoc formæ

e lфnociniũ hodie, ut Marcellus putat, negligen tibus illis imo \& à feplafiarijs noftris ignorari. Cord. Non minus tamen quam olim nafci tur,fedalio, nempe Mufcellin $\&$ afininæ laćucær noie, \& magna eius copia effe diciť Bononiæ in loco qui el Martia grand uocatur, ut Otto Brunfelfius ex Bononienfi quodam cōmentario indicat. Imo puto eam \& apud nos abundare, \& inter Buglofías numerari quemadmodü \& echiö id eft,alcibiadiü, quæ illa bu glofiæ noftratis fpecies eft, ut furpicor, qux bo raginisflores imagine aliquantulum refert,ni fi quod profundiores $\&$ minus laciniofi funt. Ino \& colore, fed conniuentes adhuc, purpus refcunt, Vbiqz fere ad itinera \& afperis locis, imo \& in muris nafcitur, in Brunfelfianis tomisprofylueftribuglofiagraphice depicta. Eius femen adeo uiperinum caput exprimít ut etiam oculi in eo conf piciantur Id quod Va lerius meus deprehendit.Meg. Duo echia \& to tidê alcibiadia animaduertifíe me recordor. Cordus. Veruntamen, tres tantum herbę̧ funt, nam priusechion etiam alcibiadium, utiă audifti, dicitur, fic \& altera anchufa. Alterüuero echion ocimoides, id eft, ociøpaftrüàDiofco- $m$ ride nominat.Mego.Nonfatis admiraripof- 
fum arcanam illam naturx, nefcio qui dicant, energiam ne an benignitatê, quæ foris conf́pis cuo aliquo iudicio intus latentê herbarú uim prodit, ut in eodẽ echio apparet, cui 9 uiperina illa capitaefficacem cốtra uiperas facultatem indicant. Cord. Sic etiä fcorpioidis feufcorpi herbær femë, ut Diofcoridesuel ut Theophra ftus $\&$ Nicăder aiunt:radix fcorpionê referç̄s contra idem infectúfalubre eft antidotum, fic \& maius heliotropium indicắte id finilicaurdæ fcorpionum flore, unde et f́ corpiurus dicta herba, Quinetiam mox fequens alterum, id eft minus heliotropium fimili uerucis fenine cô tra eafdemualere deprehendit, hinc 8 ueruca ria dicta \& $\mathrm{ipfa}$, quemadmodum \& altera. Mego. Idem in pluribus alijs fit, nam fic $\& \mathrm{fa}$ xeum lithofpermi, id eft, folaris milij, femen, fuăcontra calculum facultatem innuit, Ralla. Quam nos uerucariam putamus huic, quam lego hiftoriæ nihil refpondet, Nulla eft in flore fcorpionis cauda, imo necille, ut hic pingitur, candidus purpurafcit,fed aureus fulget, neque aliquas unquam inea quafiuerucas uidi.Cor. Intelligis audio, calendulam, nameam helio-

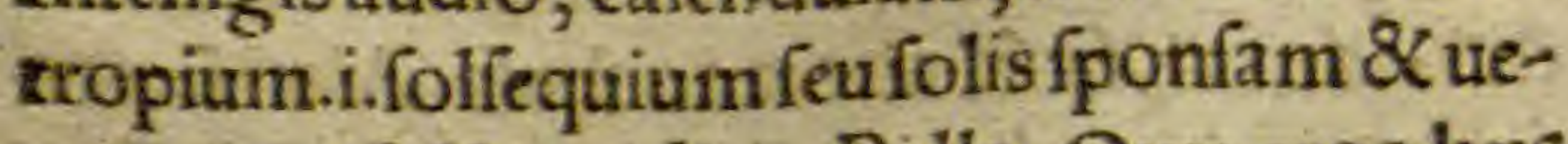
rucariam falfo creditis. Ralla. Quz ergo hae eadem calendula eft: Cordus. Non pudet eam 
gnorare me fateri, cum ipfe Manhardus pra ceptor meus idem facere uideatur, cŭ Lyfimachium cam effe aliquădo fufpicatumfe dicat. Alibi tamen omnium menfium florem uulgo appellari tradit. Nos ringelblomen, id eft, circularem florem uocain', uel à femicirculo quë femë refert, uel quod ad folê circulariter nutet, ut \& ,quod heliotropium creditur, error ille ir repferit, quemadmodum \& eorum, qui agrefte illưd inty buun, alias cichoriü $\&$ a mbubeiä dictum, pro eodem helitropio accipiunt, Ral. Nunquid Germanice uocatã vuegevuardt feu vuegevuiffe, id eft, cuftodiens feu indicans uiă, \& apud Saxones hinlaup,intelligis? Cordus. Hancipiam, RALLA.Cuperem omnia intyborum genera meexacte noffe, \& fuis fingula nominibus diftinguere poffe. Cord. Nonua, cat,nequ adeo operepreciú duco, in his iam' diù tius morari, cum quafi eandem ferme omnia facultatem habeant, neque facile iple fua' fingulis nomina tribuerim, quandoquidem in di uerfis ea locis promifcua mutuant. Ad Virs gilium Marcellum \& Iacobum Manlium de intybis tractantes uos remitto: MEGOBACCHVS. Saltem quxe cicerbita fit, doce, nam hanc congenerem intybis \& ualde antidotariam herbam aiunt. Cordus, Cicerbitam 
olim eam effe putaui quă Germanice in Saxo" nia hafen koel, id eft, leporinami braffică, ut hic genffe difteln, id eft, anferinü carduum uocant, \& quidam idem ei taraxacon credunt, quam meam opinionem confirmauit rediens ex Ita lia Chriftianus Schroterus Frăcobergius qui eandem herbam ibidē \& lactucellam \& crifpinum appellari dixit, quę etiam fonchi id eft cicerbitæ nomina funt. Duplex eius genus eft alterum afperius ac nigrius, altep, uero initius \& minus nigrüatq̧ eccum in hac utrüq̧ area. ubiqz enim featet, Ral, Anferinü carduũ endiuiamuulgares herbarij nominant pro qua ta men aliam nos accipimus, maiorë fcilicet, quę per dorfi ípină aculeata folia habet.Cordus. Hinc \& Italice fcariola .i. ut ego interpretor, ferriolauocata, Mego,Equidem endiuiam ab intybo, cui eadē eft, paulatim corruptauoce de ductam puto. Cord. Recte,fed nihil \& tu iam exItalia ueniês de cicerbita illa edifferis? nam uereor ne errem, funt eñ qui crifpam ac teneram laciniofam'q̧ lactucam, uerẩ cicerbită, \& quain ego cicerbitam, illihieratiū effe conten dant, in qua opinione \& ego aliquădo fui. Ves rumtamen idem, quem dixi Schroter ${ }^{9}$ Italos crifpam illam lactucä inter inty ba, id eft, endi uias referre affirmauit, Meg, Ingenue fateor, 
BOTANOLOGICON.

alīs ftudijs occupatior eram quă ut inquiren145 disherbis me dedere potuerim, frepecicerbitã in acetarijs edifie me reor, terum non animad uerti. Niger.Quæilla candidis lanuginofifque folips \& purpureo flore?. RALLa, Germanice campulofa\& marien rofen, id eft, mariana ro fa uocatur. Cordus. Quædam uerbafci fpecies eft, illa fcilicet quę Diofcoridi lichnitis, \& thry allis dicitur, quod ex conuolutis ficcatifque eius folins feruientia lucernis elychnia fiant. Eft etiam, fed rarior inuentu, flore candido. GALLVS. Et mihi qua illa fit, dicere non tedeat. CORD V S. Ophthalmica feu ocularıa, quæ alias euphragia \& adhil, Germanice uero aughen troft, id eft, oculorum folacium appellatur. Gallus, Atnon hac facie Bruno felfianus codex euphragiam fuam exhibet. Cordus. Forte ab hacaliam Brunfelfius no uit, qua perinde oculis medeatur. Ralla, Non fponte hic natam fed e natalibus fyluis huc tranfplantatam pirolam illam puto. Cordus. Vix coaluit, quamuiseam una cum matre ter $r$, fic ut non auulfum fituber, infoderim.NIger. An ufpiam \& huius Diofcoridesin her barum fuapy cenfu meminit? Cordus, Nifilimonium fuerit, nefcio, Nam hẹcà quibufdam Germanice à fimilibus. If folijs vualtmangolt 
146 EVRICII CORDI

id eft, fylueftris beta dicitur, quo nomine Plis niủs limoniam eadem ex caufa uocat. Ipfe quoque Diofcorides limonium fuum talibus decem \& aliquando pluribus folins defcribit, \& tintinnabulum terræ à Romanis tum dictum ait, forte à fimilibus tintinnabulo floribus, qux omnia in hac pirola conf́piciuntur, Imo rubrum etiam femen. Vnum hoc me fufpendit, quod lilijaltitudine caulem ei autor ille tribuat, cuius quidem aliqualem fimilitus dinem florens pirola refert, fed multo mino-. recaule, ut qui pedalem altitudinem raro excedit, Gallus.Sed limonium in pratis wpalus. ftribus locis prouenire hic lego, Cor. Duplex eft pirola, mafcula fcilicet quę iuxta fluuios, \& in aquofis nafcitur, cuius folium arboris pyri folio fimile eft, hinc pyrula \& corrupte paula tim pirola appellata. Fomina altera, quæe in umbrofis \& fylueftribus featet, chirurgis \& tonforibus noftris optime nota, uulnerariam enim adftrictoriamque uim poffidet, quam etiam DIOSCOR IDE Slimonio tribuit cum id celiacis \& inteftinorum torminibus opitulari \& rubras foeminapy fluctiones com pefcere dicit, Nolo tamen omnino hic decernere, fed uos, ut exactius hæc perpendatis \& ipfide hinc iudicetis, admonere. Quemadmo 


\section{BOTANOLOGICON.}

dum in hac proxima herba. RALLa. Quam demonftras: CORDV S. In hoc nafcentem alueolo, quam aliquando alyíma, ideft, damafonium putaui, \& adhucin eadem fere opi nione hæreo, quod uideam eam damafonij hi ftoriam exprimere, fimilibus fcilicet plantagi ni $\&$ in terram aliquando reflexis folijs, candi dis floribus \& poft illos in fummo (qui cubis talis eft) caule enatis capitulis, Effodite etiam radices \& eas graciles, odoratas, modice pingues, demum nigro ueratro fimiles inuenietis, nifi quod non ita nigricant.Modo nigrum tue ratrumrit, quod hic omnes id effe putamus.

Veruntamen remoratur me quod hac femper binis nunquă pluribus folijs confpiciatur, \& hoc eius quafi proprium fit, quod tamen Dio fcorides in damafonio, omnino dicendum, prętermifit, GALLVS, Qui Germanice uoca tur. CORDV $S$, Nunquam appellari aus diui, diceretur tamen non iniufte aquatica plá tago, finon barbafyluana hoc ei nomen pręripuiffet, licet damafoniǘfeu alyfma ( almea corrupte in uulgaribus herbarijs legitur) quidam fiftulam paftoris dicant nulla ad hanc herbam comparatione, quare incertus eam relinquo. RALLA. De nigro ueratro, quod tamen omnes nos nouiffe credimus, es 


\section{EVRICII CORDI}

tiam te dubitare uideo. CORDVS. Non

- temere necfine ratione fi modo $\&$ tu dictam Germanice chirtivurt;, id eft, CHRISTIAnam herbam \& rangen (quod interpretari nequeo) intelligis. R A LLA. Non aliam. CORDVS, Huic nigri veratri hiftoriam confer, concipeque animo chriftianam illam à primo ortu ad fupremam ufque confiftentiam, \& confidera an folia platano feu (fiplaranum, ut peregrina Germaniæe eft arbor, forte nonnolcas) incipientibetæ imo $\&$ lauro fimilia racemofos uero $\&$ in candido pur purafcentes flores habeat, ut ex Theophrafto DIOSCORIde \& Plinio de nigro ueratro colligitur RA L LA. Nulla in his eft fimilitudo interim tamē obfcurus ille foliorum uiror \& fcabra afperitas atq, ipfa radicü gracilitas nigredóg, \& quafi ex cepofo capite exiens multitudo imo \& purgatoria uis non ab* ludit. Cordus, Si eft ergo ueratrū nigrum per melibere manebit. Megobac. Si qux dicitur, Chriftiana eft,nullam cuiğ uim nullam iacturam infert, neminem turbat, fecura \& $\&$ non uio lenta fumptu eft herba. NIGER, Num illam naturam tale nomen adepta herba poffideat $i$ gnoro, certe plerique hoc titulo infignes homines magni nequain \& nebulones funt, 


\section{BOT ANOLOGICON.}

CORdus. Iduerum effe fxpius quaim par \& utile mihi exat, expertus fum, Ralla. Ferax eft lacertarum hortus tuus uideo. Cordus. Ego has non ueras fed chakidicas lacertas, id eft,fe" pas effe crediderim. Nô em ut in Iralia magnæe \& uirides funt.Mego,Tales in Germania, qua tenus ego peragraui, nusg̈ uidi,Cor. Sed interim non adeo abfimiles falamandras. Mego, Nefcio. Cord. Nunquid nouifti beftiolas illas quas Germanice ulmas feu mulchas dicimus? Meg.Hos ftelliones effe didici,Cor.Ipfiffimæe falamandrę funt. Ral,Inigne falamandras uiuere $\&$ inueniriuulgo creditur. Cordus, Cur tunc non nifi in magnis imbribus prouenire, \& fecuta ferenitate deficere folent? Id uerum fua eas frigiditate glaciei modo ignem reftinguere, \& aliquădiu in eo incolumes uiuere pofs fe, fed fi diutius mäferint nonfecus ac alias res comburi. Ralla. Quid fi Marpurgenfen tibi ciuemnominë, qui exfalamandræe pilis deducta fila habeat?quę nullo igne abfumi queant? CORD. Forte Iohannes Vernemus eft. Ral. Is ipfe. Cor.Ludis anferio hæedicis? Ral.His oculis uidi. Cord. Quis ung̈ pilofas falamandras totundit Nunquid legifti Plinium, qui eiufmodi non tantum fila fed \& coỏtextas hine telas adeóg concinnatas ueftes tradit, non ex 


\section{EVRICII CORDI}

falamandrinis, qui nufquam fant, pilis, fed cer to ac incóbuftibili quodam lini genere. Quod tamen quale fit $\&$ ubi nafcatur nefcio, dubicoque num amiăthum ibi intelligi debeat, de quo tales telas fieri certum eft. Megobacch. Tefte Diofcoride. Sed qui ftellióes funt: Cor. Dictre in Italia tarantulæ. Mego. Iam fimiles lacertis beftiolas agnofco. Ral, Forteftincos intelligitis? Cordus. Quos ftincos? RALLA. Aquaticas lacertulas, CORDVS, Vt in ipfa nomenclatura fic $\&$ in re omnes ibi fepla fiarijerratis.Scingus em̌ non ftincus, nec aqua tica lacerta illa, quam uos accipitis, fed terreftris crocodilus dicitur, qui adeo non hic inuenitur, ut uel ex Aegypto, uel India, uel Lybię Mauritania,uel erubro mari afportetur. Ral. Nos non alium fcingum quam dictas lacertu Ias accipimus, an fimules hre uirtutes habeant uos, qui hunc errorem non corrigitis, uideritis, CORDV S. Decerpe mihi puer unum $\&$ alterum menthæramulü. Maxime hoc \& abrotani edere oblector, utæque mihi hre iă herba ac olim adhuc puella pluroni, grata fit, ut côgruú fibi apud Gręcos uocabulüideonaEta merito uideatur.Mego.Miror grauiflimú autorem Ariftotelë in probleumatis fuis men tham belli tempore non ferendả dicere, quod 
refrigeret, ợ genitură abfumat, cum id cốtra ipfam tum experientiam tumomnium medi cosz autoritatêfit. Cord. Nititur Hermolaus Barbarus id ita diluere, quod menta per fequi dem calefaciat, uex per accidens refrigeret, id quod ei nõ ita facilis credo, q̊d calefactoria illa uis cum quadă adftrictione mifceat,, imo \& Ve nerẽ tefte Diofcoride, ftimulet, q̊d non poffet, figenitură, ut Ariftoteles credidit, abfumeret. Gal. Hunc florê Brüfelfiani tomigraphice de pictũ exhibêt, fed nö intellecta mihi nomëclatura, qd ganfs bloumen fignificat? Ral. Anferinum florem. Cord, Ioanninus hic flos dicitur, quod ipfo Diui Ioannis die fuperftitiofum uulgus fuperliminaria \& fores his florib' $\mathrm{ex}$ ornare, atq3 folenni quodam ritu conuenientes puellæ factú hinc topiariũ opus ducto trăfuerfoper plateă fune nuper ante fublatas ceremo nias furpenderefolebătt. Sed pronuncians hoc uocabulŭ uulgus Ioăs bloumẽ dicit, quod fere gans bloumen fonat. Meg. Parum imo nihil refertutro noieuocet, modo quæ $D$ Diofcoridis herba fit conftet, Cor, Eius chryfanthemú \& Romanożcaltă effe, fúfpicor. Ni, Nổ temere, ecceem̆ fruticofam herbă,leué eius caulë, diưifa in cifuris folia, \& luteos egregiíg, in medio Splendoris flores, inftar oculi i orbē circulares. 
IS2 EVRICII CORDI

Meg,Idcirco idem buphthalmo chryfanthe muin quidam exiftimât. Cord. Fallütur, nam alijs uiribus, aliter alıa \& feorfim ab hac defcri ptaeft buphthalmus, a deó̧́ $\beta$ illa qux Germanice kouthill, id eft, uaccinum anethum dicitur, à medicis uero cotula non fetida. Nam di ctx fetid $x$ cotulæ quam nos hondtsdill, id eft, caninum anethum uocamus, per oinnia fimilis eft, nifi quod candidiora robuftiora'ç for lia, maiores flores habeat, tetrum'q z $_{3}$ odorem fpiret. Eft tamen commune Chryfanthemo buphthalminomen, quod fere idem utriufque flos appareat. Maior tamenille in hoc chryfanthemo eft, quare in quiburdam etiam locis nonuaccinus fed equinus oculus uocatur. Nô contemnenda in medicina herba ad difcutien da fteatomata, quas hodie nattas uocant, \& reddendo auruginofis colore. RALLA.Gra ta igitur mihi \& illius erit cognttio. CORD V S. Et hæc fimilis'́z altera quaedam affabre expreffam in tomis tuis effigiem habêt, fed non uero interim nomine indicantur. Ral. Nos perficariam dicimus, Cor.Ego hắcDio fcoridis hydropiper \& Plinị filiquaftrü feu pi peritida credo. Nec obftat quod Hermolaus Barbarus de hoc dubitare uidetur inquiês. Eft $\&$ in folio perficarizlitura maculæ modo in- 
Icripta, qux fi fuiffet in hydropiperi fortaffe non omififfent authores. Non animaduertit doetiffimus diligentiffimufq 3 alioqui fed feden tario tantum ftudio forte deditus homo alteram perfecariæ f peciem, quæ acri mordacitate pungit, nullam habere maculain, qux uero habet eam fatuo ferefapore effe. Dubito tamen hic nonnihil q̊d Auicenna caninú piper ab hydropiperi, q̊d idẽ fufpicabar feparat. Ga. Brunfelfíus pulicariam uocat. Cord. Id ei nomen cogruere poffenon nego, quod \& $\mathrm{ipja}$ pu lices necare uulgo creditur, fed propterea eandem Gracorum conyze efíe nemo mihi perfuadebit, Ral. Satureiam hancin quam commodum incidimus, Iacobus Manlius in luminari fuo minorem Gracorum conyzam effe oftendit. Cord. Vt in plerilqa aliss fic $\&$ in hoc hallucinatur, Ral.Parcius. Dicıt à grzeco id ho mine, néfcio ubi, didicifie, confirmat'́z quiburdam uerficulis. Cord. Ridiculis nimirum \& fe dignis, nam eoldē \& egolegi.Ral.Non omnes poetæ effe poffumus. Cord. Neq3 id ego in eo requiro, fed maiorem in monftrandis herbis diligentiam, quanquamnon adeo infcelixearundem, quod prius dixi fcrutator eft. Si eadé conyzze fatureia effet non duobus eas capitibus defcribens Diofcorides quafiebrius [epa- 
raffet.Sed confer huc minoris conyzz hiftori am, et hinc tute iudica. Vtpedalis altitudo qua dret, fubamarus tamen \& luteus eius flos, qui in lanugenofos pappos euanefcat, manifefto indicio difcrepat, ne aleagina interim folia imputem.Nig.Si eadem thymbręfatureia eft, ut ipfum capitis lemma oftendit, miror Colus mellã canere.Et fatureia thymi referẽs thymbrzeq ${ }_{3}$ faporem, Cord. Vt paucis te expediam Fito duas thymbras, id eft, ut Latini appellant cunilas effe, alteram agreftem feu rufticam,al teram fatiuam hanc, qua quia minori eft acri monia, in condimentario genere edulijs concoquitur, hinc à faturando, quafi proprium fa tureiæ fibi nomen inuenit. Quod tamen agrpftis illa ab hac aliquando mutuat, peculiariter aliogui thymbra dicta, Nunc facile intelligis Columellam thyinbræe nomine rufticam cunilam, \& per fatureiam, faliuam feu hortulanam hanc cunilam fignificare. Ral, Recte, 0 lim etenim cum Brunfuicitecum effem, audiui Saxones fatureiam ibidem hortulanami cunilam appellare.Cord,Noftras quoq; gens mul tis in locis ficuocat. Ral. Sylueftre ferpillum etiam hic cunilam dicunt, fed parü,ut fit, cortupto nomine. Gal. Quo ergo! Ral. Cunel \& quenel.Meg. Quid fi hoc ipfum fylueftre dictu 
Serpillum hrec ruftica cunila feu agreftis thym bra fit ? Cord. Si aliud fylueftre ferpillum demonftrares, facile tecum fufpicarer, ad quod accepta hæc per ueterum manus Germanica nomenclatura, non paruam \& mihi occafionem dedit. Imo et complura a lia pronum ani mum trahunt, quorum id primum eft, quod plenam floribus ficam habeat. Ral. Sed non uiridi colore, qualem hic ei Diofcorides tribu it. Cord. Hunc ego non florum fed herbx intelligi deberi credo.Megob. Perge. Cordus, Secundum quod grata apibus herba fit, quaIem Columella thymbram commendat. Ter tium quod \& thymi \& fatureiz fimilem tum odorem tutum faporem referat + Nig . Theophraftus quoddă ferpilligenus à fatureiç odore fatureiatum dicit, quare ne temere pronuncies uide. Cord. Id non libenter foleo. Siomni no herbarij noftri ferpillum fuum tueri uolüt, per me magno ocio licet,fed uelim interim mi hi dicant, qui zygidos nomenei conueniat, Abfurdü enim uidetur, fi quod quidam uolüt, à trutina, quam graci zygon dicunt, ob fimi? lem fcilicet ramulorum rectitudinem, qux in multis alins herbis euidentius apparet, uocari debeat, aut quod eo uites ingentur, idenim $z y$ gèj gracis nonnunquă fignificare audio. Non 
156

$$
\text { EVRICII CORDI }
$$

eft tantus huius herbulx lentor, non tanta lon gitudo, ut aliquis fit ad uinciendum ufus . Ral. Si hoc fylueftre nobis ferpillum abftuleris, nul lum aliud relinques, nullum enim aliud herbarij noftri oftendunt. Cord.Ego multis iam an nis laboraui ut hortenfeilludferpillum cogno fcerem,fed fruftra, quantumuis uulgarem alibi \& omnibus notam herbam,Nifi fortafie fit quod hic pulegium credimus, huic enim hortenfis illius ferpilli hiftoria admodum congru it.Serpit hoc per terram, \& afcendit adminicu la,pêfilíg ex horto perpetua ramulorum pro pagine in quamlibet longitudinë demittitur. Ita ut fępe mecum cogitarim num $\&$ in demổ ftrando pulegio errauerimus. Hanc fuf́picionem meam auxit quod aliquădo legerim græe cum quendam fapientem prolatam in publicum pultem immiffo pulegij ramo identidem mifcuiffe, graui fcilicet diffidēetes lafciuientefą̧, ciues caftigandi amaritudine $\&$ arcano documento. Debilior tenerior'qz eft putati pulegí noftrif ftipes quă ut eo puls mifceri agitarique poffit. Accedit \& illud, quod in polycnemi hiftoria pulegium umbellam habere innuitur, qua credituin pulegium noftrũ caret, nifiuerti culares orbes illos, quos ubi defloruerit, often dit, umbellas dicere uelimus, Adde quod \& ne 
fciam quod fimili imagine uerŭ dictamnum referat, quod tamen adeo fimilia pulegio fo: lia habet, ut hinc fylueftre \& ceruinum pulegi um appelletur, nuncea ipfa tomentofa et lano fa pube obducta funt, qualia pulegium noftrü non habet. Quinetiam Plinius utrunque echium pulegio fimile dicit, ualde diffimile ad pulegium noftrum comparatione. Gal.Et Paulus Aegineta uetonicam pulegio æequiparat. Cor. Sed non Romanam \& uulgarem illam, quam Diofcorides ceftron dicit, imo alteram, nam duplex eft uetonica, ut ibidem uidere eft. Meg. Non melius confilium in hac controuer fia dedero, quam ut pecoriguftandum pulegi um noftras porrigatur, ei tum, $f$ it uerü id pule gium fuerit, balatus quam primum excitabit. Ral.Non facile communë omnium noftrati um medicortm opinionē $\&$ confenfium pofthabebo. Cor. Neq; fuú illis pulegiü furripiă, fi hortenfe mihi ferpillum oftëderint. Sunt em̃ $\&$ multa quæ hoc idem pulegiŭ ues; pulegiü effe perfuadeant. Video enim facilem eius coa lefcendinaturam, ut fietiam minutiffime inci datur \& ferat,,tamen crefcat, quin $\&$ derelictis animo egris magna refocillandi facultate adhiberifoleat.Multx etiam mulieres eo contra uaria locorum fuorum uicia,efficaci, ut ipfę pu 


\section{EVRICII CORDI}

tant, ui utuntur, ut cæteras eius uirtutes prateream. Nig+ Sed quid ad eam, quam fuper hoc induxifti contentionem dicendum Cord.IIlud uobis alijśa dum relinquo, quorum latam hic fententiam libenter audiam. Ra1.Oculatos, diligëtes acrique perfpicacitate præditos homines difcenda medicina requirit, Meg.Non ab re facrifin guntur Aefculapio dracones.Cord, Feftucam feu(ut Gaza uertit)feftucaginem illam, quam gręcam Plinius, Vergilius Maro fterilem aue nam,græci uero ægilopa dicüt, uobis ex Theo - phrafto ac Diofcoride cognitam effe, \& inter fruges adeoq, earundem uitia referri uel apud Galenum noftrum legiffe uos puto. Idcirco uos ipfi hic iudicate quantü errent, non folum uulgares herbarjifed magni iuxta medici quidam, qui hancaquileiam nobis dictam herbam Gręcorum ægilopa credüt,omneśq̧́ eius facultates eidem tribuunt, Meg. Nihilinea q̊d agılopis hiftoriam referat cófpicitur, nec tam ab anguilla cancer diffidet. Nig. Quam hanc aquileıam apud Diofcoride effe putas? Cord. Cum didicero dicam. Ral, Pergamus igitur adeas quas nofti.Cord. Ex hacf crobe perficã exftirpaui. Ral.Quam ob cauffame Cor.Obumbrabat mihi hancaream. Ral. At habuifles 
tua hinc quotannis mala . Cord. Plura quam uelim mala fuppetunt, Ral. Siniftre interpretaris, ego de fructibus intelligo . Cord. Non admodum magno eorum defyderio teneor, quandoquidem mala funt hrec mala, ut qure frigida \& humida noxium; quia facile corruptibilem fuccumgignant, Gal. Aliter tradit Diofcorides, qui ea edendo effe \& froma cho ualde accommoda commendat. Cord. Non hæe perfica fed perfra intelligit. Gallus, Quain facis ergo perficorum \& perfxorum differentiam?Cord.Hrcperfaę, illa ueroperficę mala funt. Nig. Vt audio perfaza \& perfica diuerfær funt arbores.Cor.Omnino.Gal.VirgiliusMarcellus tamen perfęamperfică quoq3 indifferenter nominat. Cord. Sic etiă Theodo rus Gaza. Verum non ita in græco haberi cre do. Ral, Perfica fæpe fed perfæa nunquam ap pellari audiui . Cord.At Galenus tuus Galle, cuius tam affiduus es lector, de perfaa et perfica arboribus feorfim duobus capitibus egit, \& diuerfas eis uires tribuit, aitque illam in Ale xandria fibiuifam, quafidignum fatu fpectaculum innuat, cum hrec ubique uulgaris con fpiciatur. Meg. De noftrate non poteft intelligi quoddicinur, apud Perfas fructumtan tæ perniciei ferre ut edentes interimat, \& in 
Aegiptum tranfplătata eundem in efculentum 8 innoxium mutare. Cord. Neqg illud quod Theophraftus in hũcfenfum tradit. Efle perficam ( fic Gaza perfęam uertit) afpectu magnä formofam'qz, folio, flore, ramo, totáq, figura potiffimü pyro uicină, nifi quod altera folio perpetuo altera deciduo fit, Fructü abüde parere, omniqg tempore perficere. AtqB id in Aegipto et proximis eilocis, et in Rhodo $u f q, 3$ ad florem duntaxat deuenire. Noftras per fica non fimilia pyro fed qualia nouiftis folia fert, eaq; quotannis remittit, et femel tantú in anno fructificat, fructumq $q_{3}$ abfoluit fub Septentrionalietiam colo. Ral, Vulgare hoc eft olus, fed nondum latinum eius nomen audiui, nam Germanice beneth appellatur. Cord Bli teum te merito dixerim qui blitum ignoras. Meg + Spinaciam quoque, quam Germanice fpenet dicimus, fcire uelim an uf piam Diofcorides inter herbasfuas locarit. Cord ${ }_{+}$Nufqua ut credo, fed nouam 'ueteribufq, incognitam fuiffe fufpicer. Quamuis fint qui eam blitum, de quo iamiă dictū, effe falfo putent.Nig. Hăc maluam effe putarē, fin nô incifuris diuifa folia haberet. Cord.Sunt qui alcæam credăt, quod fic affirmo, ut fi fuerit non meam fidem pe* riclitari uelim, certe in leoniceni Diofcoride, 
quem mihi commodato dedit, ad margineni iuxta hoc caput, eius ipfius manu notatum legi alcæam etiā, ut maluam caleolos ferre, quos hic uidemus. Gal. Germanice mihinomina. Cord. Hoiuchluchte quafi altam lucernam di cas, \& fickmars vurts, quod nomen interpreta ri nequeo, forte deductum ab eo quod Symeo nis herba à quibufdam dicitur. Nig, St graca cum latina uox componi poffet, crederem in Diofcoride galeopfin pro galiopfi legi debere, effeque hanc herbam cuius flores galeę afpe ctum, ut frep animaduerti, referunt.Ral. Nos barocum Latine \& Germanice behenfuchen, id eft,apifugium uocamus. Nig. Neque grauis odor, quigaliopfi tribuitur, deeft. Cord, Vide cur Brunfelfius nofter per galiopfim dictam fcrophulariam innuere, quam $\mathrm{fi}$ Diofcorides intellexiffer, tefticulatas illas radices, quib $b^{9} \mathrm{ma}$ xime indicaripoterat, non preteriffet, ut ilJa, que dum matura eft, habet, capitula taceam. Meg. Vidi alıquädo fimilem urticzealiam hoc baroco multo maiorem, purpurafcente \& fimilirapunculo, nifi uaftiore tấtum Hore, quid filla galiop fis fuerit? Cord. Nihil decerno fi tamê id omnino cogerer, rria'ìm ad Nigri fufpicionem inclinare. Ral. Simillima huic alia tum facie tum odore albos flores ha 
152

$$
\text { EVRICII CORDI }
$$

bet.Cor.Forte ea quă Plini 9 lamiú dicit.Meg; Nihil dubito quinfeias quod Leonicen' hunc pedem coruinum non effe ueterū coronopoda contendat, quod tñ fere oēs adhuc medici putant, Cord. Totam fuper hoc difputatione legi, \& ut ueriffime, eius fententiæ fubfcribo. Gal.Idē facere Brunfelfium hic uideo, Cord. Sed quid tuncin contraria adhuc opinione hę ret, \& non aliam coronopoda credit, quă quæ hodie crus galliuulgo dicitur, uel pueris etiam nota, qui eam legentes mutuo ueficas cient, quod huic potius coruino pedi cốuenit , ut uel ob idetiam flammula uocetur, tria coronopodos genera nobis idem exhibuit, quorum tamen nullum eam effe iudico. Spargitur erm humi coronopos, cum omnia illa recto caule rollantur.Meg +Quid Galle tam diftorta \& quaficacantis facie ringeris? Gal. Stomachus meus ftomachatur, luctantes nimirum uentos \& fonoras tempeftates continet . Cord, Aeoliam audio. Nig.Claudiano edicto parēs fiue ut per utrunque guttur emicent, non eft turpe prrefentibus medicis Aethontem agere. Gal, Scio unde contraxerim, edi hodie rapas. Ral,Entibigalangam an forte hac manfa refidere uelint. Cord. Interim fub his cerafis recumbamus.Nig.Nufquam apud Diofcori- 
dem galangæ hiftoriam inuenire potui, Cord. Non mirü cum nufquam pofuerit. Sút $\&$ aliæ plures Arabumn medicinæ, quarü nec llle nec alius quifpiam ex ueteribus Gracis, quod ego fciam,meminit, earum complura nomina in fchedulam quandamnotata penes me in pera, ut reor, habeo.Meg. Ea nobis recenfere ne pigeat. Cord Non inuenio, memoriter aliquot enumerabo. Sunt igiturilla, ambra, anacardion, feu anacardus, behen, bellirici, bel, camphora, cafia fiftula, quam ita iam uocant, coton, Jatine goffipiü, culcul, dadi,dend, doro nici,emblici,fagre, feleng, faufel, $\&$ iṕa de qua iă dubitas galanga, kadi, kanabel, lingua auis, mofchus, manna, macis, fi nố machir eft, mirobalani citrinæ, chabulę \& Indæ, nifi quis eas inter palnulas Diofcoridis reputet, michad, mummia, múa, feu maum, nerfin, nux mufca ta, nux metel, nux mechil, \& forte nux hende, nuxindica, nifi hæc fit quam Galenus regiam nucem appellat, \&c feptem uncias continere di cit, nux uomica, modo \& illa non fit, ut quidä nolüt, thitymali caryitis fruct? , phel, piperella, licetuiticis fenné ita etiă dicat̆, ramech, ribes, fa deruă, fandalü,fel,fene, tamarindj, turbith, uir5, zarnabü, zeduaria,zelim, zurumbeth + Meg. His uocabulog: mốftris luname coelo deduci 


\section{EVRICII CORDI}

poffe crediderim,Cord.Anacardij \& zarnabl tamen(fed arnabi nomine) Aegineta memi niffe puto. Vbi fciēdü Serapionē duo zurübet ponere, \& altepze ei fignificare Auicennz zarnabū \& Aeginetx Arnabo,alterum zedoariă, quang̈ Auicenna de zedoarra zurübet zarnabo, quafi de diuerfis rebus tribus feorfim capitibus agit. Ral.In mummix capite apud Serapionem Diofcoridx uerba citantur.Cord. Fa teor,fed quibus piffafphaltum defcribit,uerun tamē mumiamaliud quid à piffaŕphalto effe, tot ab Arabicis medicis memoratæe eius facul cates arguunt.Multo enim acrius calidius, ac

$\therefore$ fortius quid effe oportet, fi huiufinodi poteft, quam pifiafphaltum, quod ut picis $\&$ bituminis nomina fic \& facultates poffidet. At illę nó rot neq, tantre funt. Ral. Citatur apud eundem Serapionem, ab Aben Mefuai \& Galenus mumiam inter oculares medicinas referens, his uerbis fi recte repeto. Galenus memorauiteä myamm in almaym, quando locutus eft de foda in li bro quarto \& dixit quod ex medicinis oculorum funt quxedam calidx, acutx, ficut mummia \& afa \& ferapinum \& euphorbium \&uniuerfaliter omnis medicina quæ calefacit for titer \&c.Nig. Tantum te medicum effe nefciui, Ral. Comparatus mihi Galenus quafi con 


\section{BOTANOLOGICON.}

tepptiffimus ueterinarius fuerit, fed caue ne de cumbens meounius tantum confilio utaris. Dum in taberna mea ociofus aliquando defideo, in Serapiốe legeréfoleo. Cord. Interpres illius libri Nicolaus de Regio qux tu recitafti ficuertit. Cótrarijiffima autem materia corú taisum eft ea quę eft acrium operú, ueluti ciri naci(ego Cyrenaici puto legendum ) \& indici \& ferapini \& euphorbij \& fimpliciter dicendo calefacientium uehementer, Vbi pro mumia lafer(nam fic latini Cyrenaicum opon, id eft, fuccum appellant)intelligendum quis fufpice kur, neqz immerito, cum Arabes medici eafdë fere mumiæ fuxe facultates, quas Diofcorides Cyrenaici fucci,recenfeant, Nifiquis tran'pofi tisuocib? Indicum ibi fuccum pro mumia, \& Afam pro lafare accipe uelit, ut oēs hodie me dici faciunt turpiffimo errore, cüeadé af́a uetus illud lafer non aliter, ac humanum oletum fuauiffimumbalfamum, referat,Meg.De Indico multa Leonicenus, fed, quod hue ad mumiam pertineat,nihil.Nig.V anum, ut hinc ui deo, commentum eft, quod quidä humani cor poris tabidam faniem aloe \& myrrha commi xtam \& e fepulchris effluentem, effe mumiam dicunt. Cord.Idut crederem nunquam adigi potui. Ral, Cun tamenilliteftem habeant Se 
rapionem? Cord.Sed ubi Diolcorides, cuius de piffárphalto ibi caput ille citat, id teftatur? Quitn̆,fialiqua talis ex hoie medicina fuiffet, certe ut alia pleraq, quemadmodum faliuam, urină \& fudores non præterijffet. Ral.Nonfacile pendentes ex Arabibus medici permittêt, ut hancufitatam hactenus mumiam $e$ tabernis noftris auferas, quam adeo ufurpant, ut, cü uera haberi neqt, æmulam eius nos conficere cogant, acceptis fcilicet e patibulo aliq uel rota humanis pulpamentis, eiff' ${ }^{\prime}$ aloe ac myrrha. Cord,Quã habetis, Ral,Aliquandiu maceratis. Cord. Facitis hoc iṕo anthropophagio, ut fapiētes \& qui nố uultures funt hoies, tabernas ueftras nôfecus ac foedas carnificinas merito abhorrere, fugere \& execrari debeãt. Qui unğ Lęftrigones tăfpurce crudeles fuerant? Satis fuiffet abominabiles nocëtiffimake uiperaßz carnes aliquot antidotis mifcere, \& $\mathrm{ab}$ humano tabo faltē abftinere. Ral, Nihil non auden * dum \& ferenduin eft, ut oim rerum preciofiffi ma fanitas, fiq hi amifla fuerit, recuperet. Cord. Age bone Ralla, quxe effe pótueftræ illius mumiæ tanta uis \& efficacia, ut t t̆̌ naturæ piacu* lum æquet:Miror tam ftupidam medicorum credulitatēe,ne uecordē cæcitatē dică, quæ tă ua nă fruftrationē p tot annos non pcipit. Liceat 
BOTANOLOGICON.

mihihic etiā empiricos quordă perftringere, qui humanũ adipẽ in unctióes fuas fuperfticio fe expetunt $\&$ inquirunt, planéq ctiffimam'alioqui medicinain polluunt, nó fine fallace rapinarüdecipula.Meg . Quid tü de illis, quifanguinê etiam humanum medicinis fuis mifcent, magna, ut ipfi putant, nutriêdi \& refocillandi potentiac Cord. Integrũ \& in cor pore noftro detentü adhuc fanguinë optimü quidē \& utiliffimú effe fuccú haud dubito, an aũt, ubi foras profunditur, idẻ permaneat, nefcio. Vtid maxime fiat, tř huiufmodi medicinas uel mifcere nedũ accipere abhorrerē. Ral. Quorfum ab inftituto procurrimus! Serapio, uolebam dicere, ben deferibens etiam Diofcoridem citat. Cord. Ego nó ben fed behen ptuli.Nig. Quid idē ben tū́cillieft:Cord. Myroba lanus. Ral. Numerafti tř \& mirabalanos inter ea, de qbus dubitas an ueteres fcripferint. Cor. Alię̧ füt Diofcoridis myrobalaniàueftrisiftis, licet ferme oés, hodie medicieafdem illis, quas Diofcorides fuis, facultates tribuant, \& eafdem etiam res putêtt, manifefto raris tamé de prehenfoerrore. Meg. In Galenianis fecretis \& experimentis non folum oês, nempe quinq, myrobalanorŭ noftrarüfpecies, fedetiă cam• phoram, doronici, galangă, nucem mufcat $\tilde{z}_{2}$ 
nucem Indicam,turbith,zedoariam, zurume ber, Imo omnia fere, quzerecitafti, adeo'gs plura legiffe me recordor,Cord. Hæc eadê acab: furda quadam alia, in cauffa funt, quo minus li bros illos Galen effe credam, ufq; adeo arabi. ciffant, q̊d decem ifti tractarus Myamirnō faciunt, imo quantumuis Arabica interpretatio ne corrupti $\&$ infecti, latente tamen genio authorem Galenū referunt. ut fallantur qui hŭc nongermanum fed adicriptitiư libruin exifti mant.nef́cientes eum effe, qui de cốpofitis medicamentis fecundum loca infcribitur , Nig. Eofdem tractatus, ut ex Plateano noftroacce pi, Ianus Cornarius infignis \& mire literatus medicus, nobis propediem, ut nuper Aetium, Latinos exhrbebit.Meg.Vtinamnon Torinia na affectatione. Nig.Imo puriffimo, quod fyn ę̧rum eius iudicium eft,fermóe. Cordus. Hũc ego, licet a facie nondum cognitum, inter primarios tamen anicos meos collocatũ nốuul gariter diligo, fperóg non paruam opem iacenti \& iam refurgere conanti medicinæ latu rum.Nig. Turbithetiam ueterum Gręcorum tripoliū effe uolüt. Cord. Eius caput Serapio quidé ex Diofcoride citat, Imo funt qui eiufdé pityufam autumēt, ggo ỳo neutră. Dequa re, quia amplius dif gutare neqg libet nequacat ad 


\section{BOTANOLOGICON.}

Leonicenum \& Manhardum uos remitto. Meg Quin \& fenam, funt qui delphinium effe putent.Cord. Nontamen undequaq; refipon dente hiftoria. Quod fi maxime fuerit, nonta menueteres de eo quicğ feripfifle crediderim. Nam adiecticiú hoc in Diofcoride caput hine arguitur, quod in antiquiffimis id codicib, nỏ inueniatur, neq3 Galenus neque Aeginetaneque Plinius del phinijufg̈ meminit, quantum ego obleruarim. Meg. Quandocü'q \& \&à qui* bufcunqzreperta fit, quomodocunq, etiam uo cetur fena multis laud b . predicata, quia multis uiribus prędita eft medicina. Cord. Hine non immerito \& folandros dicta, quod hom nem fcilicet fópitet. RAL. Dammarum pro f́icio, in quo uuulariam nalcià quodam hic cucullione olim audiui, quam ut illine mihi colligeres, nuper literis meis te rogaui,fed qui nihil accepit ego fum.CORD. Dijte perdant eum tua hac demonftratione, finniorum nidú indicafti. Ego tum ardentiffimo caniculęreftu eum confcendi,fed nihil prater fterilitatis in dices erycam f́cilicet \& geniftam inueni.Meg. Putas Diofcoridem uuularię ufpiam meminif fe:Cord.Puto, eamíg, effe eandem Alexandri, nx lauro, quod mihi non credens eius hiftoria conferat,GAL. Herbam forte intelligitis qua 
biflingua uocatur, Cordus. Eam ipfam. Ral, Nullam inea, qua vuulę medeatur,facultatem inuenio, à qua tamen hoc ei nomen inditur, ut hinc etiam Germanice houckblat id eft vuula rium folium dicatur. Imo ne aliquem foliorü quidemufum, CORDVS, Fuiffe tamenolimnon parumm illum ex hypoglotti $\&$ hypo gloffidinnomenclatura conftat, qux hine pro. culdubio facta illieft, quod fub lingua tenerifolita fint folta, ut uel hodie, non tantum apud infubres, ut Vergilius Marcellus ait,aliassque alibigentes, fed etiam in Germania nos ftrafit quoties abundantem puerorum faliuam $\&$ deftillantem in fauces humiditatem, unde uel prolixa Columella, id eft uuula, uel faciens balbuciem lingur impedimentum ori tur, cohibere \& ficcare opus. Aliud me remo ratur quod filicet DIOSCORIDES huius. alexandrinæ lauri folia rufci, quem uos brus fcum dicitis, folijs fumilia tantum minora pin gat. Rufcum inItalia uidi, fi qui indicarunt non fefellerunt, fimilibus quidem fed minoribus, quam uuularia habet folijs . RA L LA * Si tam ut:lis eft radixut hic legitur, non do nipetas illos agyrthas qui tam multam utula riam circumferunt orabo, ut $\&$ ipfam una cum herba euulfam mihi portent. NIGER. 


\section{BOT ANOLOGICON.}

Quxerice illa eft quam cum genifta ibi te ins uenifle iam dicebas, CORDVS. Vulgas riffimus frutex ille quem Germanice heyde nominamus. Mego.Ateamliteratores myricam uocant, CORDV S. Sic Græci tamaricem noftram apellant, cui eryce adinodum fimilis, nifi quod minor fit, defcribitur, pe culiare apum oblestamentum, unde fi non as deo generolum qualecunq3 tamen mel confis ciunt, NIGER. Memuntme apud Nican- drifeolaften legiffe erycem herbam efile hedes rho hay re folijs, quibus dicta heyda nihil accedit * CORDV S Nef́cio quantum fidei huic, quifquis fuerit, habeam, in pluribus mihi non optime dixiffe uidetur , Clara funt Diofcoridæuerba quibus, fiplacet, adde quæ \& Plinius de eodem frutice fic tradit, erycem, inquit, graci uocant fruticen non multum à myricæ differentem, colore roris marini \& pene folio, de quocunque rore marino intelligas (namplures eius fpecies prius audiftis) minuta tenuiaque non hedere fimilia folia defcribuntur. Decepit forte fcholiaften quod Nicander explicantem folia fua erycem dixerit, ut Lonicærus uertit, id quod ego non ad lata folia fed ad diffúos ramos refero. NIGER * Non uelis indignari. 
172

Corde fiex ipfo Diofcoride contra hane opiniopem tuam alum adhuc locum citauero. Cordus . Quafi non audieris toties me die centem quod uel àminimis pueris abfque ullo pudore difcere paratus fim, nedum à nobis doctiffimis uiris, atq hac fola cauffa uobícü exiui,alias iam domi compotaremus, ne for teid me refugere, \&ciumptü dolofe detrectare putetis. Nihil mihi unquam gratius continge re poteft gu ut,ubi aberrauero in uiam quis me reducat. Cupio admoneri \& doceri, quod ta" men plaroffq adeo pudet, ut erroneum potina opus emittere nonnunğ malint, quàm $\mathrm{ab}$ alijs quicquam interrogare, quod tamen tam liben ter facerefoleo ut fepe moleftus fin. Sed dic tandem quis ille locus fit. Nig. Diofcorides ca* pite de cori, herbameam fimilia ery ${ }^{\prime}$, minos ra tantum folia habere dicit, Conftat corin in ter hypericigenera numerari,aliqua, ut credo, foliorum fimilitudine. Nuncomne hypericon latiufcula folia habet, ut minima faltem rutä zquent, Si nunc minora ea corios quàm ery cæe fcilicet, qui eryca frutex, qui heyde dicitur, effe queat, nổ uideo.Cor. Vt ingenue? fatear, torfit \& medudum animaduerfus modus ille, que tamen ad Alexandri Magni exemplum, hoc gladio diffoluo, quod duorum infignium az- 
thorum, Diofcoridę fcilicet et Plinit,erycê my ricę, id eft tamarici côparantium aperta et cla ra effeuerba uideam, \& potius inibi forte erroremlatere, quam Diofcoridem fibijpficon. tradicere putem. Vel igitur maiora tantum is bi legendum(quanquam ne fic quidem fimilitudo refpondet) uel aliam erycen eff́e putandä eft,Meg.Magnas ac multas in fimplicibus dif ficultates effe uideo, \& mirornô maiori ea di, ligentia à recentioribus medicis inquiri, imo tanta fupinitate negligi, inueteratis'́, eos er roribus potius oblectari.Cord? Adde \& qua fi Vatiniano odio contumeliofis'q3 conuicijs fcrutantesueritatem uiros profequi. GAL. Non mathematicus diuinator fum, tamen ue rum erit prognofticon meum uereor, nos im minentem pluuiam uix poffe euadere, uidetis ut atris nymbis obductum coelú horreat? Et prope quintam eft horam. Cord. Recte admo nes, redibimus domü, recta qua uenimus uia, quanquam per Lani ripas uos ducere, fuit ani mus,ut de aquaticis quibuidam herbis etiam difputaremus,ubi \& in acoro \& gladiolo nos errare demonftraffem. Ralla.Nunquid gladio lus ille luteis lithis uerus eft acorus: Cord. Valdedubito, diffidenteradicis forma \& fapore, quipotius adfringens \& quafiinfipidus quă- 
$174 \quad$ EVRICII CORDI

dampræe fe frigiditatem fert. Ralla, Quid audio? Omnés pixidas noftras exinanire ftudes. Cord. Imo bonis ac ueris potius medicamen tis implere. Nig,Forte xyris eft, Cor. Facile id crederē fiflos non obftaret, qui xyridos purpu - reus eft, imo alius etiam natalis eft locus. Ná xyrinin agro inter fepes nafci Virglius Mar: cellus teftatur, cum hæe planta femper aquarú uel accola uel incola fit. Neq; fimilis ei \& codé natali gaudens alia herba uerus, quod credimusgladiolus eft, qui fecũdū Diófcoridē etiâ purpureo flore, binis adeo' $q_{3}$ bulbofis radicib? in aruis reperitur.Meg.Sparganion uideo etiā in ter gladiolos referri, an illud nofti: Cor. Nố aufum dicere, quanğ aliquando cogitarim, nü illa fit herba, qux prope aquas fimilis gladio fed graciliorib, \& angulofo dorfo acutiorib. folijs, \& aculeatis pilulis nafcitur. GAL. Alexăder Benedictus in quodâ de pefte libello fpar ganiü,tormentillă effe docuit. Cor. Tunc aliă, quả quxe pentaphyllon diciț, tormentillă effeo portet.Nig.Videre eft in eif dee locis \& aliá eno dicaule lógis \& ad gladij formá accedẽtib, fo lijs graciliorib.tamē, denfo nelcio flore ne an paniculo dicā.Cor.Typhă herbă audio deferi bis, quæ Germanicenarrêkolbể idè,,morionis ceftus diciț, quang̈ apud Theophraftü quod et 
hír me aliquantulü furpēdat, legi. Ral. Quid ex go p fcripto mihi acorofuccedaneü accipiä. Cor.Diçũ hodie cala mú aromaticú ego pro acorofcribo, \& eundē etiă effe fúpicor, dubitō que uehemëter nüuepz calamú odoratū habea $\mathrm{m}^{2}$, res em̌ eft exotica et ṕciofior, quă ut tot tä tiq; illius pleni colei ubiqis pftêt. Ral. Spero te faltē noftras nobis fabas relinqure. Cord. Exq̊ ita mihi illudis, illudă \& tibi, \& fr nố has ipłas abftulero, faciă tamê preftigiis meis ut né́cias an habeas, $\mathrm{atq}_{3}$ hęcnoftra erit, donecurbê ingrediamur, difputatio,Meg. Age dic, libenter hunc ludum tuü audiam.Cord. Principio que ro te RALLa, quas nă fabas intelligas, nüquid illas qux oblonga \& aliquantulum plana cópreffia'c; facie nunc binx, nunc ternæ, nunc qua terne $\&$ nunqua $m$ fere plures quam quin $x$ in fingulis filiquis nalcuntur, nigro umbilico feu oculo tă grandes ut duæ drachmă ună pendắt quas Germanice bonen dicim?. Ral, Quas alis as.Cor.Bene.Sed uerę fabæ his multo mino: res $\&$ rotúd $æ$ funt id quod hinc colligitú, quod apud plærofq́ medíeos, ubi de aurium incốs modis agunt,tale lemma inuenias, Si faba uel aliud quippiam rotundūin aures ceciderit. Et CORNELIVS Celfus epinyctidas inftar fa barum puftulas defcribit, nimirum paruas 
176

EVRICII CORDI

ac rotundas intelligens. Sicetiam legimus che crum in mammillis fabr fimilitudine incipere. Quod fi hæec tibi leuia uidentur argumenta lege totum Diofcoridem \& fape exigua rotũ da'qz femina fabis comparari reperies, quemadmodum,ut unumfaltem exemplum profe ram, in iunipero uidereeft. Quin ipfe Gales nus multipedas feu onifeos propterea etiam cyamos,ideft, fabas appellari dicit, quod, dú contrahuntur, fabarum figuram imitentur. Nunc eafdem beftiolas in rotundiffimas pilulas conuolui author eft Scribonius. Ral.Dudú obturatum eft mihi os. Cordus, Sed audi que plura Galenus de aphaca \& uicia dicit, Horú inquit,feminum figura non rotüda eft ueluti fabarum, fed aliquanto latiufcula fimiliter len ti.Idem inlibello de ponderib. In Aegiptia in quit,faba obulus femis eft. Nunc is duodecimam drachmę partem ęquiparat. Cum ergo Aegiptiæ fabæcominunibus fabis, quas authores intelligunt, maiores fint, \& tamen earum duodecim drachmä unam faciant, quot putas communes illas, qux minores funt, drachmam conftituere? Forte non pauciores xvij̄: Adde quod $\&$ Plinius inuentum fcapum centum fabis onuftum tradat. RA L. Define candemuictum uincere. Cord.Sed pofíem hic 
piura addere quibus tamen breuitatis caufa prudens fuperfedeo. Tu modo, an hæc de noftratibus fabis intelligi queant, cogita, quarũ funt quędă adeo magnę, præérertim purpureæe illz, ut fingulę fingulas drachmas pëdant. Ral. Ego ftatim in principijs concido, uos triarij mihi milites fuccedite, pro me refpondete, $\&$ periclitantes fabas afferite oro, quantũ en̆ per me ftat prorfus actũ eft de illis. Meg. Vtuideo Corde ferio ludis, \& me quoq 3 nonnihil, imo multum dubitare facis, adeo urgētia producis argumēta. Quę tamē hic refpödëda reor, poft coenă referuabo, cum iam nô fatis tēporis fup petat.CORDVS,Tum ego quoq fententia meam dicam, \& fimilia plura de alins leguminibus proponam, quorum plurium, ut Cerea lium etiam feminum, difficilis iam eft cognitio,eorū præefertim quæ olim ut omnibus co" gnita nulla ultra nomenclaturam hiftoria def́ripta funt. Hinc ego quid pifum, quid \& loliü fit, imo quo nomine frugem illam, ex qua con fectum pané quotidie edimus, uocemus, ignorare nos contenderim. RALLA. Et multa ho die didici \& multa iuxta dedidici, pro quibus tamen omnibus non uulgare tibigratiam habeo.Meg. Eandem \& nosalij. RALLA. Vnü 
tamen adhuc reftat, quod interrogare oportet. Nü omnia quę contra inueteratumufum? docuifti,fecũdü hane demonftrationē tuăaccî piă:Cord,Neceffe eft hic te folertem \& cautư effe, \& nó ftatim deprehenfis aliquot harủ res rumerroribus cú hominũ periculo fciolū oftentare, imo uidere quis fcribentis tibi medici intellectus, $\&$ qux abs te côpponendæ medicin̨̧ ratio \& qualitas fit, \& an conducat præfcripta eius fimplicia mutare, non en̆ id temere neque femper fieri debet, ubi tu alia earū nomina f́cineris. Vt me capias: Scribet forte quifpiam tibi pro ducendaurina quam uocatis receptulä, in qua \& fenetio legitur. Hic fi tu continuo ue ram fenetionem acceperis,peccabis non leuiter, quoniam nố hane fed cardaminen, ideft, criffonem illeuoluit, \& conficiendum medica mentum poftulat. Eodẻ modo ipfum quoque medicum animaduertere oportet, ex quonam 2uthore medicinam fuam tranfiumat, uetere ne fciliceruel an recenti, \& qualia etiăille fimplicia intelligat.Nă fi quis(ut et hic exemplum addam) in Galenouel alio quodam, qui uel an teuel nö adeo multo poft eum tempore uixit; mifcendam cafiam legerit, noneam, quæhodie fic uocatur, fed cognominatam ligneă ace 
cipiat, cum illa à recentioribus inuenta, hrec ue ro antiquis tătum cognita fuerit. Ral Nifiad ingreffas nundinas properem, craftino quoq3 die apud te manerê, ut fimili deambulatione per uicinas iftas fyluas ac ualles plures ex te herbas difcerē. Cor.Dú reuerteris, huc rurfus obiter declina,operã meă tibi ultro polliceor. Meg, Sed ubi ego tú fuero:nă cốtinuo ut craftina luxemicuerit, Caffiliä, hinc Erffurdiam, mox Lypfiă concedă, neq huce Fräcoforto di uertiffem, nifi te tantủ \& iá plusğ in tribus annis nố uifum amicū meũ nỗ inuifere, cum tam prope effem, grande piaculü, imo icelus duxirfem. Cor. Omnes illic communes amicos nomine meo falutabis plurimũ \& reuerêter, ut'q́ Cordo fuo aliquădo fcribăt, 8 in iftis, quas iả patiț,eü aduerfitatibus confolenț,admonebis. At tu candidiffime Niger apud nos hic aliquãdiu ages, nec oblată tibi prouinciam rencies. Nig.Si commodus ei fuffecero, \& illam, qua te àquibufdam hic exerceri audio, perfecutione effugere potero, CO RD V S.Peffimusille fit oportet, qui te optimun uirũ odiffe poteft.Nig. Affectu tuo compofitis colorib 9 me pingis,ego tă difficile acquifitu ac rariffimis dignú no men nổagnofco.Qualis qualis tamë fum, oë M 2 
180 EVRICII CORDI

bonos amo. Meg. Tunc neceffario phylautus es.Nig.Qua caufla:Meg. Quia fic \& teipfum amas.GAL. Incommodū hoc, quod una cum redeunte ex pafcuis armento ingrediamur, ex pectemus parum dum tranfeat, non libenter pecoribus mifceor.Cord.Difcede ergo e Mar purgo,Quin imus? Meg,I tu prę,nos te fequemur.Cord. Pontem contigimus, nunc iterum binis nobis ire \& colloqui licet. Meg. Domus tua Corde egregium habet af́pectũ. Quidex tam imo pectorefuŕpiras? Cor, Quod eadem ipfa tot tătos'́g mihi inimicos cóciliauerit, $\&$ ut meliorẻ alibi prouitiă negligerë, dum uana me proprïfperetinuit, coegerit.Meg. Dolendum eft certe iniquă fortunã perpetuo bonis uiris aduerfari,et nố nifi iprobos nebulones re fpicere, Cor, Quid attinet multa cốqueri? ego fus'́g dég, fero, cedă inuidix nihil dubitans me fatis habiturü quocunq̧ peruenero, cû́ inimici mei,etiam ubi has æedes deglutierint, famelico adhuc rictu efuriant,Meg.Mirúfite, modo ré nofcës,princeps difcedere patiať, Cor.Qui mi hi facilêa ab eo dimiffionê impetret mifi. Meg. Forte qui te hinc amotum uelit? CORDVS. Acupictor effe deberes. Meg. Sed qua ratione perfuadebit? CORDVS. Non deeritMer 
curio oratio, quametiam iuuabunt Augufti Sebaftiani Nouzeni miffx ifthuclitere, quibus me apud eundem principem, quafiiam decem feptimanis pralectio mea interquieuerit, $\mathrm{accu}$ fauit,Id'q3 totius fcholæ, cuius iam Alpha eft, cömuni nomine, fed manifeftifíima calünia. Abfui quidem hinc aliquandiu Bremam pro fectus, interim tamen fubftitutus alius prouin ciam meam integro menfe fubijt. Dehinc fequute funt feriæ, ita ut non totidem horis, quot ille feptimanos indicauit, penfum meum intermiferim, nulla tamen torpens negligen" tia, fed urgente coactus neceffitate, cum eo tëpore apud principem de reddendis $æ$ dificij ex penfis, non citra magnum incómodum meum agerem. Hanctam infignem iniuriam quo putas animo feram? Tam diligenter, fcio,tam etiam bene, fpero, quàm quifog alius fuum, hic locum meum defendi,Addeetiam, tantre utilitati,imo \& laudi huic fcholæ fui. MEG. De hoc nondubito, CORDVS. Et hanc nunc gratiam recipio, Non tamen omnes collegas huius accufationis infimulo, imo plurimameorum ( qui amici mihi fauent) partem ea laruit,credo.Siquidem cum quotquot fuper hac re expoftulaui,omnes fe eius inf́cios effe refpö M 3 
182 EVRICII CORDI

derunt.Gal.Ego hac gurguftiuin meum rectà petam,Cór. Quo is?una nobifcum coenabis. Gal.Magnam tibi gratiă habeo, eft quod uerear.Cord,Nihil tibi metue, nos coctos nõ cru dos gallos edimus, Gal. Debilem uëtriculum habeo, quem ut curem oportet. Cord. Bene er go uale. Gal. Vale et tu. Cor.Ingrediar culinä, \& quiuxor focum inftruxerit, uidebo, uos ins terim in æftuariü afcendite, moxadero. Meg. O miferum Cordum noftrum q tain commo dum ædificium, in quod omnê fubftantiam fuam profudit, deferet, redditis tamen, ut fpero,expenfis,Nig. Vtinam quam eft candidus tam effet etiam cautus, \& libertaté fuam cohis bere, imo nōnung̈ ciuiliter blädiri, affentari $\&$ adulari poffet, melior quondain proculdubio fucceffus ei uiciffim arrideret. RAL. Fruftra optas, fium habet, quod obtinebit, ingenium. Meg.Amici mores noueris non oderis, Cord. Quid nunc agitis, efuritis ne egregie? parum uobis expectandúeft.Meg.Noftra cauffa nihil aecelera.Cord. Exuite tunicas ueftras, ut has beam quo uinum emam. Ral.At mea tantinö eft, ut pro una amphora oppignorari poffit Cor.Vtinam ex tot noftris, qui alibi funt, ami cis, ,altem Georgius Sturtius, Eoban' Heffus, 
\&Martinus Hunus iam adeffent, ut tamẻ per fectum conuiuium feptem conftet, uade puer, $\&$ uoca Adamum Cratonem, Petrum Platea num \& Petrum Nigidium. Duos adhuc alios inuitarem, fed terret me uulgare prouerbium, quo dicitur, nouem conuicium. Ral. Satis fuperq́a fumptus nos tres tibi faciemus, non eft opus plures uocare Cord.Quantum intelligo immunes uos hinc abire putatis, fuum quifque fy mbolum dabit,Meg. Quantumuis infer, , $a$ tis diuites ac liberales hofpites habes, fed caue ne cras abituris nobis aureos quoldâ cyphos clàm bulgis noftris inferas, \& hinc eos quafi furta repetas, Cor.Illudis mihi intelligo, quod non fplếdide inftructũ abacum exhibeam. At hre qux lignea creditis, intus funt aurea poct $\mathrm{la}_{+}$His ea cruftis ideo operui, ut à talibus harpyis fecura fint. En uobis alueolum, in eo uos, donec uocati illi adueniant, exercete, tum aliumuobis ludum proponam, qui histefferis, qux in ore funt, ludetur.

$$
\text { F I N I }
$$




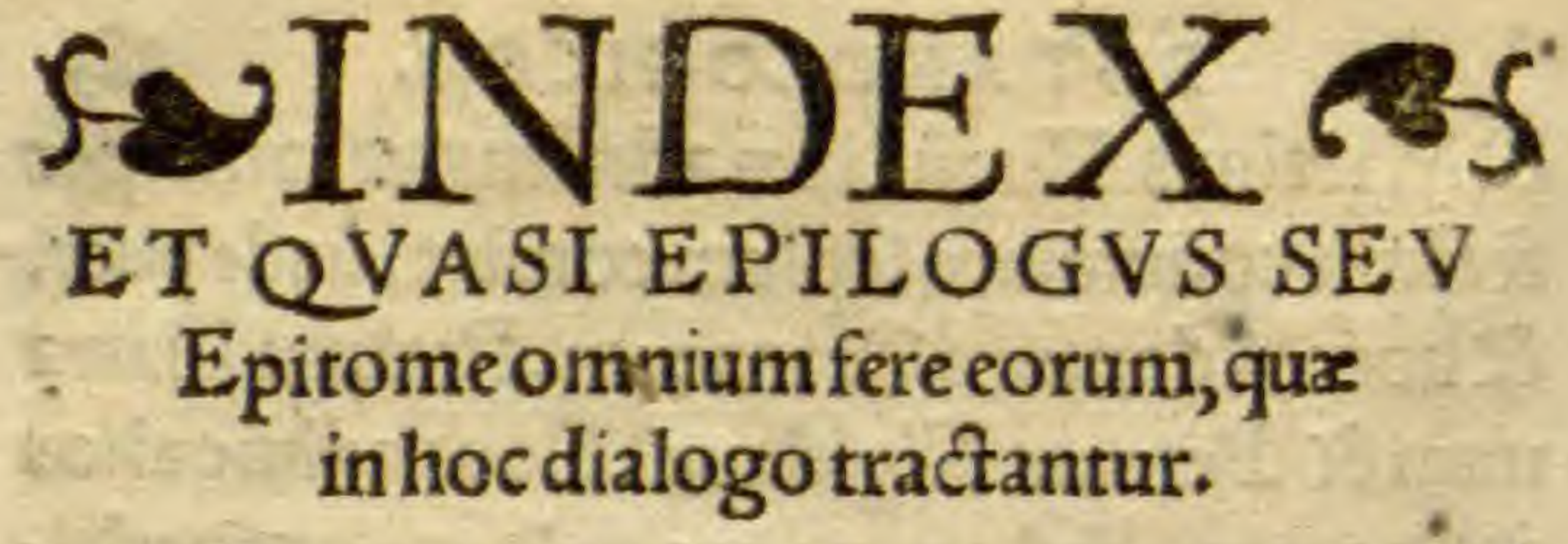

Epitome omnium fere eorum, qua
in hoc dialogo tractantur.
Cacia uera non eft agreftiü prunellorñ fuccus, , $\mathrm{d}$, nafcentis in Acgyptia cuiufdam foinz fruttur $7^{8}$ Acanthus, branca urfina Romana hodieab Italis di citur.

Aconitum alterü,id eft, ly coctonō, wwolffs kraut.

Acorus, non eft Gladiolus ille noftrâs luteis lilin's.

173

Acutella, Diofcoridis eft ononis, Germanice haw hechel, \& ftallkraut.

Adianton, non eft muraria rutha, Germanice maurautē. 70 Aegylops nō eft dieta aquileia herba, fed fortè auena quam Virgili' fterile cognominat. feftucago d̀ Gazza uertie. 158 Agrimonia hodie dieta, uerü eft antiquog* eupatoriü. $\quad 90$ A iuga.i.chamepythis, qus hodie iua molchata dicitur, core rupto fcilicet ab ibiga (quod item ab abiga eft corruptũ) nomine.

Albinus, uide gnaphaliú \& torminalis.

Alcęa, fortè qua Germanice Hochleuchten \& Sickmarf

kraut nominatur.

138

Alcibiadium fortè fylueftris bugloffa habet enim femé quae fi uiperinum caput.

141

Alibiü, id eft, inguinalis \& ftellaria bubonium's.

114 Alfine duplex, maior quz caprifolium \& materfyluia : Minor, quxe altera auricula murts dicitur. Alyfina, quod uulgares herbarih alineam corrupte uocant, aquatica plantago eft, alia kamen 2 barba fyluana. 147 Aly ffon qualia folia habeat. Amaräthos duplex, purpureifcilicet \& aurei fioris, hac ftę? chas citrina hodie ditta, ill a flos amoris. Amaracus in Galeni fimplicibus eadé matricarix, meter, mu terkraut.fic \& famíchon sognominatur. 
Ambubeia, agrefte cichorium, wegewart, wegewiffe, $x$ hindtleuff.

Amianton, uide Salamandra.

Amomum, Hierichuntis rofa, qux ut facrum fpectaculum in natali Chrifti nocte, quafi tuncaperiatur, hactenus in tem plis oftenfa eft.

Aimpeloprafon, uineale porrum, wildiouch.

Androlaces forte qua hodie cufcuta dicitur.

94 Androfamon, ultima hypericifpecies proprie dicitur- $\quad 98$ Angelica apud Diofcoridem fmyrnion. Antyrrhinon, herba quẹ aliâs iam Orant dicitur. Et fortć ca dem cynocephalas.

Aparine Germanice klebekraut. $35.8 \times 30$ Apijgenerum difficiliseft hiftoria. Apios, herba quae \& raphanus agreftis rotunda radice. I;3 Apium paluftre fortè Gierfca uel Angelice fpecies. Arbutum, id eft, unedo, quo etiam nomine epimelis, id eft, fie tanium, mefpilum dicitur. Arabum pleręg medicina quarum apud ueteres nulla men tio.

Argallicũ apud Aurelianü fymphitü eft.i. wal worurt; . Ariftologia rotunda non eft, quæ Germanice hoelwarty ap pellatur, quod hiftorix minime refpondeat. Armeniaca mala Germanice amarelien. Aron omnib.eodem uulgo nomine cognita, cui ferpentaria In uiribus fimilis, nō habet, ut Plinius tradit, magnam radicem.

134

Afa noneft, ut hodie medici putant, Lafer feu Laferpicium, fed alius ueteribus fortè ignotus fuccus. Afclepias fallò à quibufdam ea herba, quàm uulgo gundel. reb dicunt, creditur.

Afcyron, eft fecunda fpecies hyperici perforata, quam uulgo kunrat, barthaw, \& unfer fra wen betftro noiant. 98 Afpalatos, arbot ignota, quã Arabes Darícif́cahanfeu darfi fahan uocant.

Afpergula Germanice liddegenge. Afphodelo carent Germanifeplafiarti. Ios Afplenos, id eft, fcolopendria, non tamen ceruina lingua, fed M 3 


\section{BOTANOLOGICI}

quę Arabice ceterach \& Germa. ftyenkahrn uocat. 3* After Atticus, eft inguinalis, quam male apud Serapionem pro Eryngio accipiunt nomine decepti herbarij. $\quad \mathrm{II}_{4}$ Auena Grace Aegylops à Plinio dicitur. $\quad 158$ Aurelia uide Stochas citrina. $\quad{ }^{36}$ Auricula muris, qux Græcis idem fignificante nomine Myo fotis dicitur, nô eft pilofella, quam Germanice meuffohr uocamus,

129

B

Barocus forte Galiopfis, Daubeneffelen, behniaugen. 16I Bechion, tuffilago Latine, farfarella, \& ungula equina terre ftris, Germanice Eftelfihub, branthlattich.

Behen, ignota antiquis Gracis radix, $\quad 163$

Behrwurtz forte Daucus Cre: $\quad 47$

Ben apud Arabes, idem myrobalano, quam Djofcorides my repficam cognominat.

167

Berberi,fructus Spinz que Gracis Oxy acantha, id eft, acida f́pina dicitur, Germanice furich,erbfel.

Bettlerfleufe, forte Gracorum Xanthium. 103 Bitorta quse $\alpha$ biftorta, non eft, ut creditur, ferpentaria, $i$ mó plus ad britannicam accedit.

132

Blattaria, fpecies eft Verbafci, non ita hirfutis fed uiridiori bus folins.

Ilo

Blitü Germanıce benet, $8 \mathrm{eft}$ hęc uox à Latina uoce benedi Eta corrupta, alia ta mẻ eft à benedicta illa quę Cariophyl lata dicitur.

Branca, urfina Romana herba eft topiaria, qux acanthus Grzece uocatur \& Paderates, de qua Virgilius in bucolip cis.

Braffica uulgare olus, Germanice koele. 96 Braffica marina, qux a medicis hodie foldanella uocat. 96 Britannica credi poffet fort è eadem biftortx, quam falifo ferpentariam dicunt.

Bubonium. i. Alibiu, inguinalis, after Atticus, ftellaria. 114 Bucramonà Gal.dieta, antyrrhinos eft.

Buglorrç hodie plures uocant, uix tamẻ uera hic cognolcié, quã Leonicenus Cixfion putat,Sylueftris forte echiō,i. AI cibiadionefta 


\section{N D E X.}

Bulb' agreftis gręce Colchicō, germanice herbftbloumé.s26 Buphtalmus non eft eadern cum Chryfanthemo, fed quę uul go kow thill.i.uaccinium anethum dicitur , aliâs cotulanon fetida.

152

\section{C}

Acalia eadem cancano $8 x$ non diuerfa, ut Aegyneta pue tauit.

Cachrys cuius herbx fructus.

Calamus odoratus fortè non hic habetur, \& qui fic hodie di citur forte acorus eft.

37.8175

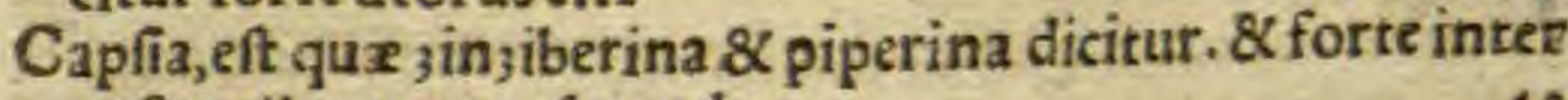
nafturting genera referenda.

Caputium hodie dietum olus, germanice caputz, braffice ge nus eft, quod Cumanü Plinius uocat, feffile, folio \& capite paululum, non tñ ubiq firmiliter prouenit.

26

Cardiaca, fortèmeliffophyllo adnumeranda, uel marrubij ipecies.

Cardus panis, Eryngï foecies creditur. IIs

Caryophylli flores antiquis ignoti. $\quad 48$

Cataputia minor, germanice Lathyris: maior cici fiue cro? ton, Arabice cherua feu kerua.

Catanāce nó eft altera fpecies tormétillı feu bitortz.

49 Catanäce nó eft altera fpecies tormétilla feu bitorta. 137
Celtica nardus, non eft illa Lauandula, quod quidam uó-
lunt.

Cenraurum maius eft, quod rhaponticum hodie putant. ita uerum rhaponticnm hic non habetur.

III

Centum capita ctiam Arabice, forte bubonium feu after $\mathrm{A} z$ ticus dicitur.unde error, quod after Atticus in Serapione pro Eryngio credatur:

134

Centunculus, uulgaris herba qua contra tormina uetula utunt, hine Rodekraut uel R hurkraut.i.torminalis,gre ce Gnaphaliü, ğuis Plin.diffıcilć eius hiftoriam faciat. 13 \& Ceruinalingua, noneft fcholopendria, fed ea herba quam Diofco.Phyllitida dicit . quamuis Leonicenus ceruinam linguam Hemionitida putet.

Ceterach, uide fcolopendria.

Chamędris, nô alia é à chamęrope, ut putauit Aegineta, nee ¿ Gamädrea, ut uulgares of 


\section{BOTANOLOGICI}

qux germanice Loge uel Gamanderlin uocatur 37.8128 Chamaleonesnon funt, ut quidam putant, duo ifti cardui, $q$ rú alter uiediftel, alter Mariendiftel uocat. 115.8116

Chamæciffus, non uiderur effe quæ uulgo gundelreben dip citur.

$92.8 \times 93$

Chamæecypariffus non eft cupreflina, fed quze germanice cy preffenkraut dicitur. Soronaria eft herba

Chama pythis, id eft, ziuga, abiga, ibiga. Vnde ibica, \& de' hinc paulatim Iua ab odore mofchata dicta. In quo errant uulgares herbarin.

Cheiri non funt frigida, nec inter murarias uiolas computa ridebent

Chelidonion, minus uulgaris herba in humidis locis in $\mathrm{Ma}$ io tantum confpicitur. hinc germanice Meykraut. Saxo' nes fcorbocks kraut, Hieronymus feyck wart;enkraut ap pellat

24

Chryfanthemon male ab Hermolao Barbaro buphtalmus creditur, eft ea herba qua germanice Iohans bloumen, $\&$ pferdes ouge dicitur

152

Cicerbita, id eft, Sonchus grace, germanice hafenkoel, quidä \& taraxacon putant.

144

Cichorium, intybum fylueftre wegeweis, hindtleuff 143

Cici,uide kerua

50

Cicuta femine male hodie medici pro ruthafylueftr is femine utuntur, quamuis à Leoniceno erroris admoneantur.

Cirfion grace quafi uaritaria, creditur à Lenoniceno eff́c, quar bugloffa hodie

$14^{\circ}$

Ciffampelus, altera fpecies helxines, qux latine conuoluulus 8 germanice,

Citrago,dubitat an ea herba fit, quả aliâs meliffophyllō, \& iã ubiç meliffa credite. qũ apes ea nō delectantur. $\quad 62$ Colchicon, bulbus agreftis germanice herbftbloumĕ, nō eft Narcimus, ut Brunfelfius putat, nec fortè hermodactylus, licet id Serapio credat.

Columbinus pes, herba Rupertiana, fpés gruinz herbs, ger manice fchartë kraut.alia fpecies acus mulchata dicit, gue maximo errore pro amomo creditur. 


\section{I $\mathrm{N} D \mathrm{D}$ E X.}

Conuoluulus 3 caunglocken, grace ciffampelus, 8 helxine altera.

Cony 3 a non eft, ut Brunfelfì tomi pingunt, व̃ germanice floehekraut dicitur, nec thymbra, ut putat Iacobus Manlius.

Cordumeni Cardamomum \& carui agrefte.

153

Cornus, arbor, cuius fructus Dirlas uocant.

Coronopus non eft hodie difta pes coruinus.

Corrigiola, proferpinaca.

Cirenaicis fuccus, id eft Lafer.

Crifpina uua.

Criffon non eft fenetio, ut torum ferme medicorum uulgus credit, fed altera fy fy mbrri f́pecies, quz cardamine, id eft, nafturciaria dicitur -

34.8162

II]

165

83

Croton, uide kerua. Croton, uide kerua.
Cucumis agreftis, unde elaterium, de quo authores uariant
quod optimum fit.

Cunila fortè qua hodie ferpillum fylueftre creditur, altera feilicet thymbrze fpecies.

Cuprefina, non eft chamacypariffus, fed chamapythis. 53 Cufcuta, fortè eft Diofcoridæ androfaces.

D

$D^{\text {Amafonium, id eft, alyfina, a quatica plantago, non tae }}$ Darfíahan Arabum, Diofcoridze eft Afpallathus, 2 nō fyle ueftris punica.

Darfifahan, id eft, afpalathos. Manardus Sandalifpeciem putat. putat.
Daucus Creticus, fortè behrwurt s, qua hodie Meum credi-
ditur.

Delphinion dubitatur an fit fene, ut quidam putant. $\quad 169$ Dietamno uera caremus. Dieramno uera caremus.
Dracuneulus quz dracontia \& ferpentaria \& colubrina, nơ
eft bitorta, fed Aro fimilis

E

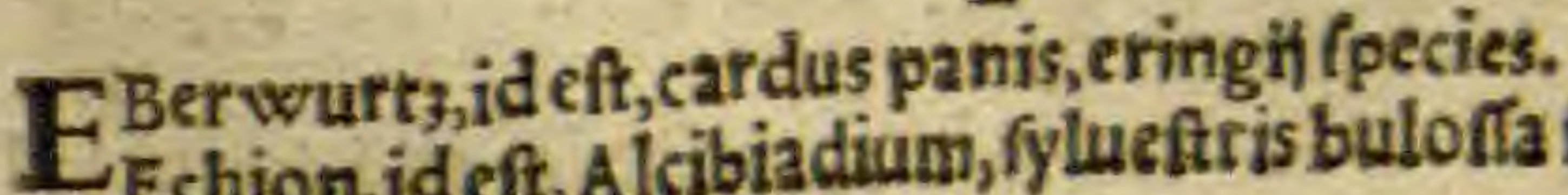




\section{BOTANOLOGICI}

Elaterium quod optimum \& peffimum fit, authores uariăt. 28.822

Endiuia corruptum ab intybo eft, nomen multarum herba rum, quæ omnes feridis appellatione à gracis comprehëe duntur.

Epimelis mefpili fpecies, unedo, tefte Galeno, etiam Latıne dicta.

Equifetũ fortè pro altera fanguinali poffet intelligi, cũ credi tũ hodie equifetũ hiftoria non undiquaģ rcfpödeat 117 Erigeron nō eft carduus benedictus, fed herba uulgaris, çuæ germanice creut; wort; dicitur, latine fenetio, quo nomie ne male criffonem mediciuocant.

107,8109

Erinos eadem echino, ex quibus tamen Aegineta duas facit herbas.

Eryca, uulgaris frutex eft, $q$ heyde germanice uocatur. $17 \mathrm{t}$ Eryngü fpecies non facile nec temere ab omnibus cognof́ü tur, nec ubiq inueniuntur.

Eufragia male picta eft in Brunfelfio, alia enim eft quàm il la apparet.

Eupatorium antiquorum eft ea, quæ hodie Agrimonia \& inuerfa lappa dicitur.

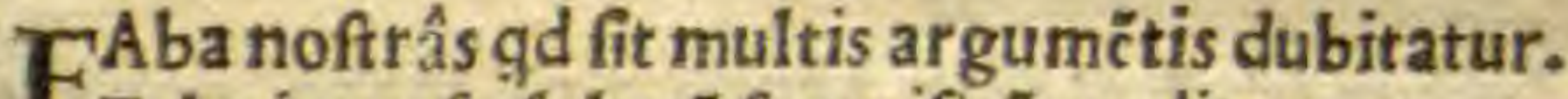

F Faba inuerfa, folanñ fomnificũ creditur.

Flos amor is alterum amaranthin purpureo filicet flore. 37 Flos autumnalis, colchicon, bulbus agreftis.

Fraxinus male à Pandectario uertitur, cum ulmus eo capi* te intelligi debeat.

Frugem qua ruggen dicitur, non recte nominamus, $\quad 177$

Alanga.

G

Galiopfis fortè barocum, qux germanice behnfugen dio citur,eadem forté urtica fatua.

Galion herba uulgaris, minor quàm aparine.

108 Gladiolus Diofcorıdis in Germanıa non temere nafcitur, \& noneft aquatica illa herba, qua hic fchwertlen appellatur, fed in aruis inuenitur,

Gnaphalium, latine centunculus, germanice rodckraut uel 


\section{N D E $X$.}

thurkraut,uulgaris in hortis \& alins laboratis locis her" ba,Albinus etiam dieta.

Gorgilon qux aliâs Tordylon 8 hordylon, carui agrefte, \& à quiburdam cordumeni dicitur, quo tr̃ nomine carda momum ab Arabibusuocatur.

Goflipium, hodie cum Arabibus coton dicunt \& bombace, uuigo boum woll.

16)

Gramen græcis agroftis aliudeft à polygonio, quod tamé etiam gramen dicitur à latinis.

II3

Gummi Arabicum Serapio acaciz fucctí putat, cü graci id non affirment:Imò apparet gummi Arabicum fortè idé effe cum tragacantha, quantum ad uires attinet.

79 $\mathrm{H}$

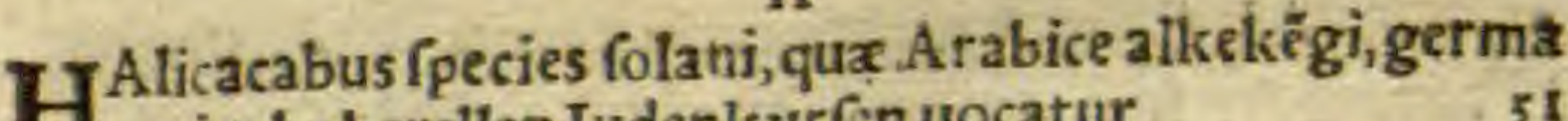
H nice boberellen Iudenkyrfen uocatur Heliochryfos à Galeno amaranthus dicitur, licet Aegineta duas has herbas putet. Efíg illa qu hodie ftoechus citrina \& germanice rheynbloume \& motterkraut uocatur. Male quidam hanc inter abfynthin genera referunt. $\quad 36$ Helxine parietaria uitrago urceolaris $\mathrm{eft}$ non tamen ca her ba qux luteis $\&$ fimilibus purpureis fioribus infignis, tag Hemionitis à Leoniceno ceruina lingua creditur, cum tamé ceruina lingua phyllitis fit, \& non fcolopendria is Herba flaura, id eff, planta leonis, grace Oxytriphyllon, uel fimpliciter triphyllon, hoc eft, trifolium acutî, uel fimplï citer trifolium dicitur. Non eft uulgare illud pratenfe, ute hactenus erratum eft, rrifolium. 75 Herba tunici a Magno Mediolanenfi Polemonion Diofcori dis dicié. Sunt thî qui dietos caryophyllos fiores purêtr. 49 Herbftbloumé colchicon, bulbus agreftris, nõ e Narciftus, 126 Hermodact ylus, forte alia eft d Colchico, licet in Serapione hoc caput, Surugen Ic;, hermodactylú in lémate habeat. Iis Hawheckel uel ftallkraut, id eft, Ononis, acutella, refta boHieracium duplex, foncho fimilis herba, quz à quiburdà ha fenkoehl \& genffediftel putatur, quas tamen ego fonchos feucicerbitas puto, 


\section{BOTANOLOGICI}

Hippice herba famem fitimg; fedare dicitur.

Hipporelinon, grande apium, fpecies angelica, uel Gierfa maior

122

Hippuris, id eft, Equina cauda feu Equi'etum, quafiignorap rividetur.

Hordylon, uide Tordylon.

Hyacinthus non eft, ut poctza fabulantur, regum nomine in fcriptus flos, fed quod latinis uascinium dicitur, uacinium uero non eft heidelbehr.

Hydropiper, fortce eadem qua perficaria mordax, qua non habet maculas, à Plinio piperitis \& filiquaftrum dicta.

Dubitatur an piper aqua \& piper caninü idem fint, certe Auicenna feparat.

Hypericon proprie dietum non eft perforata, feu herba Io hannis, feu fuga demonis, licet \& haz hypericon cognor minatur, cum proprio nomine afcyros uocetur.

Hyffopus noftrâs non congruit defcriptioni apud Diofcori dem, ut uidere eft in capite Origani, \& a libi. Nam in pror prio capite non defcribitur.

$63 \& 64$

\section{I}

Indicus fuccus pro Afa accipi alicubi uidetur.

165

Inguinalis, id eft, after Atticus, bubonium, alibiñ, ftellaria, fternkraut.

114

Intybum, commune eft nomen omnium herbarū, qua Gra ce ferid os appellatione comprehenduntur. Id uocabulum paulatim in endiuiam deprauarum eft.

143

Iua corruptum eft $a b$ ibica(quod ab ibiga, et id ipfum ab abiga deductum eft ) nomen, et eft chamapythis, cognomi natur hodie mofchata, à bono fcilicet odore. Sic nefcien? tes quidam medici chamxpythin norunt.pro qua tamen hodie uarias alias herbas non recte accipiunt.

53

$\mathrm{K}$

Kerua feu Cherua apud Serapionem, qux cataputia \& pen tadactylus dicitur, Grzece cici \& croton, Germanice vun delbaum. hinc oleum cicinum \& de kerua.

50 L.

Lacerta alia beftiola eft in It alia, quàm qua hic fic uocatur, ๆ 


\section{N D E X.}

Lamium, id eft, urtica mortua cum albis floribus, fort ${ }^{6} \mathrm{ga}$ lioptis fpecies.

Lafer, mumia Arabica uideri poffet.

Latacen herbam qui habet, omnium rerum co pia abundare creditur.

Lathyris, cataputia minor, germanice fprinck wurt ${ }_{3}$,Saxoe nice creuceboum.

Latiua corrupte legitur apud Pandectariü, quafi alia à pro xima fit, eadem enim ei eft.

Lauandula non eft, ut quidam putant, nardus celtica.

Laurus Alexandrina, id eft, vuularia, biningua, germanice hauckblat.

169

Letura etiam ex Lathyride corrupta uox eft apud Pandecta rium, \& eadem ei res eft-

Leguminum hiftoria difficilis eft.

Lepidion, idem Seiraragi apud Serapionem.

Libanotis quidam Rolmarinus eft, fed non qua hodie ficdicttur.altera libanotis coronaria filicet, eft noftras rofina rinus, cuius fpecies eft Lauandula.

$4^{\circ}$

Lichnitis uerbarci fpecies, qua \& Thryallis Grace, germa nice uero campulofen feu marienrofen uocatur.

Liguftrum non fignificat conuoluulum, id eff, 3 caungloc ken, ut literatores putant, fed frutex qui rheynweiden \& mundtholty dicitur, grace cypros, quamuis Leoni: cy' pron fimilem liguftro fruticem dicat. $81.21_{13}$ I imonium fortê ea eft, quam hodic pirolam latini, germani uero w/altmangoil, \& wyntergreun uocant. 146

L inaria eadem eft urinali, quam tamen uulgares herbard $a b$ ea difiungunt. Eadem quoque eft ofiris apud Diofcoride krotenflach $\}_{3}$. $39.8 \times 102$ Lini genus apud Plinium, unde inextinguibilis tela fit, fore te amianthon eft, lapis unde huiufmodi fila ducuntur.

$15 \circ$
Lyfimachion, herba qux germanice weiderich, id eft, falti caria dicitur, credi poffit, fi acer eius fumus mufcas necar ret.

Lolium, ignotum forte noftratibus, non enim eft quam uul go dorth appellanto 


\section{BOTANOLOGICI}

Ionchitis altera, fimilis fcolopendriæ, ex cuius figura, qua polypodio fimilis,apparet fcolopendriam non effe Ceruis nam linguam.

Lunariam fabam inuerfam, id eft, fomnificum folanum gui dam dicunt.

Lycostonon.i.alterum aconitum, wolffskraut.

89

\section{M}

$\mathrm{M}^{\text {Aiorana eadé famfycho ab omnibus dicitur, germanis }}$ Ml ce Meyran.cognominatur etiam amaracus, quo nomine tamen matricaria dicitur à Galeno.

Malua hortulana hic non ubique nafcitur, fed rara uifu $\&$ quafi ignota eft , Romana malua dicirur, Romfche pap peln.

127

Mandrogoras noneft radix illa, quæ humana effigie forma ta, ab agyrthis non cirra dolum magno uenditur.

Maron ignota hodie herba, origano fere congener.

Marrubium dicit Nicander etiam meliffophyllon feu melie phyllon.

62

Materfyluia, id eft, periclymenon Grzecorum, Latine caprie folium, Germanice Lienenbloumen, Specklitien. Ijo Melilotis uera ignoratur apud feplafiarios noftros. $\quad 45$ Meliffophyllon, Apiaftrum eft. Sed an eadem fit, qua hic pro meliffa \& citragine oftenditur \& creditur, dubitari poteft:cum apes ea nihil oblectentur, eietiam forenti nố infideant.

GI

Meliffa, uide in proximo.

Menta non eft frigida, nec abfumit humanam genituram, ut Ariftoteles fallótradidit.

150

Millefolium, non eft herba illa, quam hodie fic appellamus in Germania.

Milium folis, id eft, Lithofpermon Germanice fteynfame, Mehrhirffe.

142

Mirobalanus apud Dioficoridem alia eft ab hodie uocatis mirobalanis, qux inter palmulas fortè referri poffunt. 163

Mumia capite Serapio piffarphalton defcribit ex Diofco ride. 


\section{I $\quad \mathbf{N} \quad \mathbf{D} \quad \mathrm{E} \quad \boldsymbol{X}$.}

Myaros 8 myagros male ab Aegineta pro diuerfis herbîs creduntur, cum eadem res fit.

Myrica,non eft frutex qua uulgo heyde dicitur, fed eadem Tamarici, quam hodie Tamarifcum dicunt . Eryca uero heyde uocatur.

171

Myamir Galeni liber eft, qui de compofit is medicamentis fe cundum loca infcribitur.

168

\section{$\mathbf{N}$}

N ${ }_{125}^{\text {Arciffus nö eft autlinalisille fos, ut Brunfelfius punt. }}$ Nenufar, id eft, nymphaza, non habet cicoreze folium, ut A puleius tradit.

Neuras \& Poterion idem eft, quamuis Aegineta diuer fas her bas crediderit.

Nigella non eft herba, qua germanice raden dicitur, fed fchwart 3 komich uel fchwart; coriander nigella eft. 47

Nymphaz nenufar hodie dicitur, Germanicx fehebloumen, waffermaehn, Saxonice fehekenken.

329

Enagra Grzcis 2 uino dieta herba, quod eius odore ho mines exhilaret \& quafi gaudio inebriet.

Oenanthe credtrur 2 Brunfelfio Philipendula, fod hiftoria non per omnia refpondet. Hanc herbann dicit Verg. Mare cellus fe nufquam apud Diofcoridem legiffe, cum tamen etus caput interpretatus etiam fcholìs fuis ornarit. Eft \& cnanthe labrufca flos.

107

Ononis, qua Latine acutella, refta bouis, 8 remora aratri, Germanice hawheche], \& ab equitibus ftallkraut dicitur.

Ophthalmica, id é, cufragia feu ocularia, Arabice adhil, Ger manice augenroeft, wegelouchten.non ueram icona has bet in Brunfelfianis tomis.

143

Ofiris refpondet dictze hodie Linariz, qua eadem urinalis eft, Germanice wildfiachs, krotenfiachs. 


\section{BO TANOLOGICI}

PAEderotes Gracis aliter acanthus, Latine iam branca ur fina Romana.

Pzonia duplex eft, mafcula \& formina, altera minwenwur t 3 el, altera benonié. Vana eft quorüdam opinio Pioniam \& proniam diuerfas putantium.

Paliurus non eft arbor illa, quam Germani holfch uocant, fi femen fuum in filiquis fert, ut Theophra: ait.

Papauer erraticum germanice wildt maen, klapperrofen, kornrofen, in fegetibus nafcitur.

Parietaria etiam Parthenion cognominatur, \& Helxine grę cis, Latinisetiam Vitraria.fed uitrago \& urceolaris dieta, non eft herba quax à luteis \& fimul purpureis floribus tag und nacht appellatur.

130

Parthenion, commune multus herbis eft nomé, quo hic ama racus, id eft, matricaria fignificatur.

Pentaphyllon non eft quam hodie fic uocant, imó eadem tormentillis, germanice burck wourt 3 , blut wurt ${ }_{3}$, Saxonie se heydeckern.

$7 x$

Perfoliata ucterib' fortè ignora, Germanice Durchwachs, non fua effigie apud Brunfelfium pieta eft.

Perfica \& Perfæa diuerfa funt diuerfarum arborum ma la.

Perficaria mordax caret lituris, \&L eft piper a quaticum, pipe ritis \& filiquaftrum. Diofcorides hydropiper uocat. Ma' ximo errore pro Gracorum conyfa, id eft, pulicari accipitur.

Pes coruinus hodie dięa, \& pes cornicis ueterü diuerís her' bxfunt.

162

Petalitis idem fignificat gracis, quod Phyllitis, \& eft reuera ceruina lingua, quam hodie male fcholopendriam pue tant.

Philipendula creditur à Brunfelfio Oenäthe herba Diofco. fed foliorum hiftoria non refpondet.

Phu noftrum, id eft, Valeriana, non refpondet hiftoria Phu apud Diofcoridem, imo alia quadam magis, quz Theria caria, Theriacks kraut in Hefija nominatur

Phylliris, reuera é Céruina lingua.alia à fcolopëdria. - ja 


\section{N D E X.}

Piperitis dicta eft in Perficaria, cui eadem eft.

Piperella.
Pirola recentiorum, fortè Limonium Diofcoridiseft. $1455^{\circ}$ \&146

Piffalphalti caput ex Diolcoride citat Serapio pro mumia, fed plures fortiores'g mumia uires tribuit, quam Diofcos rides piffafphalto.

Pifum non eft quod uulgo erbes dicitur.

Pityufa non uidetur tripolium effe.

879

Planta Leonis \& trifolium uerum, de ç mediei intelligüt, a liter herba flaura feu maura dicta.

Platanus forte peregrina eft Germaniz arbor, quod fi ue" rum eft, tunc alia ab e2 eft, qua crhrn uulgo dicitur. ${ }^{14}$ Polium male tinearia, quę ftoechas citrina, id eft, heliochry, fus eft, $a$ quiburdam creditur, nifi jpfum polium etiam tinearia herba fit.

Polygonatum,eft quę hodie figillum Solomonis feu mariz dicitur, Germanice weiswurty. \& funt qui fcecacul cre? dant.

Polygonion effe putant eam qua germanice wegegras, \& wegedritt uocatur.

Poterion \& neuras eadem eft herba, diuerfas tamen Aegine

ta credidit.

Pulegium noftrâs pro hortulano ferpillo credi poffit. 156 Pulegium fyluefire, wylde poley

Pulicaria cony $3 a$ pro qua male perficariam fupra ditam accipiunt.

Pyrgitis dicitur etiam phyllitis, id eft, lingua ceruina, quod ad radices turrium etiam naf́ci foleat. Male admifcet $P$ an dectarius huic afpleni hiftoriam.

32

\section{Q}

Vinquefolium, Grzcorum Pentaphyllum, Tormentilt, birckwurt;, \& non ca quam hodis medici guinquefokum uocast? 
BOT ANOLOGICI

$R$ Habarbarum ponunt Arabes, ubi antiqui $R$ haponticü R habēt.recentior \& forte alia à Rhapontico res eft, de qua tamen expectantur Leoniceni \& Manhardi difputa" tiones.

Raphanus fylueftris, etiam apios Gracorum dicitur. $\quad \mathbf{I}_{33}$ Rhaponticum uerum hic non habetur, fed qua pro eo uen. ditur radix, centaurium maius eft.

Remora aratri iam dieta, eft $R$ efta bouis, Remora aratri,

Ononis Diofco. Germanice haw hechel, ftallkraut. 101

Rhoeas, papauer, korntofen, klapperrofen. $\quad 90$

Rorippen Saxonice diêta herba, al âs accipitrina. $\quad 44$

Rofmarinss quan Diolcorides \& ueteres medici intelligüt, longe alia ab ea herba, quam nos Germanific uocamus. Eft tamen eadem herba priori cognominis, \& Rofmarie nus coronaria.

Rubus caninus, hagendorne, hagenbotten.

Rubus fimpliciter, quem Graeci batum uocant, bramenbeher.

Rumex, herba quam uulgo lapatium, doetioresuerolapathon uocant.

Rufcus, eft guem medicorum tabernę hodie brufcum uocắt.

170

Ruthz fylueftris femen accipiendum eft, ubi hodie cicutze femen aecipiunt periculofo errore.

$S$

Slamandra non continuo nec femper in igne uiuit, fed

S aliquantulum in eo durare poteft, nec eft adeo ignotii animans:Imó illud quod Germanice eyn Olm uel Molch appellatur.Et falfum eft ex eius pilis, quos nullos habet, inexftinguibilem tela fteri. Nam huiufmodi materia eft, vel ex amiantho, uel ex quodam apud Pliniü linigenere, fi non $\&$ id amiantho lapidi idem fuerit.

149

Saluia maior feu fylueftris, apud Theophraftï Spacelos. $9 x$ Saluia uita, fortè murariarutha. 78 Sambacuel fambacus, uide in proximo. Sambucus Gracis reete dieta, Germanice hollunder, in quo frutice Hieronymus Brüfo errauit, \&Iarininos flores lew 


\section{N D E X.}

coia putans cum ea milcuit, deceptus nominum uicinita. te. Nam Iafninz uiola Leucoihs fimiles Arabice zambac uel 3 ambach dicuntur.

$59.86 \bullet 8.79$ Sanguinalis focminze hiftoria uidetur putato ęquifeto etiam conuenire.

Sanguinalis, id eft, Polygonion wegedritt wegegraly* II3

Sanicula fortè ignota ueteribus $\&$ aे recentioribus inuenta uulneraria herba, Germanice Sanyckel. Hanc falfó purtauit Collinutius contra Lconicenum Pentaphyllon effe.

Sant Peterfkraut, fi intelligitur que aliâs tag und nagt uocarur, tunc erratur in hoc quod parietaria fit. $1 ; 0$ Satureia,cunila hortulana nota herba, Germanice Satur rey,

Scarlza ignota fortè ueteribus herba.

Scingus, id eft, crocodilus terreftris, quem fincum uor cant. Non eft aquatica lacerta ut feplafiarì putant. $35^{\circ}$

Scolopendria non eft lingua ceruina, quod tamen omnes fere medici putant, fed ea herba qua olim Latinis calcifra ga, \& iam Arabice in tabernis ceterach, Germanice fteyne fahrn, fpicant, non omnes tamen feplafiarn̈ Leterum ce. terach habent.

Scordion, id eft, allium fylueftre, forte ea gua Ramp Gere manice dicitur.nafcirur in faxolis montibus odore alliti fortifitmo. In hoc errant feplafiarì uel fcorodoprafum, uel ampeloprafum accipientes.

Scorodoprafon, porrum alliatum, wild louch.

Scrophularia à Brunfelfio galiop fis creditur, quż̀m uere au tem dubitatur. 163 Scytice fitim fedat. Secacul feu facacul aliud ab Eryngio effe uiderus. Seitaragi quid fit uariant authores, lepidion tamen creditur.

Sene fortc ueteribus ignota, quamuis Delphinion apud Dio Ico.credatur, qquod tamen caput in antiguifs, codicibus n⿳亠 


\section{BOTANOLOGICI}

legitur, ne⿻̧ apud Galenũ neq; Aeginetã inuenitur. 169 Senetro non eft Creffon, qux alıâs in fy fymbrị capite carda mine dicitur, féd ea quæe uulgo. Creut; wort 3 uocatur, uul garis \& contempta herba.

Serpentaria, qux hodie fic dicitur, omnino non eft Dracone tia (quod nomen in Draganteam corruptũ eft) apud Dioe fcoridem, fed altera fpecies tormentillæ, bitorta fc3. ${ }_{132}$ Serpillum hortenfe non facile hic nofcitur. $\quad 156$ Sideritis non eft uerbena, licet fic cognominetur. Sigillum Solomonis, id eft, polygonatum $\mathrm{Il}_{3}$ Siliquaftrum Plinifi idem hydropiperi Diofcoridis, perficar riam mordacem illam effe credibile eft. Sium, id eft, Lauer, fortè waffer pungen, Saxonice lemmi-

Ise. 108

Solanum furiofum dubitarur an fit herba, quae dolenkraut imó tholkraut dicitur, cuius grana fchlaffbeehr uocăt. 5I Soldanella hodie uocata, eft braffica marina apud Diofc. 26 Sorba nõ funt fylueftria illa mala, quze Germanice holt zaffel dicimus, fed aliud genus.

Sparganion Diofcoridis non eft tormentilla, ut credidit Alexander Benedietus.

Spartaniam herbam in ore ferentes famem \& fitim fentire negantur.

Spacelus apud Theophraftũ faluia magna feu agreft is $9 !$ Spinacia non eft blitum, ut quidam putant, fed a recentioribus inuenta forte herba.

Stallkraut, id eft, Ononis, refta bouis, remora aratri, howe hechel.

Stellio, non eft beftiola qua Germanice Olm feu Molch dicitur,nam hac eft Salamandra: Stellio uero fimilis lacere tis, fed ab It alis Tarantula dicta beftia

Stoechas citrina hodie dieta, eft amaranthum Galeni, Dio foridis uero Heliochry fos reynblumé Mottenkraut, Au relia à Gaza uertitur. Male à qquibufdam inter abfinthif genera refertur.

Stratiotes herba illa qua hodie ubiq hic millefolium dici tur, quod quidem cognomen eft, fed uerum millefoltum alia eft herba.Stratiotes autem Germanice garbe, fchafflo 


\section{N DEX.}

garbe, fchafffriebbe, Saxonice relike.

Superbiam interpretatur herba, cum aliud non fit nomen, $\bar{q}$

Germani hohmut dicunt, congener fortè alteri aconito, id eft, lycoctono.

89

Symphyton maius, folidago maior, wal wurt, , fchmehre wurt 3, fchwart; wurt 3 ,groffe beynwel. $T$

T Ag und nacht non eft partetaria. ce myrica, quo nomine non uere fruticem heyde uocant. 271

Tarantula, id eft, ftellio, qui falfo apud nos Olm \& moIch di citur, cum falamandra fit. Eft 8 aliud genus tarantula. 150 Theriacaria uulgo hic Theriacks, magis refpondet biftorize phu đ̆ ualeriana.

Thryallis uerbafcifpecies, quam Germanice campulofam et marienrofen dicimus.

145

Thymbra proprie cunila ruftica qua forte eadem, qua hodie fylueftre ferpillum dicitur, Germanice Cumel, quenel, quendel.corrupto fcilicet à cunila nomine. Tamen $\& f_{a}$ tureia fic uocatur, fed hortulana.

154

Tilia Diofcoridis, non eft arbor quam nos tiliam uocamus. Et dubitatur an eadem fit, qux liguftrum creditur, tam fir mili hiftoria pingitur. Eft \& apud Theophraftum tilia, cu* ius materia fabricze expetitur, et ex cortice funes torquen tur, quæ magis tiliæ noftrati accedit , fi non eadem eft. 88 889

Tinearia à plerif Tinearia à plerif $\$$ dietta, cirrina ftacas.
Tordilon, quod 8 hordylong or gylonue, id eft, carui agte-
fte.

Torminaiis, id eft, centunculus albinus, rodekraut, rhuhre kraut,Grace gnaphalium.

kraut, Grace gnaphalium.
Tragus apud Diofcoridem, forte quam muliercula huner'
berh uocant.

Tribufus marinus fen aquaticus, uulgo unaffernuffe. terree ftris fere ignoratur. Trichomanes, altera fipecies capilli Ve neris widdertodt.

Trifolium quando fcribüt incdici, non intelligunt iltud uul 


\section{BOTANOLOGICI.}

gare ac pratenfe, longe enim alia ac rarior inuentu eft her ba, quæ aliâs hodie planta leonis, herba flaura uel maura dicitur, cuius recentis odor rutham, confiftentis bitumen olet.

76

Turbith fortè antiquis Græcis non cognita herba, quã qui dam pityufam, Serapio tripolion Diof coridis credidit, cü fortè neutra, fed alia quadam fit.

Turfilago, id eft, farfarella, Græcorum bechion, noneft, ut Iacobus Manlius tradit, ungula caballina aquatica. Nam hac nymphrea eft: Tuffilago uero Germanice huffiattich, brantlattich, efelfhuph

Typha, Diofrorida herba paluftris, qua Germanice narren kolben dicitur.

\section{$\mathrm{V}$}

$V^{\text {Acinia non funt hey delbehr,ut literatores apud Virgi }}$ lium interpretantur, fed uacinium hyacinthus eft. 82 Veratrum album male in uulgaribus herbarij's pingitur, cif ea effigies magis polygonato conueniat.

Veratrum nigrum dubitatur an chrift wurt ${ }_{3}$ fit, qued tamé omnes uolunt herbarij).

148

Verbenam ueram an habeamus \& cognofcamus dubiī. 109 Vermicularis fi eft qua hic apud nos maurpheffer dicitur, ut uolunt, non eft frigida herba, ut tamen de uermiculari tradirur.

Vernilagines, ideft, chameleones herba. In quibus utrifque turpiter erratur

100

Verucaria, fcorpiuron, heliotropium, non eft, ut hodie cree ditur, calendula. Dubitatur item qua eadem calendula fit. 142

Vetonica duplex, altera qux $2 \times$ ceftron dicitur, ubi $\$$ unlga ris \& nota,altera non item.

157

Viola qua Gracis Leucoia, non bene cum nigris feu murap rijs uiolis mifcentur, quafi eafdem qua litates $\&$ facultates habeant.Nam illx calidx, hx ucro frigida funt:

Viticella eadem bryoniz, contra uulgares herbarios qui eas. reparant.

Vitraria feu uitrago, id eft, parietaria

Ynedo, id eft, arbutum, quamuis \& eptmelida, id eft, fetanie 


\section{N D E X.}

mefpilum, Galenus fic à Larinis uocari reftetur.

Vngula afinina, id eft, tufilago, farfarella, effelfnuph, de qua in tuffilagine.

Vrceolaris eadem parietarix creditur.

Vrinalis, id eft, Linaria, contra uulgares herbatios, qui has quafi duas difiungunt, Grace Ofiris dicitur.

Vuularia, billingua herba eft, quam Graci Laurum Alexandrinum uocant, Germanice hauckblat.

Yualthmeifter, herbula qux male pro caprifolio apud Brun felfium pingitur.cum caprifolium longe alia herba, imo quafi frutex fit, hodie Lienen bloumen, fpecklilien diह̂us.

Vualuurt, , fymphyton maius, folidago maior.

Vuafferdouft, quadam herba qux pro Eupatorio non recte accipitur, cum uerum Eupatorium Agrimonia iain dieta herba fit

Vuafferpungen, uel guod idem eft, bachpungen, Sium uocatur \& Lauer.

Vuundelboum, cataputia maior, cici, croton, ricinus, kerแ2.

\section{X}

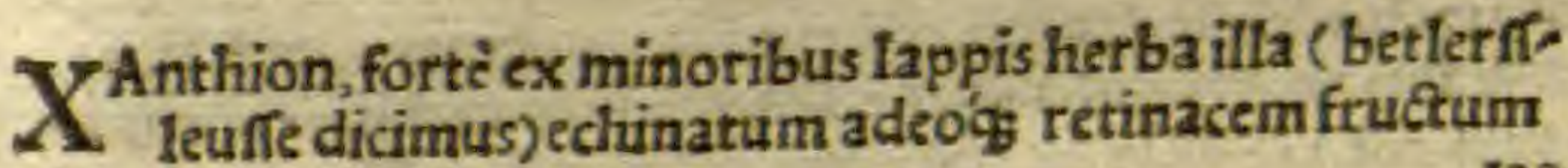
fert.

I03

\section{z}

Zinziberina, yngwerfikraut, quam Arnoldusetiam Tape fiam ( capfliam forte legi debet) uocari dicit. De qua dubitatur, an Seitaragieadem uel congener fit. 


\section{ERRATA QVAE INTER excudendum fefellere, fic}

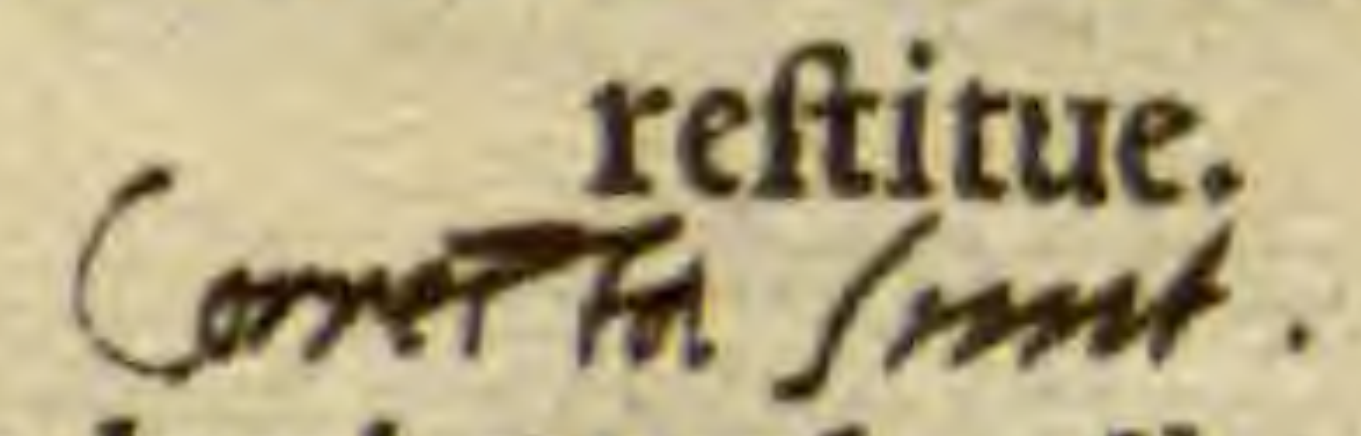

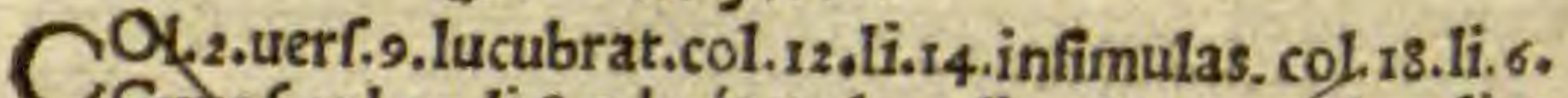
Cynof.col.19.li.8. adeóf. col.24, li, 2. At egorcol. 28.li.n muffitans ead. li.16. Vobis.ead. 1i,23, harum, ead. lí.25. Elate

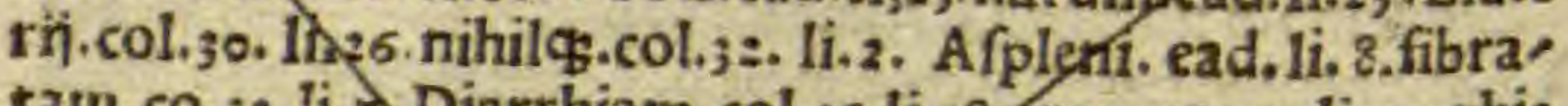

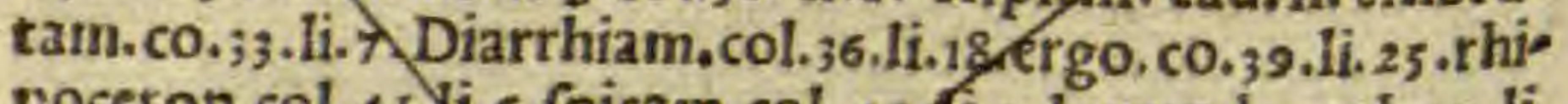

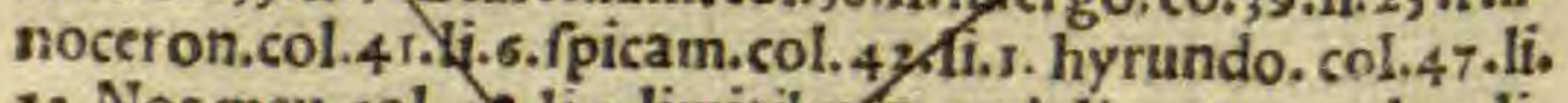

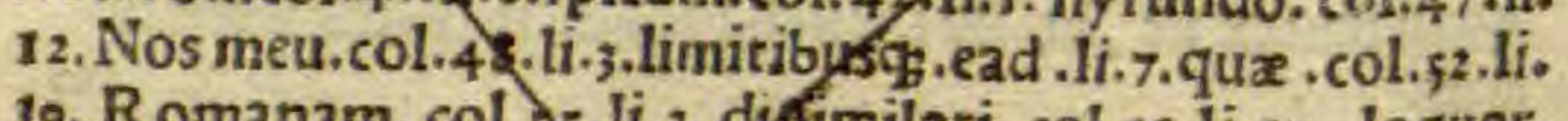
19. Romanam. col.s. .li. 3. diffimilari, col.56.1i. I7. loguar.

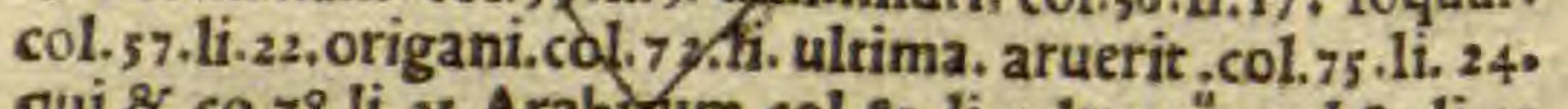

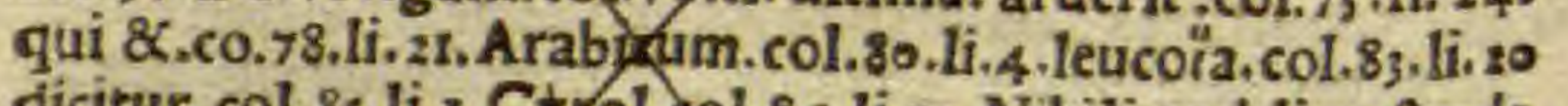

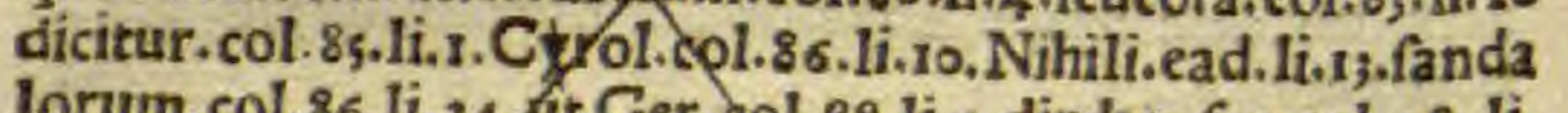
lorum.col.86.li.24, ut Ger.col. 88.li.1. dirdan, feu.col. 9 8. Ii. 7. Kunrath.ead. Hi.16.fic, col. so. li. ulti. artem. col.100. li.1. quidam. ead, li.rs. ultra quàm. cel. 103. li. 13. Eft quxedam. ead. li.21. genera funt.col. 108. li. 24. . odorato. ead.li.ulti.Ver rum ad hane. col.117. li.25. omnes. col.121. li.12. populum. ead.li.14-riy perne.col. 122.li.25. Anacreon. co.127.li. 23, reuer

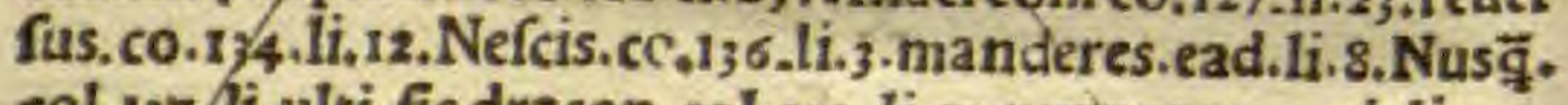

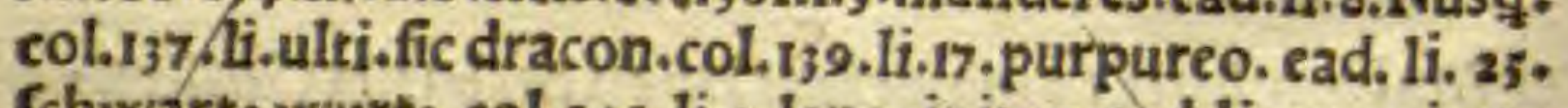

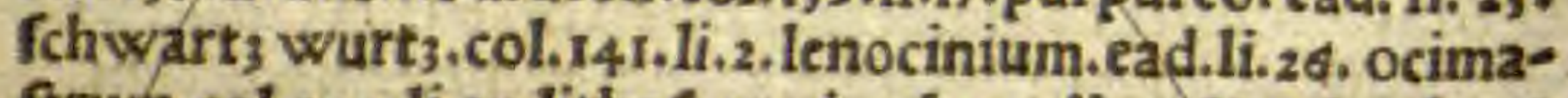
ftrum.col.142.li.17. lithorpermi.col.146.13. 13.28 pal.col.148 li.3, chrift wurtt3.col. 149.li.4. chalcidicas.co. .55 Ni...8 gen.

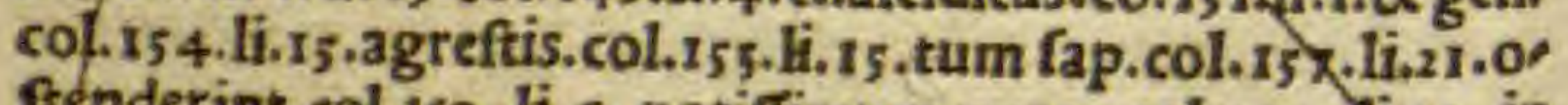
ftenderint. col. 160. li. 6. potiffimum pyro .col. 164. Ii.21. in

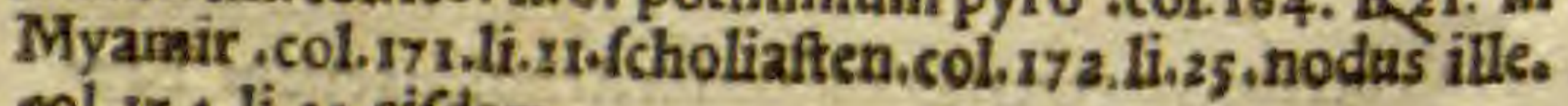
001.17 4.Ji. 22. eifdem. 